\title{
ROMAN SPIRIN
}

\section{TESTES E APLICAÇÃO DE UM NOVO IMPLANTADOR IÔNICO}

Tese apresentada à Escola Politécnica da Universidade de São Paulo para obtenção do título de Doutor em Ciências 
ROMAN SPIRIN

\section{TESTES E APLICAÇÃO DE UM NOVO IMPLANTADOR IÔNICO}

Tese apresentada à Escola Politécnica da Universidade de São Paulo para obtenção do título de Doutor em Ciências

Área de Concentração:

Microeletrônica

Orientadora:

Prof $^{a}$. Dr ${ }^{\mathrm{a}}$. Maria Cecília Barbosa da Silveira Salvadori 

Autorizo a reprodução e divulgação total ou parcial deste trabalho, por qualquer meio convencional ou eletrônico, para fins de estudo e pesquisa, desde que citada a fonte.

Este exemplar foi revisado e corrigido em relação à versão original, sob responsabilidade única do autor e com a anuência de seu orientador.

São Paulo, de de

Assinatura do autor:

Assinatura do orientador:

\section{FICHA CATALOGRÁFICA}

Spirin, Roman

Testes e aplicação de um novo implantador iônico / R. Spirin -- versão corr. - São Paulo, 2016.

$92 \mathrm{p}$.

Tese (Doutorado) - Escola Politécnica da Universidade de São Paulo. Departamento de Engenharia de Sistemas Eletrônicos.

1.Implantação iônica 2.Implantador invertido 3.Nanocompósito 4.TRIDYN 5.Percolação I.Ủniversidade de São Paulo. Escola Politécnica. Departamento de Engenharia de Sistemas Eletrônicos II.t. 


\section{AGRADECIMENTOS}

Este trabalho foi financiado pela Fundação de Amparo à Pesquisa do Estado de São Paulo (FAPESP) e do Conselho Nacional de Desenvolvimento Científico e Tecnológico (CNPq), Brasil.

Ao todo grupo do Laboratório de Filmes Fínos (LFF) do Instituto de Física da USP (IFUSP) com sua chefe Profa. Maria Cecília Barbosa da Silveira Salvadori por participação de desenvolvimento deste projeto e assistência técnica: Leonardo Gimenes Sgubin, Wagner Wlysses Rodriges de Araujo, Fernanda de Sá Teixeira, Raissa Lima de Oblitas, Dennis Gerardo Brenes Badilla, Heitor de Jesus e Martins Amorim. E também Dr. Ian Gordon Brown do Lawrence Berkeley National Laboratory, Berkeley, California, USA.

Muito obrigado à equipe do Laboratório de Eletrônica Aplicada do Instituto de Eletrônica de Alta Corrente (IHCE), Tomsk, Rússia com ex-chefe Prof. Nikolay Semenovich Sochugov que me deu o início da minha carreira acadêmica e proficional.

Aos meus pais Evgeny Spirin e Lubov Spirina quem me criaram e apoiaram a vida toda, e agora, graça a eles, eu sou quem eu sou. E minha nova família, especialmente minha esposa Sthefanny Eduarda Lessa Spirin.

Além disso Ablício Pires dos Reis e Odair Gimenes Martins por assistência técnica na parte de desenvolvimento de eletrônica, e preparação e estudo de amostras Sr. Nildemar Aparecido Messias Ferreira do Instituto de Pesquisas Energéticas e Nucleares, Centro de Ciência e Tecnologia de Materiais (IPEN, CCTM), Sra. Júlia Maria La Chioma Silvestre do Instituto do Coração, Serviço de Anatomia Patológica (HCFMUSP), Sr. Gaspar Ferreira de Lima do Instituto de Ciências Biomédicas (ICB) e Sr. Diego Davi Coimbrão da Universidade Federal de São Carlos, Departamento de Energia de Materiais (UFSCar, DEMa).

Ao Instituto de feixe de íons Física e Investigação de Materiais da Forschungszentrum Dresden-Rossendorf, na Alemanha, para o código de simulação de computador TRIDYNFZR. 
«A ciência é, portanto, uma perversão de si mesma, a menos que tenha como fim último, melhorar a humanidade.» 


\section{RESUMO}

Esse trabalho descreve um implantador iônico em termos de sua caracterização e aplicação. O texto está dividido em três capítulos que são apresentados resumidamente a seguir.

O primeiro capítulo descreve em detalhes um novo tipo de implantador, denominado implantador invertido. Nesse capítulo é descrito o desenvolvimento e a caracterização do implantador invertido. A otimização de uma parte dos circuitos eletrônicos e o desenvolvimento e construção do restante dos circuitos é dada em detalhes. Uma caracterização do implantador quanto à maximização do feixe iônico é apresentada, onde é realizado um estudo sistemático com a variação de parâmetros como potencial extrator, corrente do canhão de plasma (arco catódico) dentre outros. Finalizando o primeiro capítulo, é apresentado um mapeamento da densidade do feixe iônico no porta amostras do implantador invertido.

No segundo capítulo é discutida a neutralidade do feixe iônico do implantador invertido. Um feixe neutro viabiliza implantações em amostras isolantes, sem que haja acúmulo de cargas positivas, o que levaria a amostra a um potencial diferente do planejado. A energia de implantação efetiva foi avaliada estudando os perfis de implantação através de microscopia de força atômica condutiva (AFM-C) e microscopia eletrônica de transmissão (TEM), e comparando com simulações numéricas realizadas pelo programa TRIDYN. Os resultados sugerem que o feixe não é neutro.

No terceiro capítulo, o implantador invertido foi utilizado para modificação de superfície de alumina, gerando uma camada de nanocompósito logo abaixo de sua superfície, formada por nanopartículas de titânio na matriz de alumina. A formação dessas nanopartículas se dá espontaneamente e pode ser explicada pela ocorrência de concentração dos átomos metálicos acima do limite de solubilidade no substrato implantado, levando à nucleação e crescimento das nanopartículas metálicas. Caracterização por TEM foi utilizada para a visualização direta das nanopartículas que apresentaram dimensões da ordem de $20 \mathrm{~nm}$. Simulações utilizando o programa TRIDYN foram realizadas, gerando perfis de profundidade dos íons de titânio implantados no substrato de alumina, que mostraram excelente acordo com o perfil em profundidade obtido por RBS (Rutherford Backscattering Spectrometry). Medidas de resistividade da camada compósita foram obtidas, in situ, em função da dose implantada. Utilizando modelos teóricos de percolação foi possível determinar a dose de saturação $\varphi_{0}=$ $2,2 \times 10^{16}$ átomos $/ \mathrm{cm}^{2}$, que é a dose máxima para a qual o material continua a ser um 
nanocompósito, e para a condutividade de saturação foi $\sigma_{0}=480 \mathrm{~S} / \mathrm{m}$. A dose de percolação obtida foi $\varphi_{\mathrm{c}}=0,84 \times 10^{16}$ átomos $/ \mathrm{cm}^{2}$, que é a dose abaixo da qual o material tem a mesma condutividade que a matriz isolante. $\mathrm{O}$ expoente crítico obtido foi $t=1,4 \mathrm{e}$, como a condição $t$ $<2$ é satisfeita, o processo de condutividade se dá devido a percolação, sendo o tunelamento desprezível.

Palavras-chave: implantação iônica, implantador invertido, TRIDYN, nanocompósito, resistividade, percolação. 


\begin{abstract}
This work describes an ion implanter in terms of characterization and application. The text is divided in three chapters that are briefly presented below.

The first chapter describes in detail a new type of implanter called inverted implanter. In this chapter is considered my contribution in the development and characterization of the inverted implanter. The optimization of part of the electronic circuits, and development and construction of other circuits are given in details. A characterization of the implanter by the maximization the ion beam is presented, where is carried out a systematic study through the variation of parameters such as extractor potential, plasma gun current (cathodic arc) and others. Finally, it presents a mapping of the ion beam density at the sample holder of the inverted implanter.
\end{abstract}

The second chapter discusses the neutrality of the ion beam of the inverted implanter. A neutral beam allows implantation into insulating samples without positive charges accumulation, which would lead sample at a different potential than expected. The effective energy evaluation was carried out studying the implantation profiles by conductive atomic force microscopy (AFM-C) and transmission electron microscopy (TEM), and compared with numerical simulations performed by TRIDYN program. The results suggest that the ion beam isn't neutral.

In the third chapter, the inverted implanter was used for alumina surface modification, generating a nanocomposite layer just below the surface, formed by titanium nanoparticles in alumina matrix. The nanoparticles formation occurs spontaneously and can be explained by the occurrence of metal atom concentration above the solubility limit in the impalnted substrate, leading to nucleation and growth of metal nanoparticles. Characterization by TEM was used for direct visualization of the nanoparticles what presented dimensions of about 20 $\mathrm{nm}$. Simulations using the TRIDYN program were performed, generating depth profiles of titanium ions implanted into the alumina substrate, which showed excellent agreement with the depth profile obtained by RBS (Rutherford Backscattering Spectrometry). Resistivity measurements were obtained from the composite layer, in situ, as function of implanted dose. Using theoretical percolation models, it was possible to determine the saturation dose $\varphi_{0}=2,2$ $\mathrm{x} 10^{16}$ atoms $/ \mathrm{cm}^{2}$, that is the maximum dose for which the material remains a nanocomposite, and the saturation conductivity $\sigma_{0}=480 \mathrm{~S} / \mathrm{m}$. The percolation was achieved for dose $\varphi_{c}=0,84$ $\mathrm{x} 10^{16}$ atoms $/ \mathrm{cm}^{2}$, that is the dose below which the material has the same conductivity as the insulating matrix. The critical exponent obtained was $t=1,4$ and, since it satisfies to condition 
$\mathrm{t}<2$, the conductivity process is due to percolation, tunneling being negligible.

Keywords: ion implantation, inverted implanter, TRIDYN, nanocomposite, resistivity, percolation. 


\section{LISTA DE ILUSTRAÇÕES}

Figura 1. Esquema simplificado da (a) abordagem convencional de um implantador e (b) do implantador invertido.

Figura 2. Esquema do implantador, onde Vpg é a fonte de alimentação do canhão de plasma e Vext é a fonte de alta tensão. ..p.26

Figura 3. Desenho técnico do implantador. .p.26

Figura 4. Configuração das grades extratoras do implantador invertido. (a) Visão de topo e (b) e visão lateral. p. 28

Figura 5. Foto do mosaico de amostras para o mapeamento da densidade do feixe no porta amostras do implantador invertido. p. 30

Figura 6. Espaço de grade identificando cada amostra através de coordenadas p. 30

Figura 7. Esquema elétrico da fonte de alimentação Vpg. Este esquema elétrico é apresentado com maior ampliação no Anexo B. .p.31

Figura 8. Esquema elétrico do sistema de controle do canhão de plasma. Este esquema elétrico é apresentado com maior ampliação no Anexo C. .p.32

Figura 9. Esquema elétrico do sistema de alta tensão. .p.33

Figura 10. Oscilograma da corrente do copo de Faraday, IFC, $(\mathrm{CH} 1,10 \mathrm{~mA} / \mathrm{cm})$ e da corrente de arco de plasma, Iarc, $(\mathrm{CH} 2,100 \mathrm{~A} / \mathrm{cm})$; a escala horizontal é de $50 \mu \mathrm{s} / \mathrm{cm}$. A tensão de extração utilizada foi de $25 \mathrm{kV}$ e o catodo utilizado foi de ouro, portanto, a energia média dos íons foi de $50 \mathrm{keV}$ p. 34

Figura 11. Corrente do feixe em função da corrente do arco de plasma para o caso do Ti em sete diferentes tensões de extração (de 5 a $35 \mathrm{kV}$ ), utilizando espaçamento das grades extratoras de $3 \mathrm{~mm}$ e diâmetro das aberturas das grades de $4 \mathrm{~mm}$ .p.35

Figura 12. Corrente do feixe em função da tensão extratora para o caso do Ti em quatro diferentes correntes do arco de plasma (de 75 a 200 A), utilizando espaçamento das grades extratoras de $3 \mathrm{~mm}$ e diâmetro das aberturas das grades de $4 \mathrm{~mm}$. ..p.36

Figura 13. Corrente do feixe iônico em função da tensão de extração para o caso do $\mathrm{Nb}$ em quatro diferentes correntes do arco de plasma (de 75 a 200 A), utilizando espaçamento das grades extratoras de $4 \mathrm{~mm}$ e diâmetro das aberturas das grades de $4 \mathrm{~mm}$. p. 37

Figura 14. Corrente do feixe iônico em função da tensão de extração para o caso do Au em quatro diferentes correntes do arco de plasma (de 75 a 200 A), utilizando espaçamento das grades extratoras de $4 \mathrm{~mm}$ e diâmetro das aberturas das grades de $3 \mathrm{~mm}$. p. 37

Figura 15. Razão da corrente do copo de Faraday pela corrente total proveniente da fonte de alta tensão em função da corrente do arco de plasma (parâmetro ligado à densidade do plasma), 
sem a malha (triângulos) e com a malha (círculos) posicionada na frente da primeira grade extratora.

Figura 16. (a) Espectro de RBS típico para uma das amostras de silício (b) espectro de RBS da amostra de carbono vítreo. .p.39

Figura 17. Gráfico do primeiro mapeamento, onde o plano $\mathrm{X}, \mathrm{Y}$ corresponde às coordenadas da posição das amostras e o eixo $\mathrm{Z}$, representado em escala de cores, apresenta o valor normalizado das doses, tomando como referência o valor máximo obtido no mosaico de amostras. (a) Mapa interpolado. O círculo no centro do mapa corresponde à abertura do copo de Faraday. (b) Mapa sem interpolação. .p.41

Figura 18. Gráfico do segundo mapeamento, onde o plano $\mathrm{X}, \mathrm{Y}$ corresponde às coordenadas da posição das amostras e o eixo $\mathrm{Z}$, representado em escala de cores, apresenta o valor normalizado das doses, tomando como referência o valor máximo obtido no mosaico de amostras. (a) Mapa interpolado. $\mathrm{O}$ círculo no centro do mapa corresponde à abertura do copo de Faraday. (b) Mapa sem interpolação. .p.42

Figura 19. Esquema ilustrando o bloco formado por um filme de PMMA entre duas camadas de resina, para a realização de cortes ultrafinos. .p. 47

Figura 20. Imagem de MEV de uma tela suporte de cobre para TEM, já com um corte ultrafino da amostra sobre ela. ..p. 47

Figura 21. Perfil de implantação de Au com energia de $50 \mathrm{keV}$ em Si, as barras correspondem às profundidades das corrosões realizadas. .p.49

Figura 22. Imagens de AFM-C da amostra corroída em profundidade de $21 \mathrm{~nm}$ : (a) topografia e (b) de ORCA (mapa de condutividade), a região mais escura corresponde à superfície mascarada (não corroída) .p.51

Figura 23. Imagens de AFM-C da amostra corroída em profundidade de $43 \mathrm{~nm}$ : (a) topografia e (b) de ORCA (mapa de condutividade), a região mais escura corresponde à superfície mascarada (não corroída). p. 52

Figura 24. Simulação TRIDYN de implantação de Au em Si com energias de 18, 32 e 50 keV para dose de implantação de $1,2 \times 10^{16}$ átomos $/ \mathrm{cm}^{2}$. p.53

Figura 25. Simulação por TRIDYN de implantação iônica de ouro em PMMA com energia de 50 $\mathrm{keV}$ com doses de $1 \times 10^{15}$ átomos $/ \mathrm{cm}^{2}$ (curva preta) e $1 \times 10^{16}$ átomos $/ \mathrm{cm}^{2}$ (curva vermelha) ..p.54

Figura 26. Imagem TEM de PMMA com ouro implantado com energia de $50 \mathrm{keV}$ e dose de $1 \times 10^{16}$ átomos $/ \mathrm{cm}^{2}$. ..p.54

Figura 27. Imagem TEM de PMMA com ouro implantado com energia de $50 \mathrm{keV}$ e dose de $1 \times 10^{16}$ átomos $/ \mathrm{cm}^{2}$. Duas linhas pontilhadas em vermelho delimitam a camada de 
PMMA, uma outra linha pontilhada em cor azul identifica a região de máximo de concentração de ouro. ..p.55

Figura 28. Imagem TEM de PMMA com ouro implantado com energia de $50 \mathrm{keV}$ e dose de $1 \times 10^{15}$ átomos $/ \mathrm{cm}^{2}$ p.56

Figura 29. Perfil de concentração de ouro ao longo da profundidade em uma amostra de PMMA implantado com uma dose de $0,75 \times 10^{16}$ átomos $/ \mathrm{cm}^{2}$ e energia de $50 \mathrm{keV}$ obtida por RBS (curva preta) e resultado da simulação utilizando TRIDYN (curva vermelha). .p.57

Figura 30. Ilustração esquemática das amostras de alumina, onde as regiões pretas representam os contatos elétricos.

Figura 31. Imagens de MEV de bordas do contato obtido através de soldagem entre cerâmica e metal .p.64

Figura 32. Imagem de MEV de uma preparação de amostra de alumina em pó para TEM.........p.66 Figura 33. Imagens de TEM de pó de alumina com titânio implantado, permitindo a visualização direta das nanopartículas de titânio no interior dos grãos de alumina, ressaltados com círculos nas imagens. (a) Dose implantada de $0.6 \times 10^{16} \mathrm{~cm}^{2}$ e (b) Dose implantada de $1 \times 10^{16} \mathrm{~cm}^{2}$. Durante a observação foi realizada análise por EDS confirmando a presença de titânio na região.

Figura 34. Simulações por TRIDYN de implantação iônica de titânio em alumina com energia de $52.5 \mathrm{keV}$ e doses entre 0.5 e $3 \times 10^{16}$ átomos $/ \mathrm{cm}^{2}$. .p.69

Figura 35. Resultados de RBS e simulação por TRIDYN do perfil em profundidade da fração de titânio implantado em alumina com dose de $1 \times 10^{16}$ átomos $/ \mathrm{cm}^{2}$ e energia de 52,5 $\mathrm{keV}$ .p.70

Figura 36. Medidas de condutividade $\sigma$ em função da dose de titânio implantado $\varphi$ em alumina. Os pontos no gráfico apresentados como quadrados e triângulos e correspondem a resultados de dois experimentos independentes (amostras 1 e 2). p.71

Figura 37. Gráfico normalizado da condutividade do nanocompósito $\left(\sigma / \sigma_{0}\right)$ em função da dose de titânio implantada $\left(\varphi / \varphi_{0}\right)$. p. 72

Figura D.1. Série de simulações TRIDYN do número de átomos espalhados do alvo, por íon incidente, em função do ângulo de incidência do feixe para o caso de alvo de silício e feixe de ions de argônio. .p.79

Figura D.2. Série de simulações com incidência do feixe normal à superfície, gerando o número de átomos espalhados do alvo, por íon incidente, em função da energia do feixe, para o caso de alvo de silício e feixe de ions de argônio. .p. 80

Figura G.1. Alteração de condutividade da amostra durante tempo de 383 dias, para diferentes tensões aplicadas. p. 86 


\section{LISTA DE TABELAS}

Tabela 1. Doses de implantação nas amostras do primeiro mapeamento dadas em $10^{16}$ átomos $/ \mathrm{cm}^{2}$ e as coordenadas X e Y são dadas em milímetros, correspondendo ao centro da posição de cada amostra. O caractere “_” representa uma posição intermediária entre duas amostras e caractere " $x$ " denota ausência de amostras no local ou espectro não consistente .p.40

Tabela 2. Doses de implantação nas amostras do segundo mapeamento dadas em $10^{16}$ átomos $/ \mathrm{cm}^{2}$ e as coordenadas $\mathrm{X}$ e Y são dadas em milímetros, correspondendo ao centro da posição de cada amostra. O caractere “_” representa uma posição intermediária entre duas amostras e caractere " $x$ " denota ausência de amostras no local ou espectro não consistente 


\section{LISTA DE ABREVIATURAS E SIGLAS}

CCD Charge-Coupled Device

CCTM Centro de Ciência e Tecnologia de Materiais

$\mathrm{CNPq}$ Conselho Nacional de Desenvolvimento Científico e Tecnológico

DC Direct Current

EDS Energy-Dispersive X-ray Spectroscopy

FAPESP Fundação de Amparo à Pesquisa do Estado de São Paulo

GUI Graphical User Interface

IGBT Insulated Gate Bipolar Transistor

IFUSP Instituto de Física da Universidade de São Paulo

IPEN Instituto de Pesquisas Energéticas e Nucleares

LFF Laboratório de Filmes Fínos

MEV Microscopia Eletrônica de Varredura

AFM-C Conductive Atomic Force Microscopy

ORCA Optimized Resistance Conductance Amplifier

PDMS Polydimethylsiloxane

RMS Root Mean Squared

DLC Diamond-like carbon

Mevva Metal vapor vacuum arc

PMMA Polymethylmethacrylate

RBS Rutherford Backscattering Spectrometry

SERS Surface-Enhanced Raman Spectroscopy

TEM Transmission Electron Microscopy

TRIM Transport and Range of Ions in Matter

TRIDYN TRIM Dynamic 


\section{LISTA DE SÍMBOLOS}

\begin{tabular}{|c|c|}
\hline$\varphi_{0}$ & dose de saturação \\
\hline$\sigma_{0}$ & condutividade de saturação \\
\hline$\varphi_{c}$ & dose de percolação \\
\hline$t$ & expoente crítico. \\
\hline$E_{i}$ & energia dos íons \\
\hline$e$ & carga do elétron \\
\hline$Q$ & estado de carga dos íons \\
\hline$V_{\text {ext }}$ & tensão no extrator \\
\hline$V_{c h}$ & tensão de cilindro interno \\
\hline$V_{p l}$ & tensão de primeira grade \\
\hline$V_{p g}$ & tensão de fonte de alimentação do canhão de plasma \\
\hline$Q_{A u}$ & estado de carga de ouro \\
\hline$Q_{T i}$ & estado de carga de titânio \\
\hline$Q_{N b}$ & estado de carga de niôbio \\
\hline$I_{e}$ & corrente elétrica \\
\hline$I_{p}$ & corrente de íons \\
\hline$I_{\mathrm{FC}}$ & corrente de copo de Faraday \\
\hline$I_{\text {arc }}$ & corrente de arco de plasma \\
\hline$\sigma$ & condutividade elétrica \\
\hline$x$ & concentração normalizada de átomos metálicos \\
\hline$x_{c}$ & concentração crítica ou limiar de percolação \\
\hline$\rho$ & resistividade da camada compósita \\
\hline$R$ & resistência entre os contatos elétricos \\
\hline$\sigma_{m}$ & condutividade efetiva \\
\hline$l$ & comprimento da área implantada da amostra \\
\hline$w$ & largura da área implantada da amostra \\
\hline$\delta$ & espessura da camada de nanocompósito \\
\hline$z$ & número de vizinho próximos de cada nanopartícula \\
\hline$\sigma_{1}$ & condutividade do material condutor \\
\hline$\sigma_{2}$ & condutividade do material isolante \\
\hline$Y$ & quantidade dos átomos espalhados por um íon \\
\hline$t_{c}$ & tempo de corrosão \\
\hline
\end{tabular}




$\begin{array}{ll}a^{3} & \text { volume do átomo de material } \\ d & \text { profundidade } \\ A & \text { área } \\ N_{A} & \text { número de Avogadro } \\ M_{\mathrm{C}} & \text { massa do átomo } \\ R_{O} & \text { densidade do material }\end{array}$




\section{SUMÁRIO}

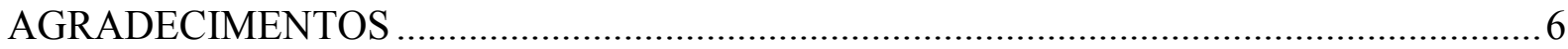

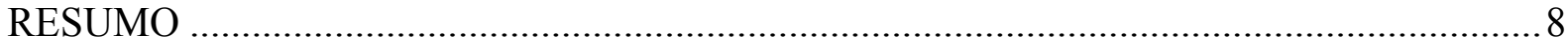

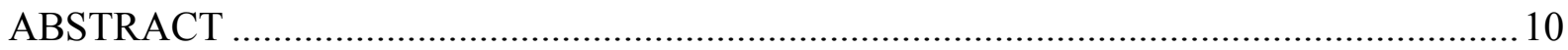

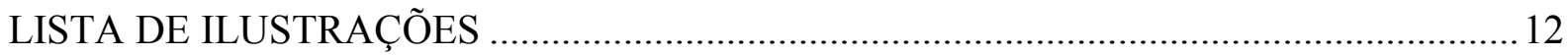

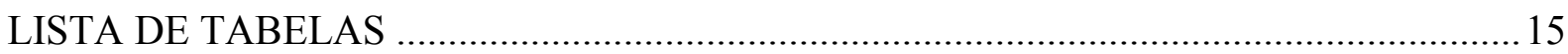

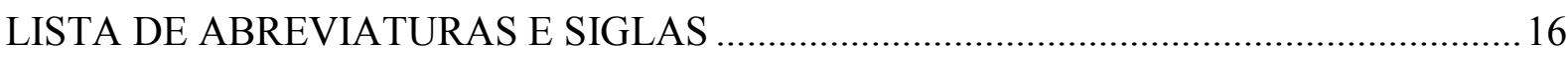

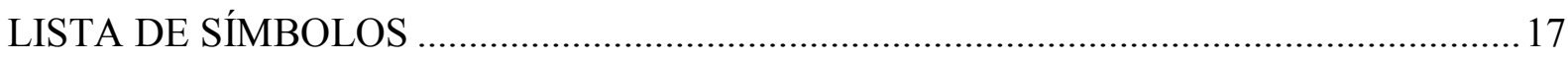

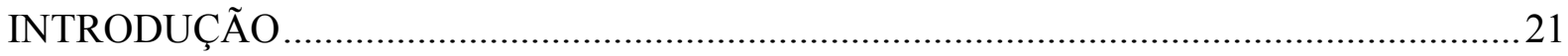

CAPÍTULO 1. DESCRIÇÃO E CARACTERIZAÇÃO DO IMPLANTADOR .....................23

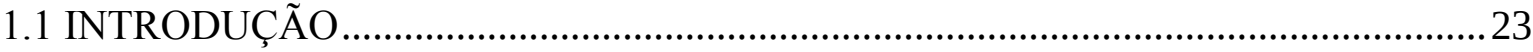

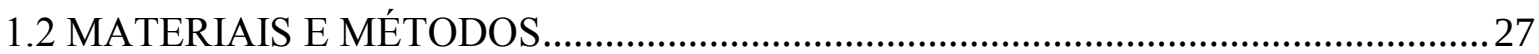

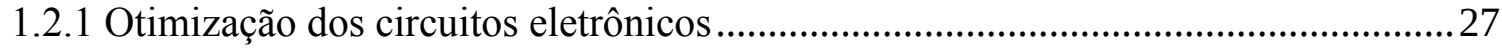

1.2.2 Otimização do feixe iônico do implantador invertido ............................................27

1.2.3 Mapeamento da densidade do feixe no porta amostras do implantador invertido ..29

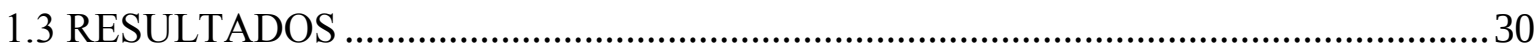

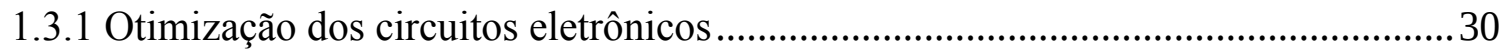

1.3.2 Otimização do feixe iônico do implantador invertido ..............................................34

1.3.3 Mapeamento da densidade do feixe no porta amostras do implantador invertido .. 38

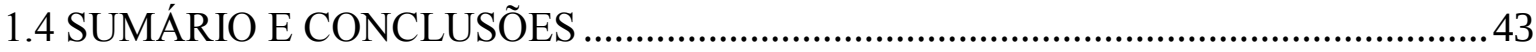

CAPÍTULO 2. ESTUDO DA NEUTRALIDADE DO FEIXE IÔNICO.................................44

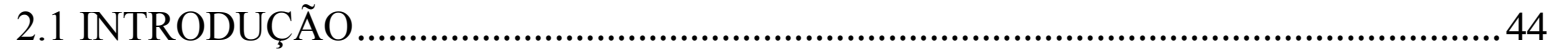

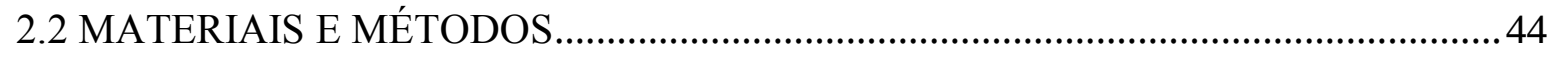

2.2.1 Amostra de silício com ouro implantado.............................................................4

2.2.2 Amostra de PMMA com ouro implantado ........................................................46

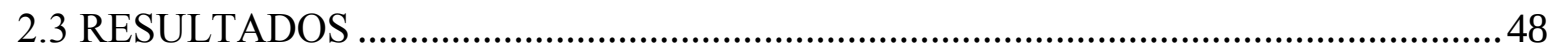

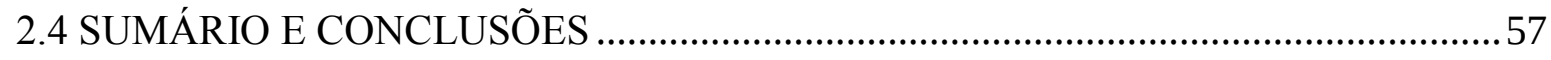

CAPÍTULO 3. APLICAÇÃO PARA O IMPLANTADOR INVERTIDO:

NANOCOMPÓSITO FORMADO POR NANOPARTÍCULAS DE TITÂNIO EM MATRIZ

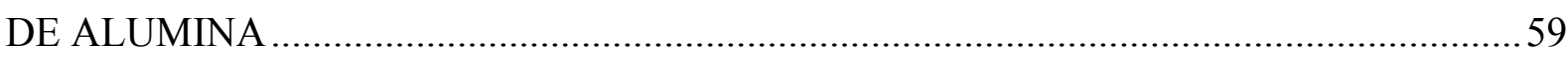

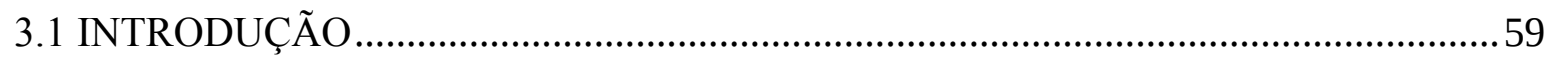


3.3 ESTADO DA ARTE: NANOCOMPÓSITOS FORMADOS ATRAVÉS DE

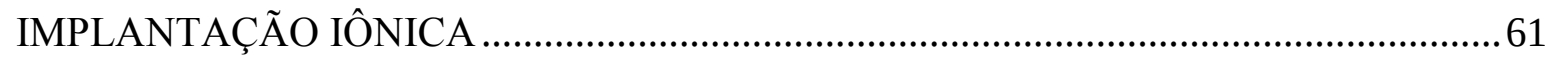

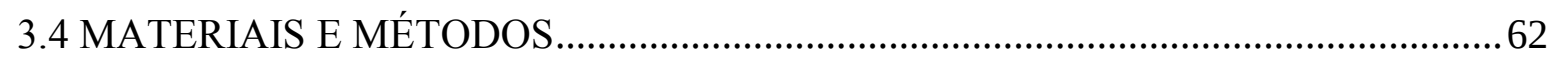

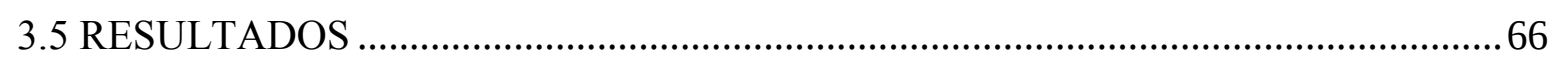

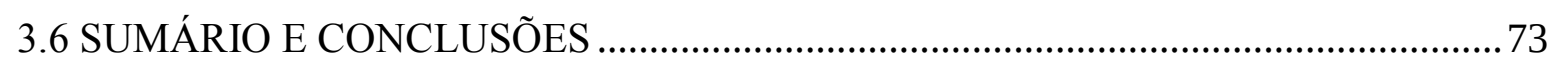

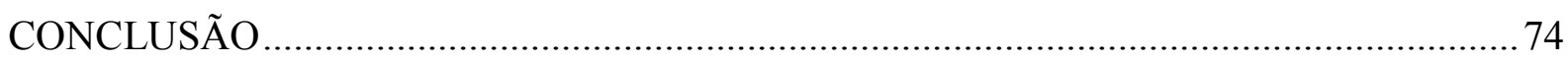

ANEXO A. PUBLICAÇÕES REALIZADAS DURANTE O TRABALHO ……………….....76

ANEXO B. ESQUEMA ELÉTRICO DA FONTE DE ALIMENTAÇÃO $V_{\mathrm{PG}} \ldots \ldots \ldots \ldots \ldots \ldots \ldots \ldots . . . . . . .77$

ANEXO C. ESQUEMA ELÉTRICO DO SISTEMA DE CONTROLE DO CANHÃO DE

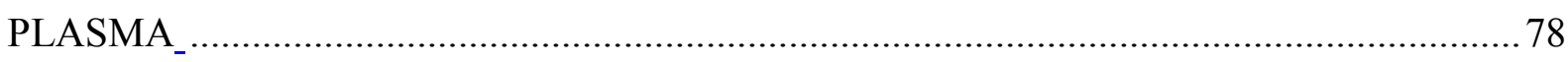

ANEXO D. ESTUDO DE APLICAÇÃO DO IMPLANTADOR INVERTIDO PARA

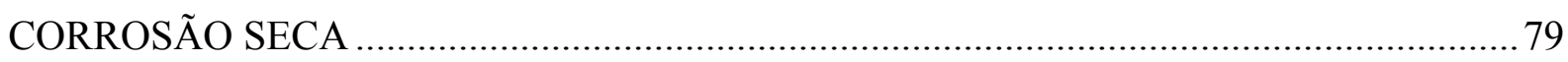

ANEXO E. PROGRAMAS PARA SIMULAÇÃO POR TRIDYN ………………………...... 81

ANEXO F. RECEITAS DAS SOLUÇÕES E MATERIAIS UTILIZADOS NOS

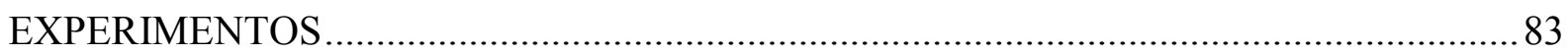

ANEXO G. OBSERVAÇÃO DA AMOSTRA DE ALUMINA COM TITÂNIO

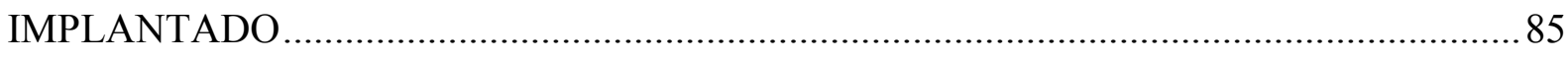

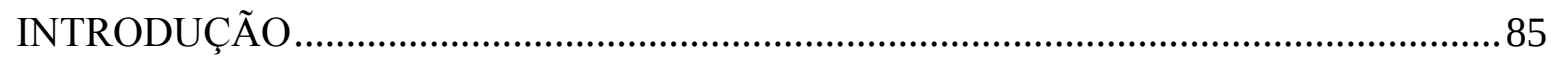

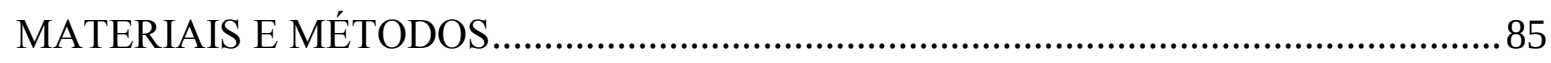

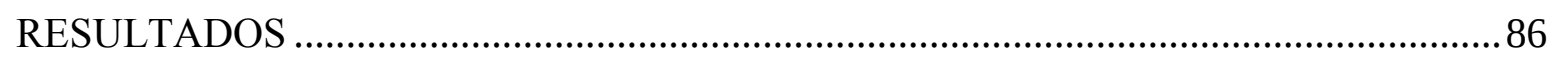

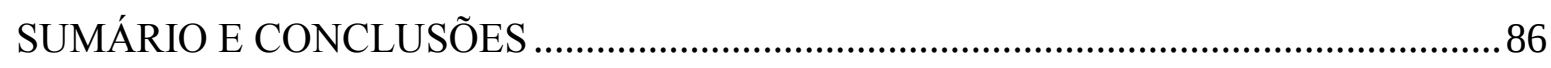

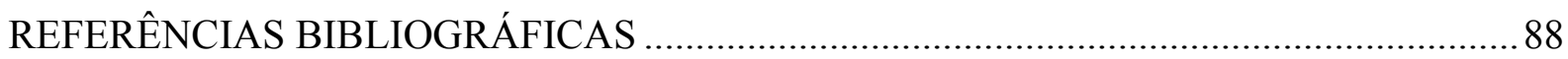




\section{INTRODUÇÃO}

A maior aplicação comercial da implantação iônica em todo o mundo está concentrada na área de microeletrônica. Também há uma grande e ativa comunidade de pesquisadores que estudam implantação iônica para modificação de superfície de materiais com diversas finalidades, como por exemplo aumentar a resistência ao desgaste [1-4], gerar compatibilidade biológica [5,6], desenvolver novos dispositivos de optoeletrônica [7-10], otimizar isoladores de alta tensão [11-13] etc.

Implantação iônica é um processo no qual íons de um dado material são acelerados em um campo elétrico na direção de um substrato, penetrando sua superfície até a completa desaceleração. Os íons perdem gradualmente a energia como resultado de muitas colisões com átomos do material do substrato. A distribuição estatística dos íons implantados no interior do substrato pode ser simulada utilizando o método de Monte Carlo, sendo que os programas mais comumente utilizados para essa finalidade são o TRIM [14] e o TRIDYN $[15,16]$. Implantação iônica utilizando energias que podem variar de algumas dezenas de elétron-volts a alguns milhares de quilovolts leva o material implantado à profundidade entre alguns poucos nanômetros e algumas centenas de nanômetros. A versatilidade da técnica de implantação é devida, essencialmente, a qualquer elemento na tabela periódica poder ser implantado em praticamente qualquer material selecionado como substrato. Essa versatilidade e as várias combinações possíveis de íons implantados permite a obtenção de uma gama extremamente ampla de materiais. Por exemplo, a técnica permite o desenvolvimento de compósitos onde duas ou mais fases podem ser combinadas e integradas, criando nanoestruturas tipo "core-shell” [17,18], o que pode aumentar consideravelmente alguns efeitos optoeletrônicos.

Este trabalho está dividido em três capítulos. No primeiro deles é descrito em detalhes um novo tipo de implantador, aqui denominado "implantador invertido" [19]. Ainda, é apresentado um estudo sistemático com a finalidade de caracterizar o implantador, o que é de grande importância para sua utilização. O segundo capítulo se refere ao estudo da neutralidade do feixe iônico do referido implantador, o que pode afetar enormemente a implantação em substratos isolantes, desde que o acúmulo de cargas em sua superfície levaria a amostra a um potencial diferente do planejado, alterando o perfil de profundidade da implantação. Finalmente, no terceiro capítulo é apresentada uma aplicação para o implantador onde nanocompósito formado por nano partículas de titânio em matriz de alumina é estudado. 
As publicações referentes a este trabalho e a trabalhos em colaboração durante a realização deste Doutorado se encontram listadas no anexo A. 


\section{CAPÍTULO 1. DESCRIÇÃO E CARACTERIZAÇÃO DO IMPLANTADOR}

\subsection{INTRODUÇÃO}

Um implantador utiliza uma fonte de íons, que pode ser de diversas naturezas, os quais são acelerados para a formação de um feixe, exigindo para isso um conjunto de eletrodos, na forma de grades, denominado de "extrator" ou "acelerador". Normalmente os íons são positivos, mas íons negativos também podem ser gerados de forma semelhante, com os potenciais extratores invertidos; aqui por simplicidade assumiremos íons positivos.

A energia do feixe de íons é determinada pela queda de tensão através da qual os íons estão sujeitos no extrator, e pelo estado de carga dos íons: $E_{i}=e Q V_{\text {ext }}$, onde $E_{i}$ é a energia final dos íons, $e$ a carga do elétron, $Q$ o estado de carga dos íons, e $V_{e x t}$ é a queda de tensão no extrator. Numa geometria simples de extrator são utilizados apenas dois eletrodos (grades extratoras ou extractor grids).

Na Figura 1 é apresentado um esquema simplificado da abordagem convencional e a nova abordagem descrita no nosso projeto, o implantador invertido. No caso do implantador convencional, (Figura 1(a)), a primeira grade, mais próximo do plasma (grade do plasma ou plasma grid) é mantida em alto potencial positivo, assim como o plasma, e a segunda grade, posicionada mais próxima da amostra a ser implantada, é mantida aterrada (grade aterrada ou ground grid). Eletrodos adicionais intermediários são muitas vezes utilizados, por exemplo, para bloquear o fluxo de back-streaming de elétrons (grade supressora ou grid supressor). É, portanto, uma parte inerente da abordagem que o plasma e seu sistema de formação sejam mantidos em alto potencial positivo (tensão de extração), incluindo toda a eletrônica da fonte de plasma. Esta necessidade contribui muito para as dificuldades técnicas e alto custo de um implantador convencional.

Existe uma série de vantagens tecnológicas e financeiras para um implantador no qual o plasma e a eletrônica da fonte de plasma sejam mantidos aterrados, que é o cerne do conceito do implantador invertido Figura 1(b). Isso pode ser feito mantendo em alto potencial negativo a grade final (posicionada mais próxima da amostra a ser implantada) e o espaço no qual o feixe é injetado. Neste caso, a queda de tensão extratora permanece elevada, assim como a energia dos íons, mas com um perfil de potencial caindo do terra para uma alta tensão negativa, ao invés de uma alta tensão positiva para o terra. É claro que tal arranjo tem limitações - não é sempre possível manter o material a ser implantado em alto potencial negativo, mas para algumas aplicações isto não é uma restrição severa e o baixo custo e a simplicidade pode perfeitamente compensar esse inconveniente. 


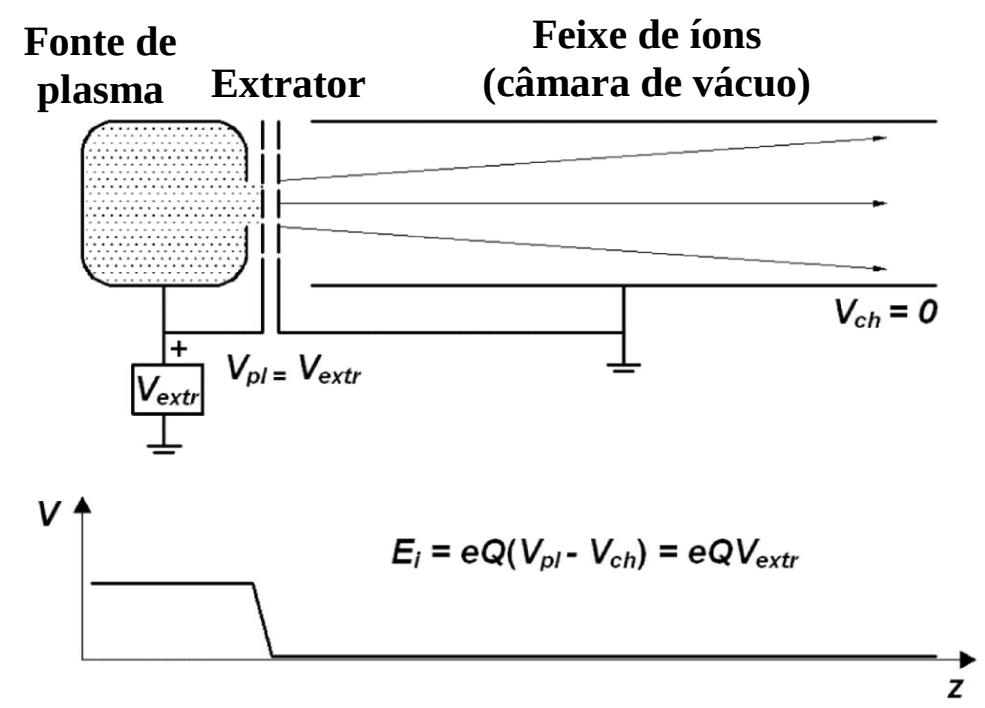

(a)

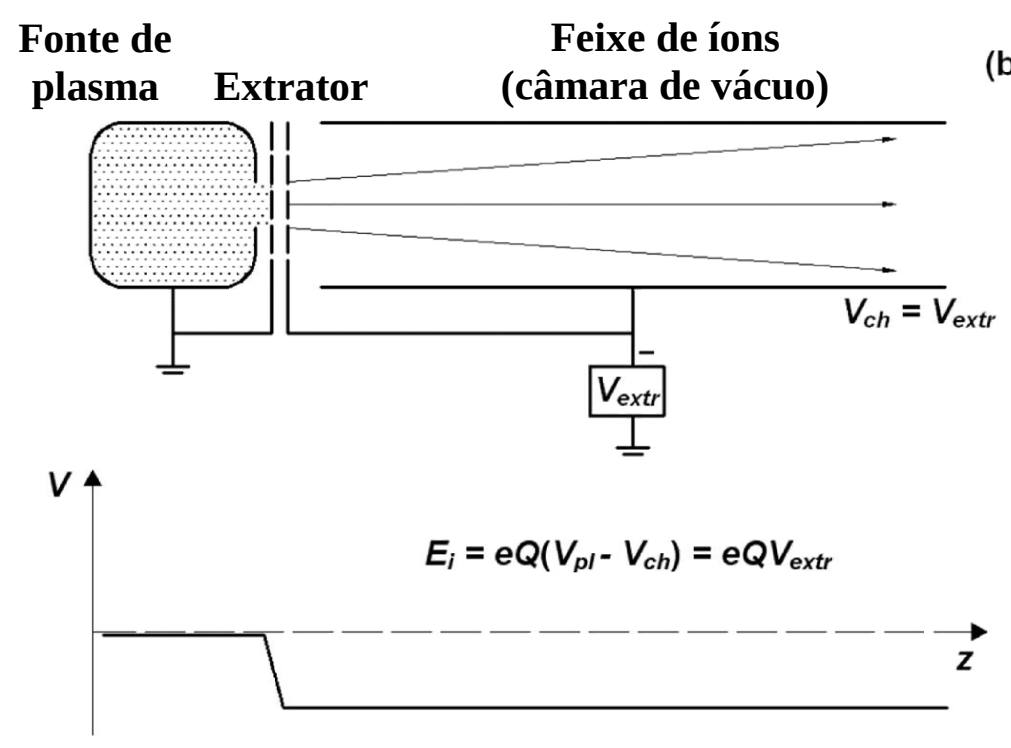

Figura 1. Esquema simplificado da (a) abordagem convencional de um implantador e (b) do implantador invertido [20].

Um esquema simplificado da montagem do implantador invertido é mostrado na Figura 2. Nessa montagem utilizamos plasma de arco catódico pulsado como fonte de íons. Este tipo de fonte é usado rotineiramente em muitos laboratórios e sua física e os princípios envolvidos têm sido bem descritos na literatura [2,3]. Essa fonte consiste em um canhão de plasma formado por um catodo na forma de bastão, do material que se pretende implantar, e um anodo cilíndrico, estando estas duas peças isoladas por um cilindro cerâmico em torno do catodo. Durante a descarga ocorre um faiscamento distribuído aleatoriamente na superfície do catodo (cathode spots), que gera um plasma do material do catodo, juntamente com 
micropartículas que também são ejetadas do catodo. O anodo é passivo, agindo como um coletor de elétrons. Ao sair do canhão, o plasma é focalizado por um campo magnético axial, produzido por uma bobina enrolada no próprio anodo e penetra no filtro de partículas, cuja finalidade é remover do plasma as micropartículas geradas pelo canhão. O filtro de partículas consta de uma bobina com a forma de um quarto de toróide ligado eletricamente em série com a descarga catodo / anodo, o que gera um campo magnético intenso e sincronizado com a descarga pulsada do canhão. A ideia para a filtragem de partículas é guiar o arco de plasma pelo campo magnético gerado nessa bobina curva, separando as micropartículas que terão trajetórias praticamente retas, por possuírem grande inércia, chocando-se com as paredes da câmera de vácuo. Assim o plasma fica livre da contaminação das micropartículas [21,22]. A fonte de alimentação do canhão de plasma consiste basicamente de um circuito LCR de impedância $1 \Omega$ e duração de pulso de $100 \mu$ s, fornecendo uma corrente de até várias centenas de amperes a uma taxa de repetição de 1 a 10 pulsos por segundo. $O$ fluxo de plasma de ouro saindo do filtro de partículas foi direcionado para a primeira grade (aterrada) do implantador. O desenho técnico do implantador é dado na Figura 3. Os eletrodos de formação do feixe (extractor grids) são a abertura de entrada para o implantador, para o qual o plasma é dirigido. Um cilindro externo (outer cup) é mantido aterrado e sustenta a primeira grade de entrada do plasma. Um cilindro interno (inner cup), eletricamente isolado do cilindro externo (aterrado), é mantido em alta tensão negativa $\left(V_{e x t}\right)$. Esse cilindro interno sustenta a segunda grade extratora, por onde entra o plasma. Assim, um feixe de íons é formado a partir do plasma através das grades extratoras e é injetado para dentro do cilindro mantido em alta tensão negativa, em direção a um copo de Faraday. O copo de Faraday também é mantido na mesma alta tensão negativa do cilindro interno, mas é eletricamente isolado dele. Na entrada do copo de Faraday é colocado um par de imãs permanentes de cobalto-samário (com ferro doce confinando o retorno das linhas de campo) que gera um campo magnético transverso. Esse campo magnético age como uma barreira para os elétrons do feixe, permitindo a entrada apenas dos íons no copo de Faraday. Este projeto de copo de Faraday é conhecido por fornecer uma medição confiável de corrente de íons do feixe, que é monitorada por um transformador de corrente isolado. 


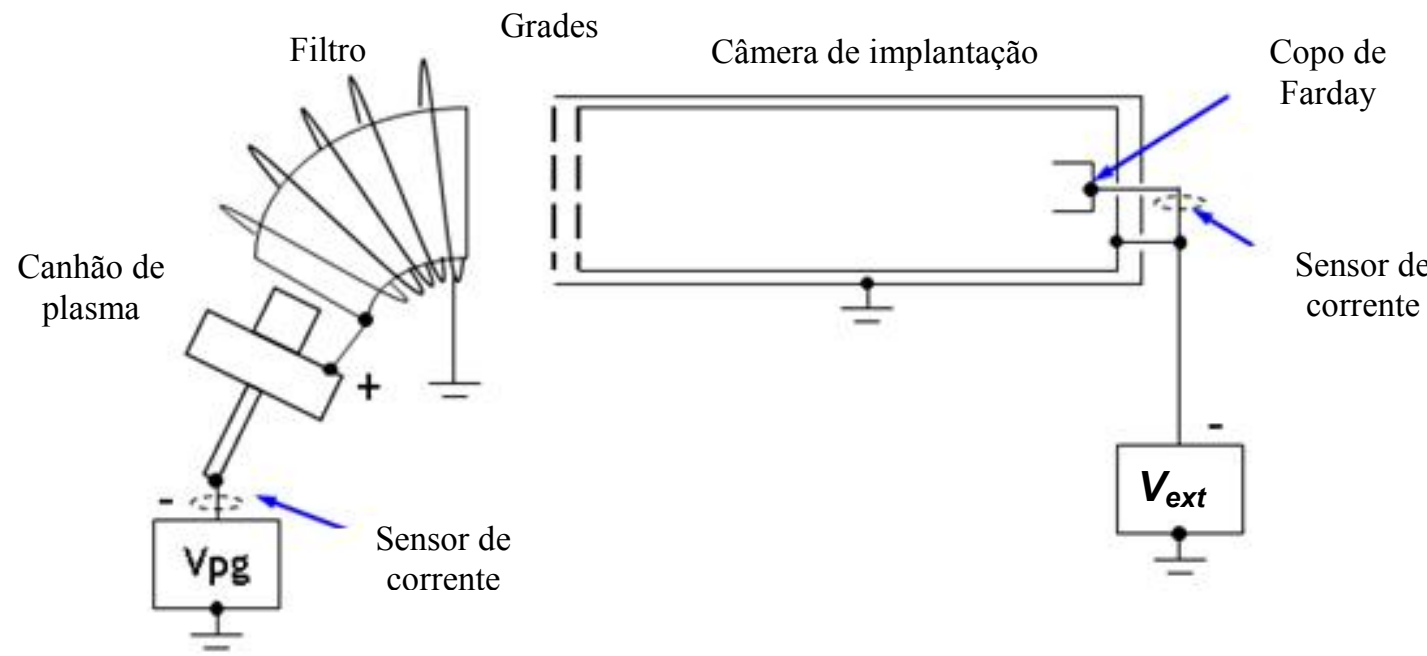

Figura 2. Esquema do implantador, onde $\mathrm{V}_{\mathrm{pg}}$ é a fonte de alimentação do canhão de plasma e $\mathrm{V}_{\mathrm{ext}}$ é a fonte de alta tensão.

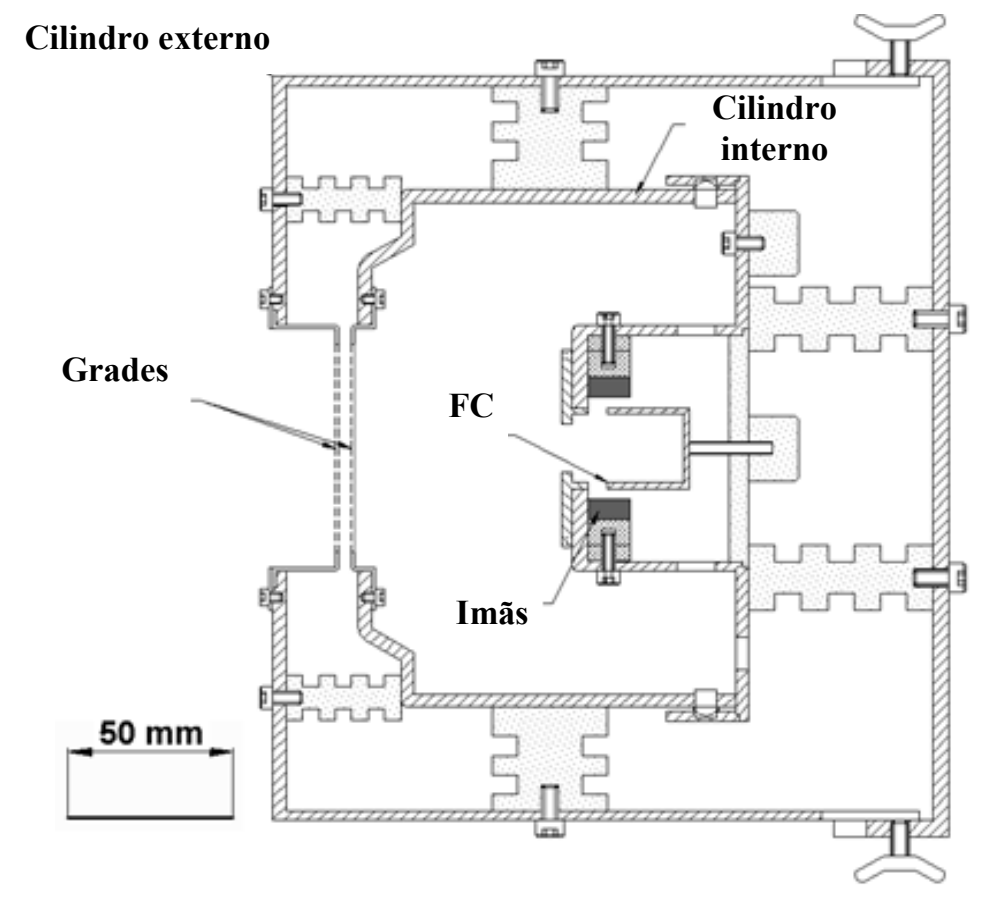

Figura 3. Desenho técnico do implantador.

A alta tensão negativa $\left(V_{\text {ext }}\right)$ foi obtida utilizando uma fonte comercial de DC "Spellman SL 300" (50 kV, $6 \mathrm{~mA})$. Para obter correntes maiores que $6 \mathrm{~mA}$ para o feixe de íons, a fonte DC foi conectada a um circuito RC.

Na configuração descrita, o feixe iônico é gerado a partir das grades extratoras que são formadas por cerca de 100 orifícios com diâmetro de 3 ou 4 ou $5 \mathrm{~mm}$, espaçados de $0,5 \mathrm{~mm}$ à $1 \mathrm{~mm}$. Assim, o feixe iônico final é uma superposição de um grande número de feixes com diâmetros da ordem de poucos milímetros. À medida que o feixe se propaga, esses feixes com pequeno diâmetro divergem e formando um feixe uniforme.

A fim de maximizar a corrente de feixe de íons que chega na posição da amostra e do 
copo de Faraday, precisa-se uma distância mínima entre as grades extratoras e o copo de Faraday, mas sem comprometer a uniformidade do feixe. Uma distância de $6 \mathrm{~cm}$ entre as grades e o copo de Faraday se mostrou suficiente [20].

Neste capítulo serão abordados desenvolvimento e caracterização do implantador invertido, estando dividido em três partes. A primeira delas se refere à otimização dos circuitos eletrônicos; a segunda parte consiste na caracterização do sistema quanto à maximização do feixe iônico coletado no copo de Faraday, mediante a variação de parâmetros como potencial extrator, corrente do canhão de plasma (arco catódico) dentre outros; finalmente, a terceira parte se refere ao mapeamento da densidade do feixe no porta amostras do implantador invertido.

\subsection{MATERIAIS E MÉTODOS}

\subsubsection{Otimização dos circuitos eletrônicos}

A eletrônica do implantador invertido tem 4 blocos que são: (i) fonte de alimentação e (ii) sistema de controle do canhão de plasma, (iii) sistema de alta tensão e (iv) sistema de medição.

A fonte de alimentação e o sistema de controle do canhão de plasma $\left(V_{p g}\right)$ foram finalizados e otimizados usando os recursos do Laboratório de Filmes Finos (LFF), além do desenvolvimento do sistema de alta tensão e do sistema de medição.

Foram ainda realizados diversos procedimentos com a finalidade de proteger os circuitos eletrônicos e melhorar a estabilidade geral do sistema.

\subsubsection{Otimização do feixe iônico do implantador invertido}

Os experimentos realizados tiveram como objetivo minimizar a divergência do feixe criado a partir das grades extratoras, para se obter a máxima corrente de feixe iônica no copo de Faraday. Para isso, a geometria das grades extratoras precisa ser adequada à densidade de plasma na entrada da primeira grade [20]. Uma vez que essa densidade de plasma não é conhecida, a determinação da geometria ideal das grades (tamanho das aberturas e espaçamento entre as grades) é um trabalho empírico que deve rastrear toda a faixa de tensão aceleradora e de corrente do arco de plasma.

Assim, medidas da corrente iônica foram realizadas mediante a variação do potencial extrator, da corrente do arco catódico, do tipo de íon metálico utilizado, do espaçamento de grades extratoras e do tamanho das aberturas das grades extratoras.

A pressão de base na câmera do implantador ao longo dos experimentos foi de cerca 
de $2 \times 10^{-6}$ torr. O comprimento de pulso utilizado na fonte de plasma foi de $100 \mu$ s com uma taxa de repetição de até 5 pulsos por segundo. A corrente de arco variou de 75 A à $190 \mathrm{~A}$, sendo controlada pela tensão da fonte de alimentação de 50 à $600 \mathrm{~V}$ com passo de $50 \mathrm{~V}$.

Os materias dos catodos utilizados para essa caracterização foram: titânio, nióbio e ouro. A alta tensão aplicada na grade extratora foi variada entre 5 e $25 \mathrm{kV}$. As grades extratoras utilizadas foram três diferentes pares (idênticos) com diâmetros de abertura $(d)$ dados por $3 \mathrm{~mm}, 4 \mathrm{~mm}$ e $5 \mathrm{~mm}$, sempre espaçados de $0,5 \mathrm{~mm}$ à $1 \mathrm{~mm}$ (veja Figura $4 \mathrm{a}$ ). $\mathrm{O}$ espaçamento entre as grades $(\ell)$ também foi um parâmetro considerado (veja Figura 4b), tomando valores de $3 \mathrm{~mm}, 4 \mathrm{~mm}$ e $5 \mathrm{~mm}$. A corrente do feixe iônico foi monitorada pelo do copo de Faraday com uma abertura de $2,1 \mathrm{~cm}$ de diâmetro ou $3,5 \mathrm{~cm}^{2}$ de área. $\mathrm{O}$ plasma formado pela descarga por arco catódico contem espécies com ionização múltipla [20]. No caso do titânio, a distribuição de estados de carga é $\mathrm{Ti}^{+}: \mathrm{Ti}^{2+}: \mathrm{Ti}^{3+}=11: 75: 14$ (frações \% de partículas), com carga média de $\mathrm{Q}_{\mathrm{Ti}}=2,1$; para o ouro $\mathrm{Au}^{+}: \mathrm{Au}^{2+}: \mathrm{Au}^{3+}=14: 75: 11$ com média de $\mathrm{Q}_{\mathrm{Au}}=2,0$ e para o nióbio $\mathrm{Nb}^{+}: \mathrm{Nb}^{2+}: \mathrm{Nb}^{3+}: \mathrm{Nb}^{4+}: \mathrm{Nb}^{5+}=1: 24: 51: 22: 2$ com média de $\mathrm{Q}_{\mathrm{Nb}}=$ 3,0. Assim, por exemplo, em uma tensão de extração de $35 \mathrm{kV}$, a energia média do feixe de íons foi de 73,5 keV para $\mathrm{Ti}, 70 \mathrm{keV}$ para $\mathrm{Au}$, e $105 \mathrm{keV}$ para $\mathrm{Nb}$.

(a)

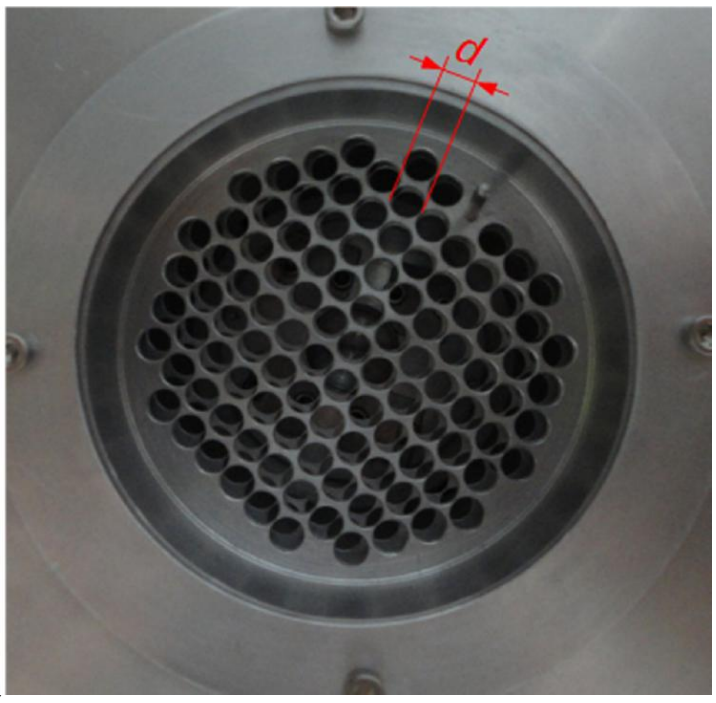

Grades extrator e acelerador

(b)

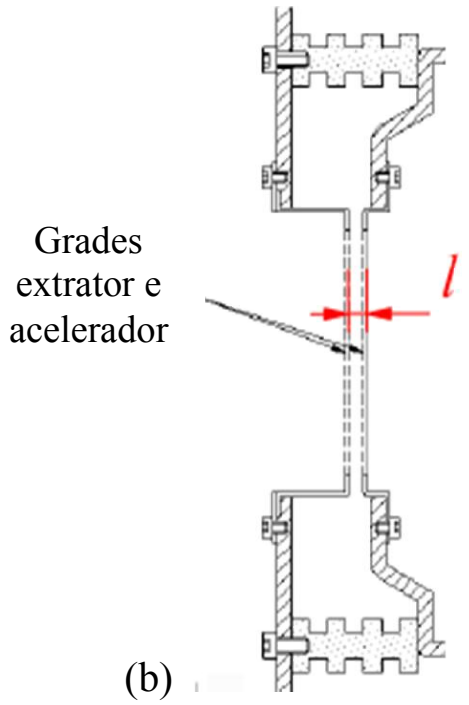

Figura 4. Configuração das grades extratoras do implantador invertido. (a) Visão de topo e (b) e visão lateral.

Uma técnica adicional que foi utilizada para reduzir a influência dos parâmetros estudados (corrente de arco de plasma, tensão de extração, espaçamento das grades e aberturas das grades) sobre a corrente do feixe iônico consiste em cobrir a primeira grade com uma fina malha condutora. Dessa forma o plasma fica restrito ao plano da malha, permitindo a utilização de uma larga faixa dos parâmetros mencionados, sem grande alteração da corrente do feixe iônico. A desvantagem no uso dessa malha consiste em uma redução da densidade do 
plasma de um fator aproximadamente igual à transparência da malha e, portanto, reduzindo igualmente a corrente do feixe iônico, mas que ainda pode ser vantajosa. A malha utilizada para essa finalidade foi de aço inoxidável de 55\% de transparência, com abertura de malha de $150 \mu \mathrm{m}$.

\subsubsection{Mapeamento da densidade do feixe no porta amostras do implantador invertido}

O objetivo deste experimento é a obtenção de um diagrama em duas dimensões da distribuição da densidade do feixe iônico no porta-amostra do implantador invertido. Foi montado um mosaico de amostras, como apresentado na Figura 5. As amostras usadas foram de silício e possuem forma quadrada com lados de $7 \mathrm{~mm}$, com exceção de uma que é circular e o material é de carbono vítreo. Esta última amostra foi introduzida para verificar se alguma contaminação poderia estar presente nas amostras, desde que o carbono vítreo permite a detecção de uma gama maior de elementos através de RBS (Rutherford Backscattering Spectrometry), técnica utilizada para análise dessas amostras.

RBS é um método que utiliza, por exemplo, um feixe de partículas alfa com energia típica de $2 \mathrm{MeV}$ direcionado para a amostra. As partículas alfa interagem com os átomos da superfície da amostra gerando um retroespalhamento. $\mathrm{O}$ detector está posicionado próximo a amostra, coletando partículas alfa com espalhamento de $170^{\circ}$ com relação ao feixe incidente e identificando sua energia. A energia transferida nas colisões entre as partículas alfa e os átomos da amostra depende da massa de cada elemento presente na amostra, permitindo sua identificação. Para a análise do espectro de RBS, foi utilizado o software RUMP.

RUMP [23] é um conjunto de subprogramas realizados no GUI de GENPLOT, desenvolvido por Michael Thompson, da Universidade de Cornel, EUA. Esse aplicativo foi projetado especificamente para a análise e simulação de dados RBS e pode ser utilizado para a determinação da composição da amostra. 


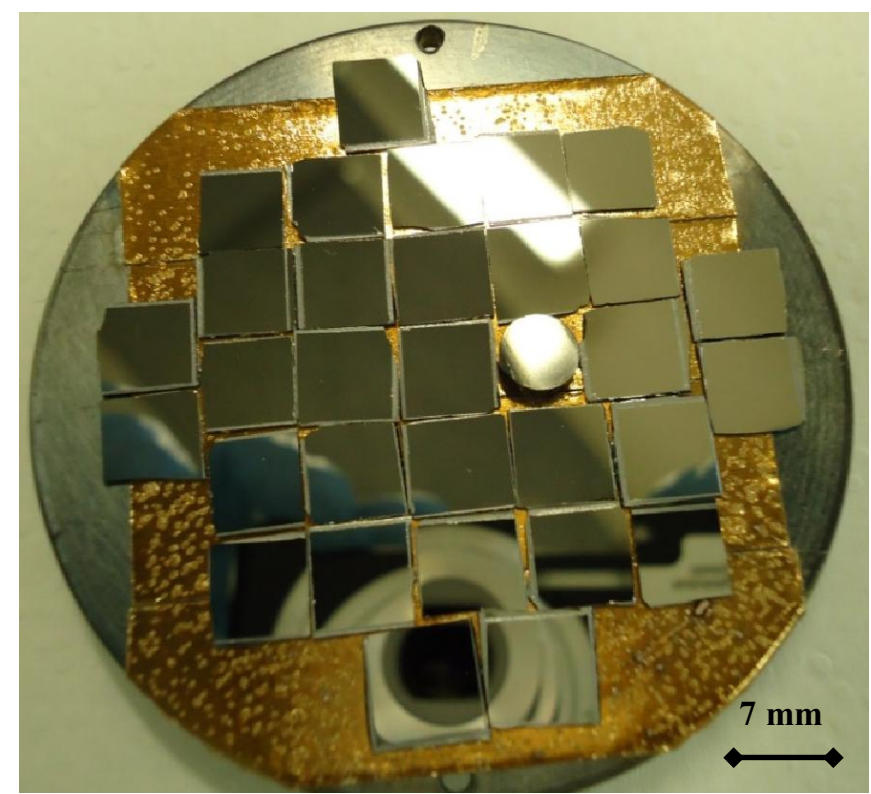

Figura 5. Foto do mosaico de amostras para o mapeamento da densidade do feixe no porta amostras do implantador invertido.

Para o referido mapeamento consideraremos o conjunto de amostras como um espaço de grade identificando cada amostra por meio de coordenadas, como é ilustrado na Figura 6. A dose de implantação de cada amostra será acrescido a esse diagrama em mais uma coordenada, perpendicular ao plano X,Y.

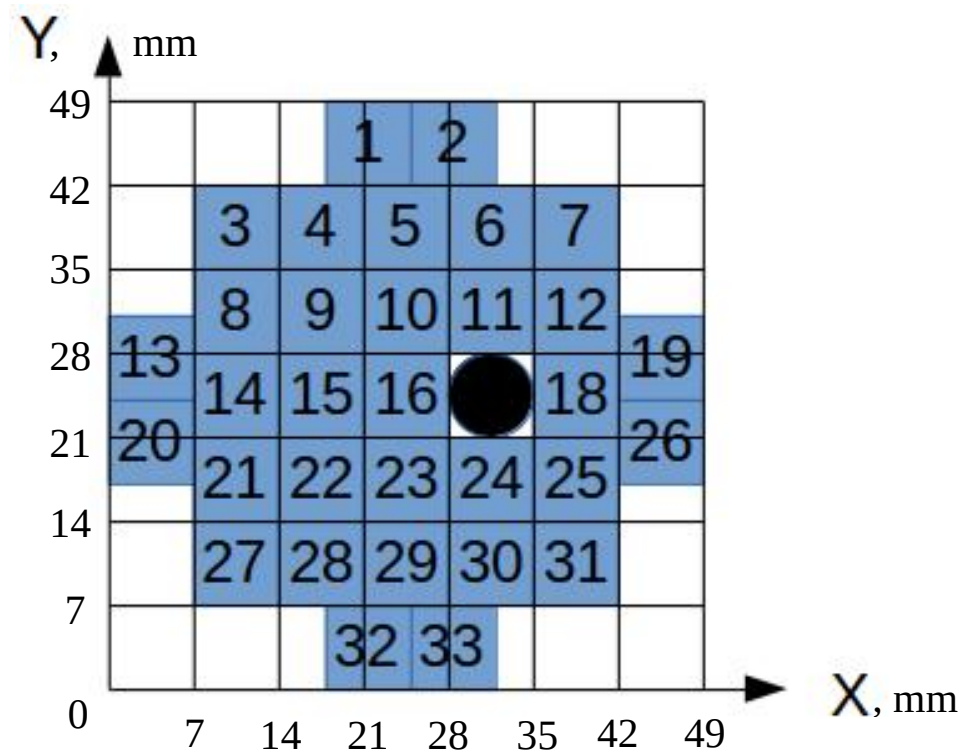

Figura 6. Espaço de grade identificando cada amostra através de coordenadas.

\subsection{RESULTADOS}

\subsubsection{Otimização dos circuitos eletrônicos}

A fonte de alimentação do canhão de plasma $\left(\mathrm{V}_{\mathrm{pg}}\right)$, definida como item (i) em materiais e métodos, é apresentada na Figura 7. Essa fonte possui um autotransformador 
variável T1 ligado a uma rede elétrica de $110 \mathrm{VAC}$, o que consiste basicamente de um transformador que permite variar a tensão de saída girando o fuso e, assim, regular a carga desejada da fonte. Após o autotransformador há um retificador VD1..VD4 e um capacitor de entrada C1 que transforma a tensão AC para DC. As chaves SB1 e SB2 com os resistores R1 e R3 mantem o controle de descarga dos capacitores C1 e C6, formando um sistema de aterramento que desativa a fonte no caso de emergência e protege o usuário após o término do uso do equipamento. O filtro composto por C2, L1; C3, L2; C4, L3 e C5, L4 fornece a taxa adequada de aumento de corrente na saída da fonte e os resistores R2 e R4 limitam a corrente que passa pelo circuito. Alterando o sinal de controle do transistor VT1 é possível abri-lo no tempo desejado, gerando o pulso de alta corrente para canhão de plasma. O supressor VD13 serve para proteger o transistor VT1, cortando os ruídos que aparecem em sua abertura e fechamento. Por fim, os diodos VD6 e VD7 protegem a fonte de breakdowns e de qualquer outro potencial externo que venha a ser aplicado na saída da fonte.

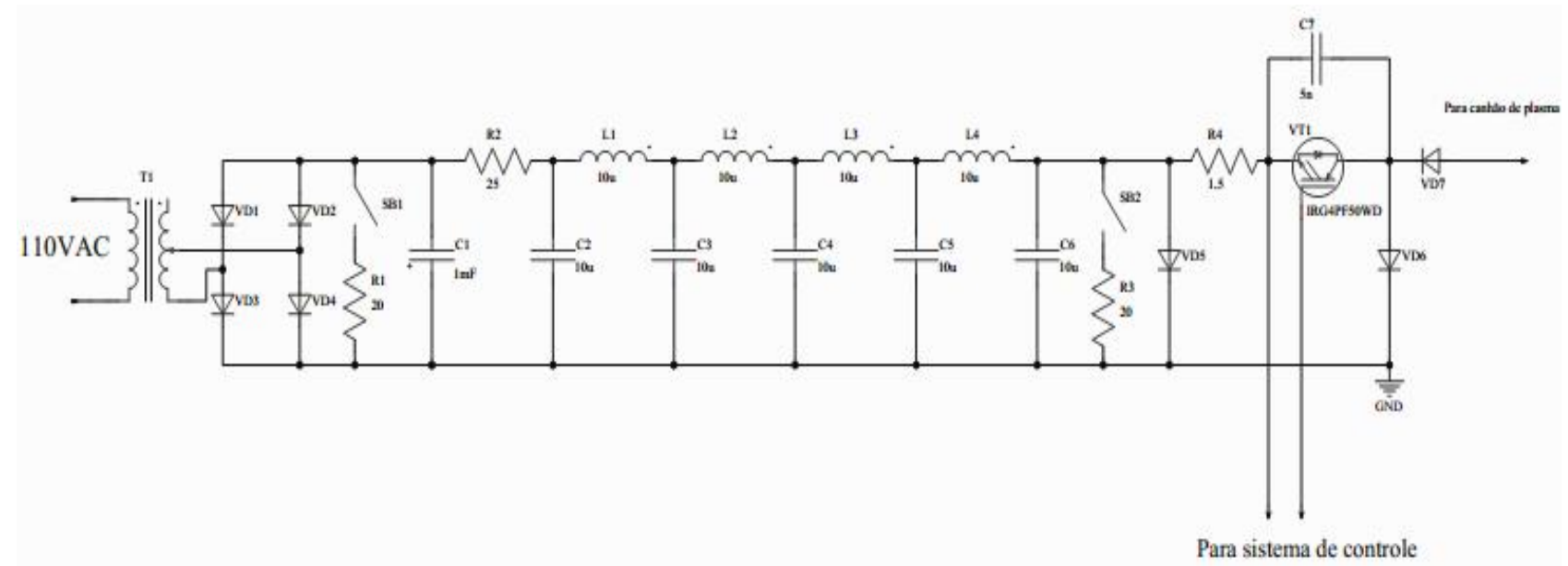

Figura 7. Esquema elétrico da fonte de alimentação $V_{p g}$. Este esquema elétrico é apresentado com maior ampliação no Anexo B.

O sistema de controle do canhão de plasma, definido como item (ii) em material e métodos, é composto por um bloco de controle do transistor do tipo IGBT, apresentado na Figura 8, e um gerador de sinais da marca BNC (Berkeley Nucleonics Corp.), modelo 505-4C PULSE/DELAY Generator. A ligação do sistema de controle do canhão de plasma com a respectiva fonte é apresentada na Figura 7. Esse sistema basicamente controla o transistor que dispara o canhão de plasma. A função do gerador é produzir impulsos temporizados para o bloco de controle de transistor que os transmite ao um buffer SN75453. O bloco de controle possui dois canais de entrada para o IGBT driver (ACPL-K342), um elétrico (BNC input) e outro óptico DA3, que controla o transistor. Ainda, fazendo parte do sistema de controle do canhão de plasma, na Figura 8 é apresentado 3 fontes de alimentação de $+5 \mathrm{~V},+15 \mathrm{~V}$ e $-15 \mathrm{~V}$ 
dos microcircuitos eletrônicos, necessárias para seu funcionamento.

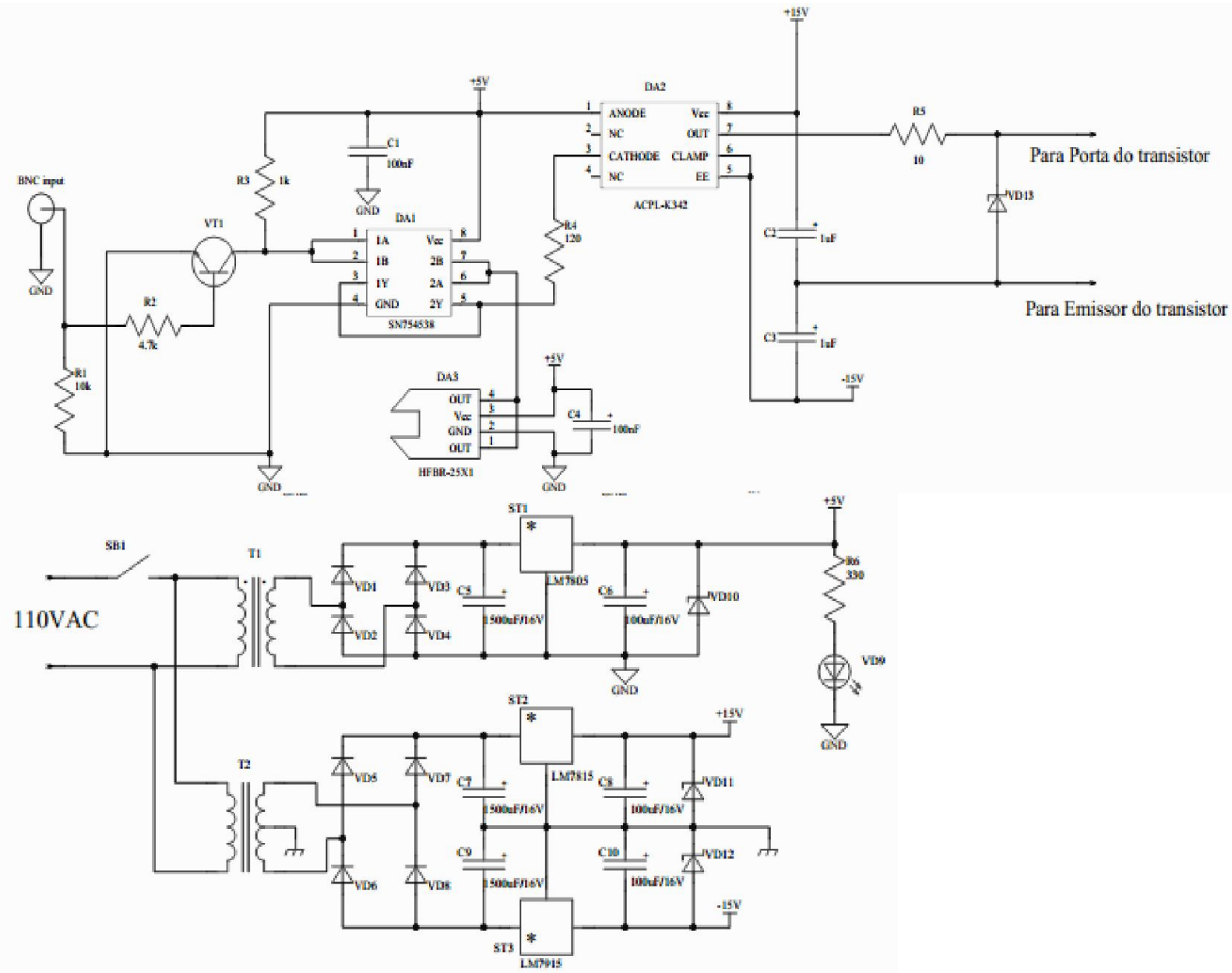

Figura 8. Esquema elétrico do sistema de controle do canhão de plasma. Este esquema elétrico é apresentado com maior ampliação no Anexo C.

Pois o sistema apresentava problemas de instabilidade e não funcionamento, levando à queima frequente do transistor VT1 e consequentemente gerando problemas no bloco de controle. Logo, porque o sistema funcionasse corretamente, foi preciso achar uma solução por estes problemas. As correções realizadas foram ajustes nos valores de elementos do filtro, seleção do transistor VT1 mais adequado, e adição ao circuito de um supressor VD13 e os diodos de saída VD6 e VD7. Somado a isso, adicionei ao circuito os capacitores e supressores nas linhas de alimentação e linhas de sinais para filtrar os ruídos. O resultado da revisão realizada nestes blocos foi o funcionamento, propriamente dito, do sistema. Antes da referida revisão, a queima de elementos e interrupção de funcionamento eram frequentes, inviabilizando seu uso.

A seguir serão descritos os sistemas de alta tensão e de medição, definidos como itens (iii) e (iv) em material e métodos. Esses dois sistemas foram desenvolvidos e montados 
durante este trabalho.

Na Figura 9 é apresentado o esquema elétrico de alimentação do sistema de alta tensão. A fonte de alta tensão foi adquirida da empresa SPELLMAN, modelo SL300, com valores nominais de máxima tensão e corrente dadas por $50 \mathrm{kV}$ e $6 \mathrm{~mA}$, respectivamente. Para obter correntes maiores de $6 \mathrm{~mA}$ no feixe de íons, a fonte DC foi conectada a um circuito RC. $\mathrm{O}$ resistor $\mathrm{R} 1$ tem valor superior ao de $\mathrm{R} 3$ para que o circuito $\mathrm{C} 1-\mathrm{R} 3$ funcione como uma fonte individual. A chave SB1 e o resistor R2 é um sistema de descarga do capacitor C1 para proteger o usuário de impacto residual da carga de alta tensão. A chave SB1 também está conectada na entrada de travamento da fonte de alta tensão para impedir o funcionamento desta quando a chave está na posição desligada. Das duas saídas do sistema de alta tensão apresentadas na Figura 9, uma é conectada ao copo de Faraday e a outra ao cilindro interno do implantador invertido (veja Figura 3).

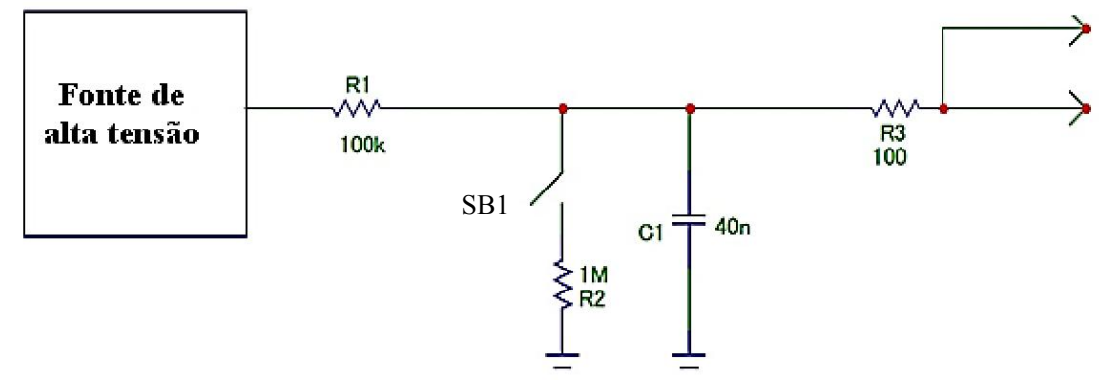

Figura 9. Esquema elétrico do sistema de alta tensão.

O sistema de medição é composto basicamente por um osciloscópio e dois medidores de corrente. O osciloscópio é da TEKTRONIX, modelo TDS 2002C, e os dois medidores de corrente são transformadores, um deles também da TEKTRONIX, modelo A621, é usado para medir a corrente do arco do canhão de plasma e o outro medidor de corrente é da PEARSON ELECTRONICS inc., modelo 3100, que é usado para medir a corrente do copo de Faraday. Os dois medidores de corrente são conectados ao osciloscópio que apresenta formas dos pulsos.

Um oscilograma típico é apresentado na Figura 10, mostrando a corrente de arco $I_{\text {arc }}$, e a corrente detectada pelo copo de Faraday $\left(I_{F C}\right)$. A tensão de extração neste caso foi de $25 \mathrm{kV}$ e o catodo utilizado foi de ouro, portanto, a energia média dos íons foi de $50 \mathrm{keV}$. O pico da corrente no copo de Faraday foi de $20 \mathrm{~mA}$ (electrical milliamperes); note que para íons de múltipla carga, a corrente elétrica $I_{e}$ é diferente da corrente de íons $I_{p}$ que é dada por $I_{p}=I_{e} / Q$, onde $Q$ é o estado de carga dos íons. Considerando a integral da corrente medida no copo de Faraday $I_{F C}$ ao longo do tempo e sabendo que a entrada do copo de Faraday possuía uma abertura de 2,1 cm de diâmetro foi possível calcular a densidade de corrente do feixe de íons 
de $10 \mathrm{~mA} / \mathrm{cm}^{2}$.

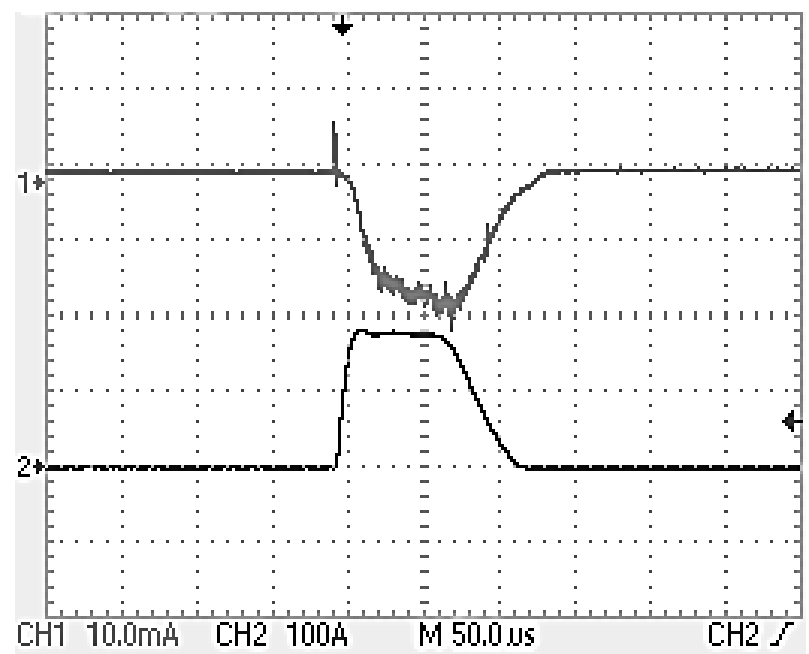

Figura 10. Oscilograma da corrente do copo de Faraday, IFC, (curva de cima, $10 \mathrm{~mA} / \mathrm{cm}$ ) e da corrente de arco de plasma, Iarc, (curva de baixo $100 \mathrm{~A} / \mathrm{cm}$ ); a escala horizontal é de $50 \mu \mathrm{s} / \mathrm{cm}$. A tensão de extração utilizada foi de $25 \mathrm{kV}$ e o catodo utilizado foi de ouro, portanto, a energia média dos íons foi de $50 \mathrm{keV}$.

Ao longo do desenvolvimento da eletrônica do implantador invertido foi tomado especial cuidado no arranjo da fiação elétrica, desde que campos eletromagnéticos gerados pela posição errática da fiação pode interferir com equipamentos eletrônicos.

Finalmente, é necessário especial cuidado com a emissão de raios-X em sistemas de alta tensão no vácuo com plasma, pois pode se tornar um sério problema de segurança pessoal para tensões de $20 \mathrm{kV}$ ou mais. Para proteção dos usuários, utilizamos blindagem para raios-X adequada (flanges de aço inoxidável da câmara de vácuo com espessura de $15 \mathrm{~mm}$ ) e monitoramento dessa radiação através de detector Fluke Biomedical de modelo 451P-RYR.

\subsubsection{Otimização do feixe iônico do implantador invertido}

Na Figura 11 é apresentado o gráfico da corrente do feixe em função da corrente do arco de plasma para o caso do titânio em sete diferentes tensões de extração entre 5 e $35 \mathrm{kV}$, utilizando espaçamento das grades extratoras de $3 \mathrm{~mm}$ e diâmetro das aberturas das grades de $4 \mathrm{~mm}$. Nesse gráfico podemos observar que, para a tensão de extração de $35 \mathrm{kV}$ e corrente de arco de plasma acima de 200 A, a corrente do feixe iônico chega a valores acima de $500 \mathrm{~mA}$, que corresponde a uma densidade de corrente acima de $150 \mathrm{~mA} / \mathrm{cm}^{2}$, dada a abertura do copo de Faraday de $2,1 \mathrm{~cm}$ de diâmetro $\left(3,5 \mathrm{~cm}^{2}\right.$ de área). Note ainda que, sendo o estado de carga médio para o Ti de 2,1, teremos uma energia de feixe de $73 \mathrm{keV}$, com a tensão extratora de 35 $\mathrm{kV}$. Com esses mesmos dados podemos apresentar um gráfico da corrente do feixe em função da tensão de extração, para diferentes correntes do arco de plasma (veja Figura 12). 
Estas curvas apresentadas nas Figuras 11 e 12 é mostrado o comportamento típico de uma fonte de íons, e podem ser comparadas com o desempenho de uma fonte de íons tipo Mevva (metal vapor vacuum arc) [24]. As correntes de feixe de íons (ou mais especificamente, as densidades de corrente de feixe de íons), obtidas com o implantador invertido são comparáveis com as correntes obtidas com a fonte de íons tipo Mevva, mais convencional.

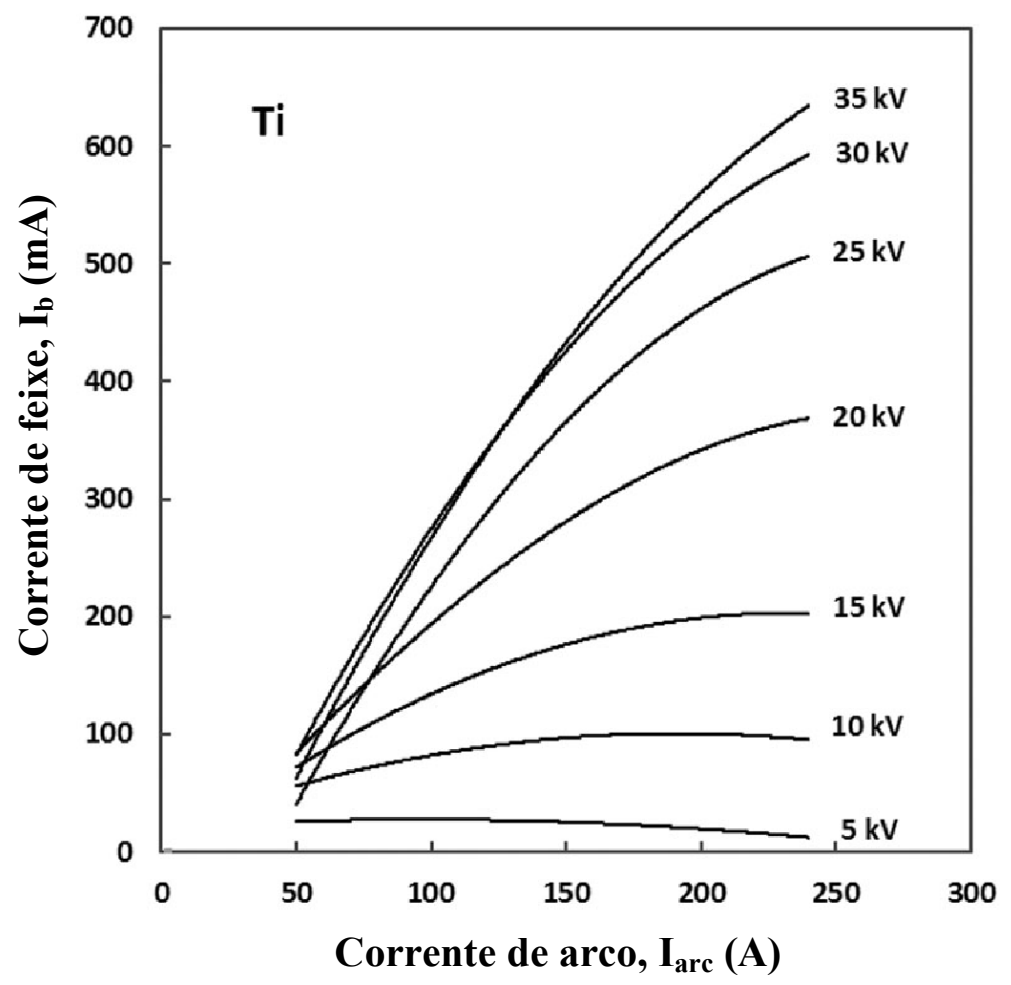

Figura 11. Corrente do feixe em função da corrente do arco de plasma para o caso do Ti em sete diferentes tensões de extração (de 5 a $35 \mathrm{kV}$ ), utilizando espaçamento das grades extratoras de 3 mm e diâmetro das aberturas das grades de $4 \mathrm{~mm}[20]$. 


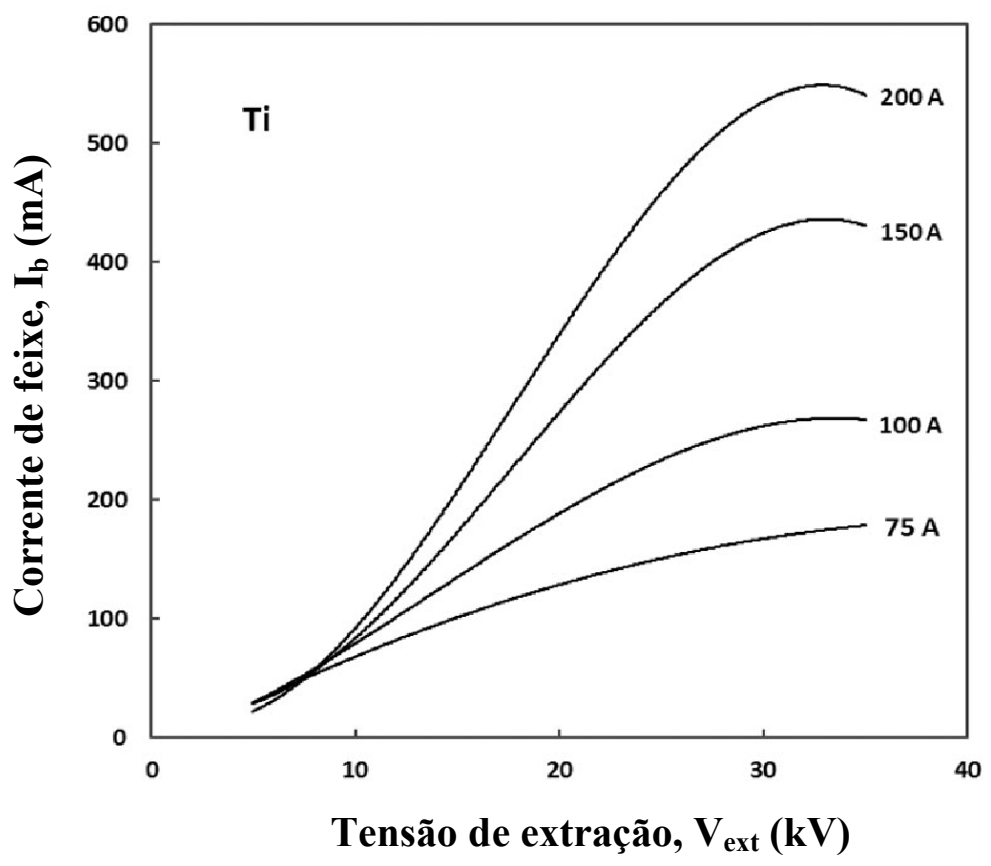

Figura 12. Corrente do feixe em função da tensão extratora para o caso do Ti em quatro diferentes correntes do arco de plasma (de 75 a 200 A), utilizando espaçamento das grades extratoras de 3 mm e diâmetro das aberturas das grades de $4 \mathrm{~mm}$. [20]

Medidas similares foram obtidas para feixe de íons de $\mathrm{Nb}$ (veja Figura 13) e de $\mathrm{Au}$ (veja Figura 14). Para os três metais estudados a fonte de íons apresentou bom desempenho. Note que o espaçamento de grades extratoras e o tamanho das aberturas dessas grades é diferente para os três casos mostrados. O conjunto completo de dados experimentais coletados explorou todas as combinações de espaçamento de grades (3, 4 e $5 \mathrm{~mm}$ ) e diâmetro das aberturas das grades (3, 4 e $5 \mathrm{~mm}$ ); e nas Figuras 11, 12, 13 e 14 foram apresentados apenas os melhores resultados, onde obtivemos os maiores valores para a corrente do feixe. Os melhores espaçamentos de grade e aberturas encontrados experimentalmente foram compatíveis com os esperados pela teoria [25], consistindo aproximadamente de $\frac{\text { espaçamento entre as grades }}{\text { diâmetro das aberturas }} \cong 1$. 


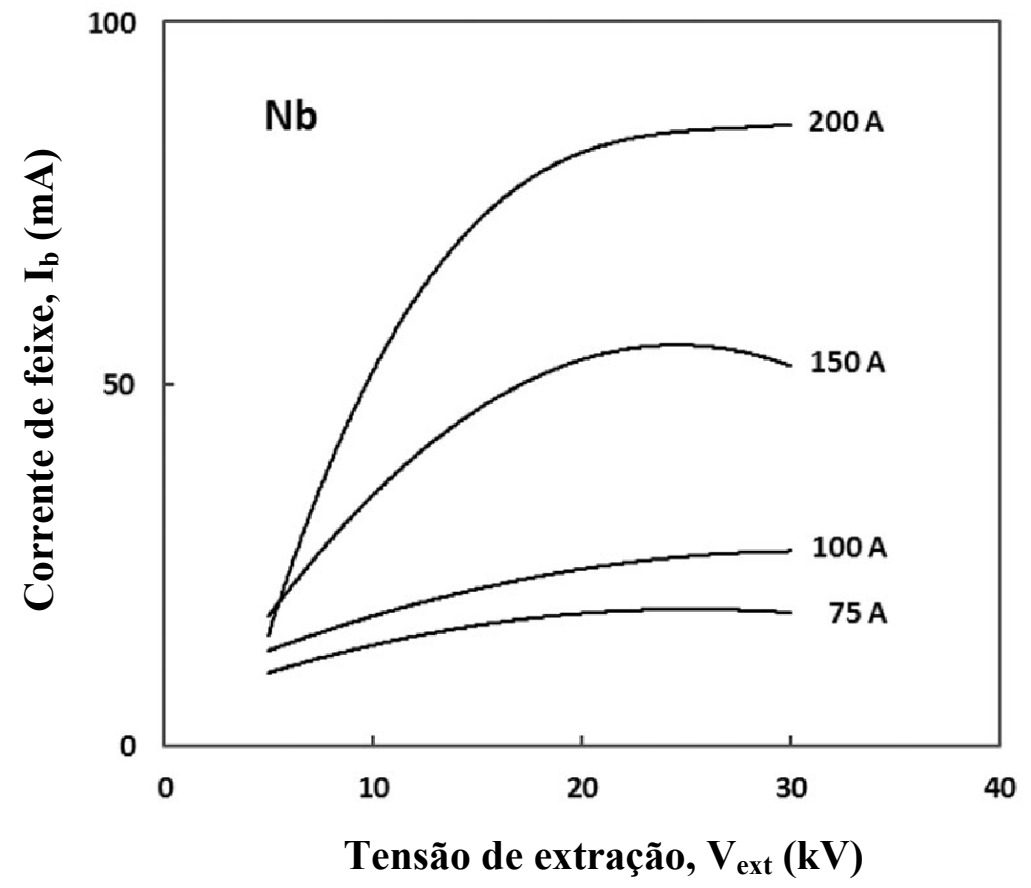

Figura 13. Corrente do feixe iônico em função da tensão de extração para o caso do $\mathrm{Nb}$ em quatro diferentes correntes do arco de plasma (de 75 a 200 A), utilizando espaçamento das grades extratoras de 4 mm e diâmetro das aberturas das grades de $4 \mathrm{~mm}$ [20].

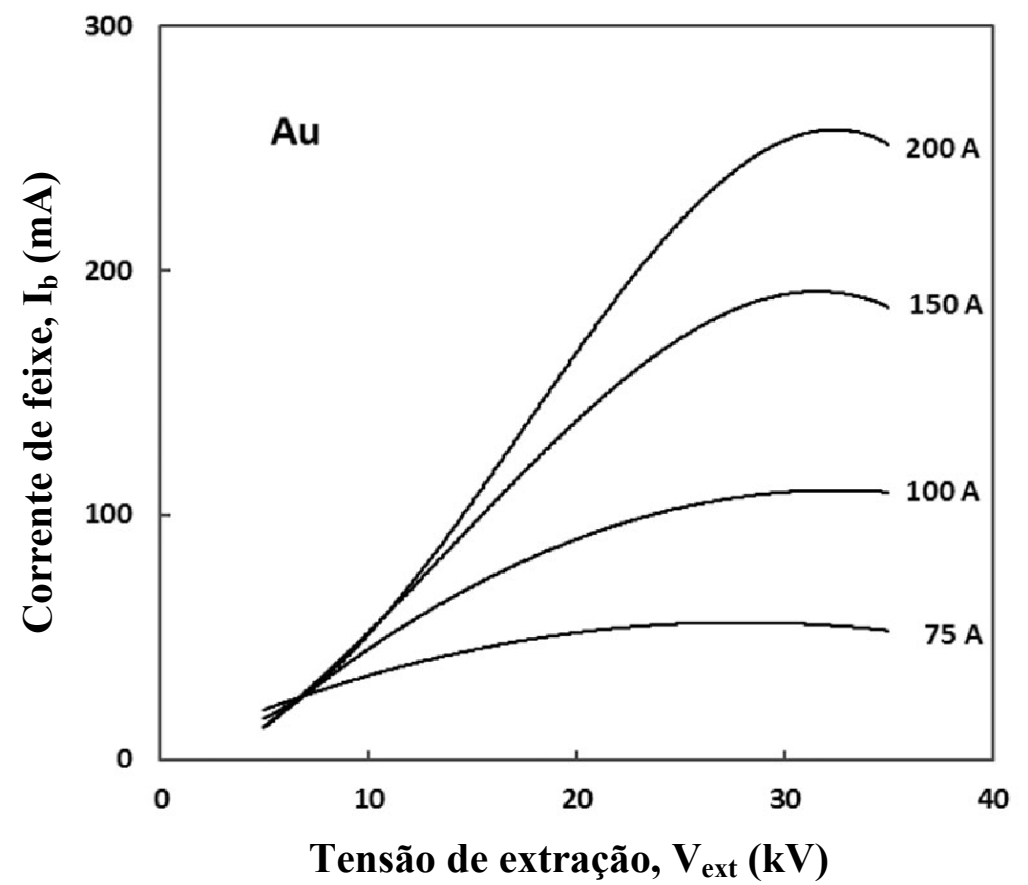

Figura 14. Corrente do feixe iônico em função da tensão de extração para o caso do Au em quatro diferentes correntes do arco de plasma (de 75 a 200 A), utilizando espaçamento das grades extratoras de 4 mm e diâmetro das aberturas das grades de $3 \mathrm{~mm}$ [20].

A seguir serão descritos os resultados obtidos utilizando uma fina malha condutora cobrindo a primeira grade extratora do implantador invertido, técnica conhecida por reduzir a 
influência dos parâmetros em estudo (corrente de arco de plasma, tensão extratora, espaçamento das grades e aberturas das grades) sobre a corrente do feixe de íons. A malha utilizada foi de aço inoxidável de 55\% de transparência, com abertura de malha de $150 \mu \mathrm{m}$. O resultado é apresentado no gráfico da Figura 15 onde é dada a razão da corrente do copo de Faraday pela corrente total proveniente da fonte de alta tensão, em função da corrente do arco de plasma (parâmetro ligado à densidade do plasma), sem e com a malha posicionada na frente da primeira grade. Claramente, a malha fornece um feixe que mantém a sua divergência moderada (óptica) em uma larga faixa de densidade do plasma (corrente de arco de plasma), ainda que reduzindo a corrente de feixe em uma parte da curva.

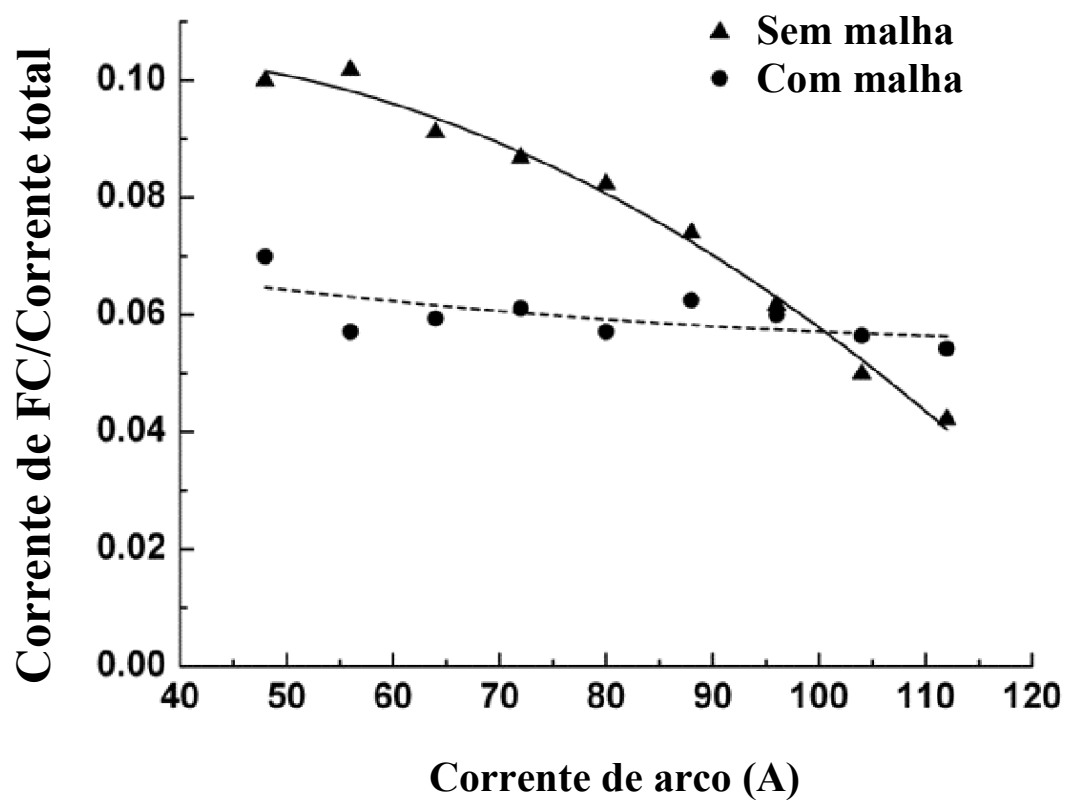

Figura 15. Razão da corrente do copo de Faraday pela corrente total proveniente da fonte de alta tensão em função da corrente do arco de plasma (parâmetro ligado à densidade do plasma), sem a malha (triângulos) e com a malha (círculos) posicionada na frente da primeira grade extratora [20].

\subsubsection{Mapeamento da densidade do feixe no porta amostras do implantador invertido}

Para o mapeamento da densidade do feixe iônico no porta-amostra do implantador invertido foi montado um mosaico de amostras, como apresentado na Figura 5, que ocupa uma área maior que a abertura do copo de Faraday, cuja a forma é circular com diâmetro de $21 \mathrm{~mm}$.

Inicialmente o implantador invertido foi ligado, sem a presença de amostras e com o copo de Faraday com abertura de $21 \mathrm{~mm}$, utilizando um catodo de ouro na fonte de plasma, tensão aceleradora de $25 \mathrm{kV}$ e corrente de arco de $192 \mathrm{~A}$, espaçamento das grades extratoras de $3 \mathrm{~mm}$ e abertura das grades extratoras de $4 \mathrm{~mm}$. Registros da corrente no copo de Faraday 
foram realizados, como apresentado na Figura 10, o que permitiu a determinação da corrente iônica média do implantador no valor de $23,8 \mathrm{~mA} / \mathrm{cm}^{2}$, nas condições descritas acima. Então, o mosaico de amostras foi colocado em frente à abertura do copo de Faraday (bloqueando completamente sua abertura) e, com base na calibração descrita acima, planejou-se uma implantação de 1 x $10^{16}$ átomos $/ \mathrm{cm}^{2}$ no mosaico de amostras.

A caracterização das amostras quanto à dose implantada foi realizada por RBS. A Figura 16(a) apresenta um espectro de RBS típico para uma das amostras de silício e a Figura 16(b) apresenta o espectro de RBS da amostra de carbono vítreo. Através do software RUMP o percentual de ouro em cada amostra foi determinado e a densidade de átomos implantados foi obtida.
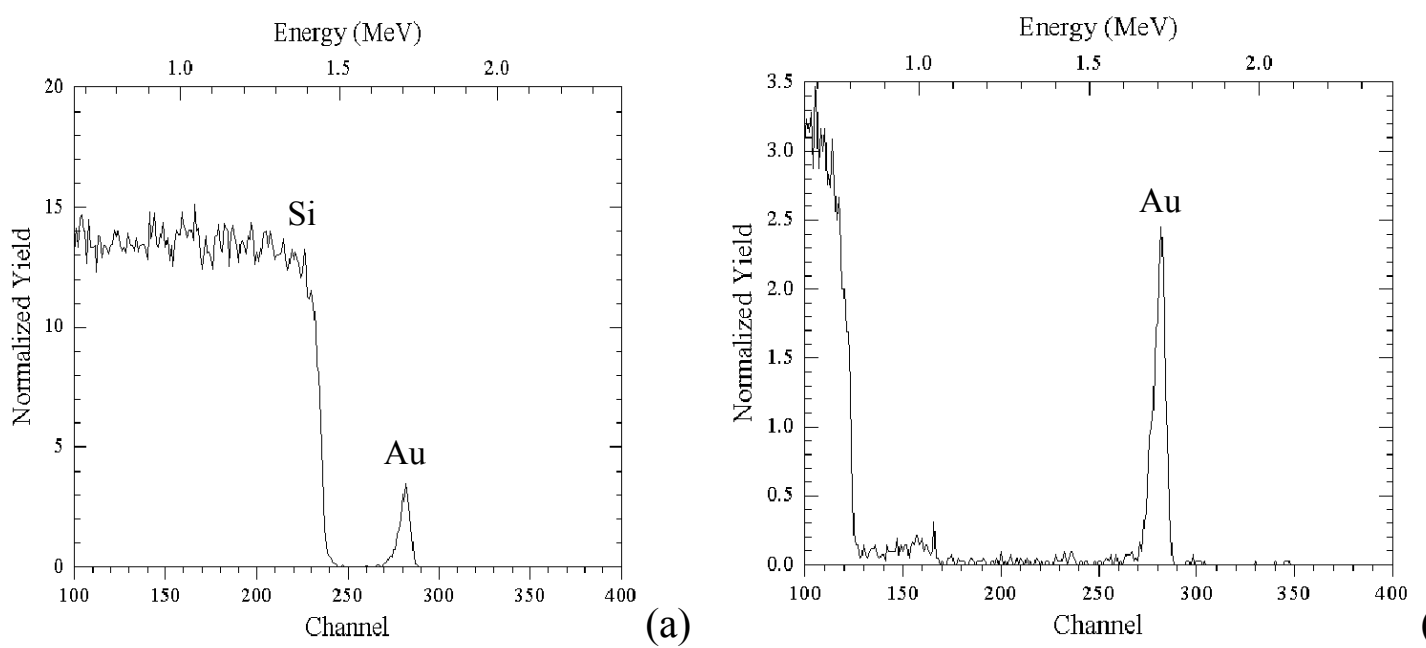

(b)

Figura 16. (a) Espectro de RBS típico para uma das amostras de silício (b) espectro de RBS da amostra de carbono vítreo.

Dois experimentos independentes foram realizados exatamente nas mesmas condições e os resultados dos mapeamentos são dados nas Tabelas 1 e 2 e nas Figuras 17 e 18 . As tabelas apresentam as doses em coordenadas e as figuras fornecem um gráfico onde o plano $\mathrm{X}, \mathrm{Y}$ corresponde às coordenadas da posição das amostras e o eixo $\mathrm{Z}$, representado em escala de cores, apresenta o valor normalizado das doses, tomando como referência o valor máximo obtido no mosaico de amostras. Nas Figuras 17 (a) e 18 (a), as posições intermediárias entre as amostras tiveram as doses interpoladas e as regiões com ausência de medida foram tomadas como tendo dose igual à dose da amostra mais próxima. 
Tabela 1. Doses de implantação nas amostras do primeiro mapeamento dadas em $10^{16}$ átomos $/ \mathrm{cm}^{2}$ e as coordenadas X e Y são dadas em milímetros, correspondendo ao centro da posição de cada amostra. O caractere “-” representa uma posição intermediária entre duas amostras e caractere " $\mathrm{x}$ " denota ausência de amostras no local ou espectro não consistente.

\begin{tabular}{|c|c|c|c|c|c|c|c|c|c|}
\hline $\begin{array}{l}\mathrm{X}, \mathrm{mm} \\
\mathrm{Y}, \mathrm{mm}\end{array}$ & 3,5 & 10,5 & 17,5 & 21 & 24,5 & 28 & 31,5 & 38,5 & 45,5 \\
\hline 3,5 & $\mathrm{x}$ & $\mathrm{x}$ & - & 2,57 & - & 2,22 & - & $\mathrm{x}$ & $\mathrm{x}$ \\
\hline 10,5 & $\mathrm{x}$ & 2,03 & 2,31 & - & 2,56 & - & 2,8 & 2,47 & $\mathrm{x}$ \\
\hline 17,5 & - & 2,26 & 2,34 & - & 2,76 & - & 2,68 & 2,19 & - \\
\hline 21 & 1,2 & - & - & - & - & - & - & - & 1,63 \\
\hline 24,5 & - & 1,264 & 1,65 & - & 2,02 & - & 2,13 & 1,9 & - \\
\hline 28 & 0,82 & - & - & - & - & - & - & - & 1,46 \\
\hline 31,5 & - & 1,04 & 1,44 & - & 1,6 & - & 1,53 & 1,58 & - \\
\hline 38,5 & $\mathrm{x}$ & 0,82 & 1,08 & - & 1,25 & - & $\mathrm{X}$ & $\mathrm{x}$ & $\mathrm{x}$ \\
\hline 45,5 & $\mathrm{x}$ & $\mathrm{x}$ & - & 0,57 & - & $\mathrm{x}$ & $\mathrm{x}$ & $\mathrm{x}$ & $\mathrm{x}$ \\
\hline
\end{tabular}

Tabela 2. Doses de implantação nas amostras do segundo mapeamento dadas em $10^{16}$ átomos $/ \mathrm{cm}^{2}$ e as coordenadas X e Y são dadas em milímetros, correspondendo ao centro da posição de cada amostra. O caractere “-” representa uma posição intermediária entre duas amostras e caractere "x" denota ausência de amostras no local ou espectro não consistente.

\begin{tabular}{|c|c|c|c|c|c|c|c|c|c|}
\hline $\begin{array}{l}\mathrm{X}, \mathrm{mm} \\
\mathrm{Y}, \mathrm{mm}\end{array}$ & 3,5 & 10,5 & 17,5 & 21 & 24,5 & 28 & 31,5 & 38,5 & 45,5 \\
\hline 3,5 & $\mathrm{X}$ & $\mathrm{x}$ & - & 1,17 & - & 0,78 & - & $\mathrm{X}$ & $x$ \\
\hline 10,5 & $\mathrm{x}$ & 1,95 & 1,72 & - & 1,5 & - & 0,96 & 0,5 & $\mathrm{x}$ \\
\hline 17,5 & - & 2,33 & 2,08 & - & 1,78 & - & 1,19 & 0,55 & - \\
\hline 21 & $\mathrm{x}$ & - & - & - & - & - & - & - & 0,25 \\
\hline 24,5 & - & 2,98 & 2,8 & - & 1,98 & - & 1,22 & 0,86 & - \\
\hline 28 & 2,83 & - & - & - & - & - & - & - & $\mathrm{x}$ \\
\hline 31,5 & - & 4,08 & 2,75 & - & 1,96 & - & 1,22 & 0,66 & - \\
\hline 38,5 & $\mathrm{x}$ & 2,82 & 2,47 & - & 1,76 & - & 1,08 & 0,5 & $\mathrm{X}$ \\
\hline 45,5 & $\mathrm{x}$ & $\mathrm{x}$ & - & 1,68 & - & 1,14 & - & $\mathrm{x}$ & $x$ \\
\hline
\end{tabular}



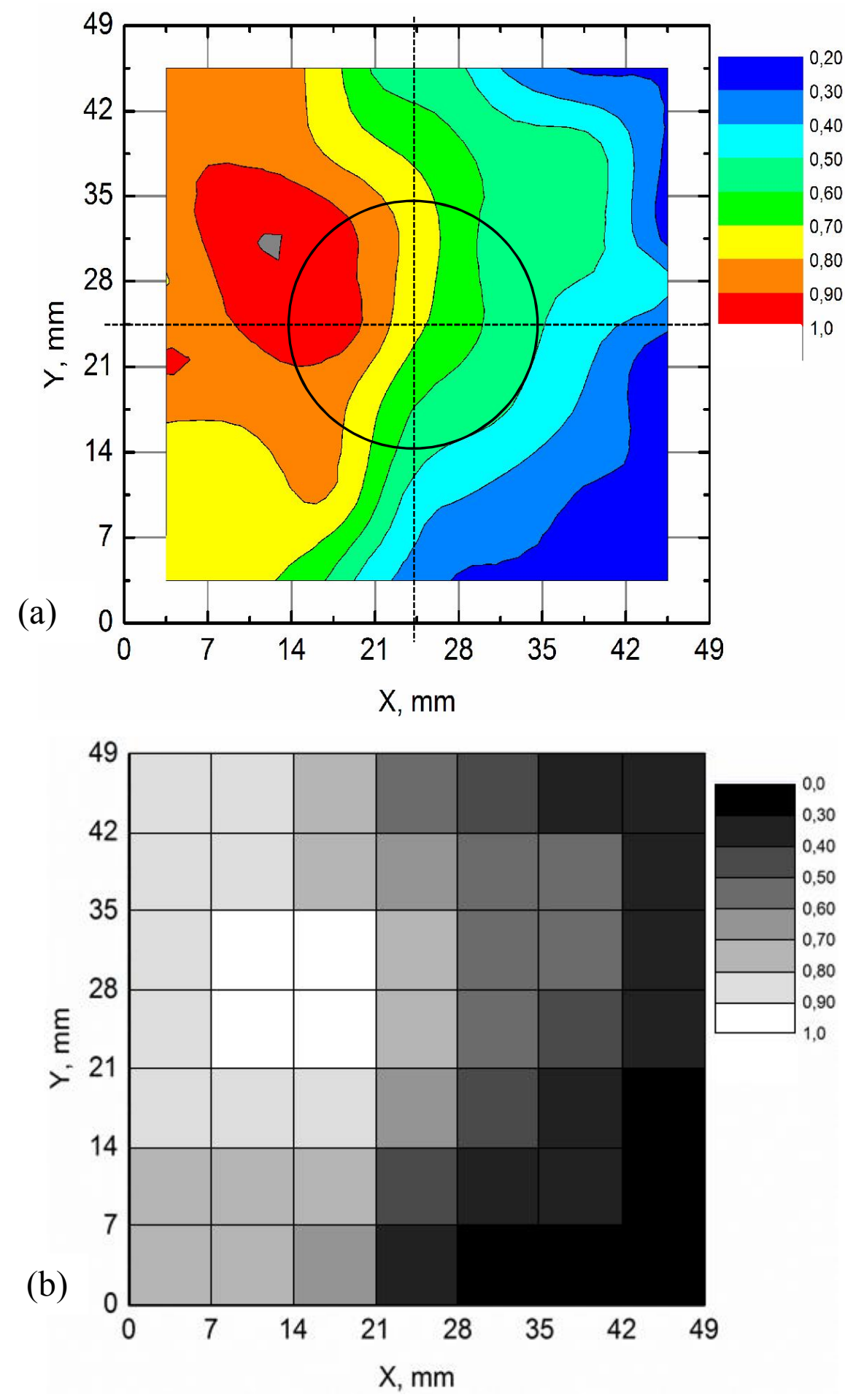

Figura 17. Gráfico do primeiro mapeamento, onde o plano X,Y corresponde às coordenadas da posição das amostras e o eixo Z, representado em escala de cores, apresenta o valor normalizado das doses, tomando como referência o valor máximo obtido no mosaico de amostras. (a) Mapa interpolado. O círculo no centro do mapa corresponde à abertura do copo de Faraday. (b) Mapa sem interpolação. 

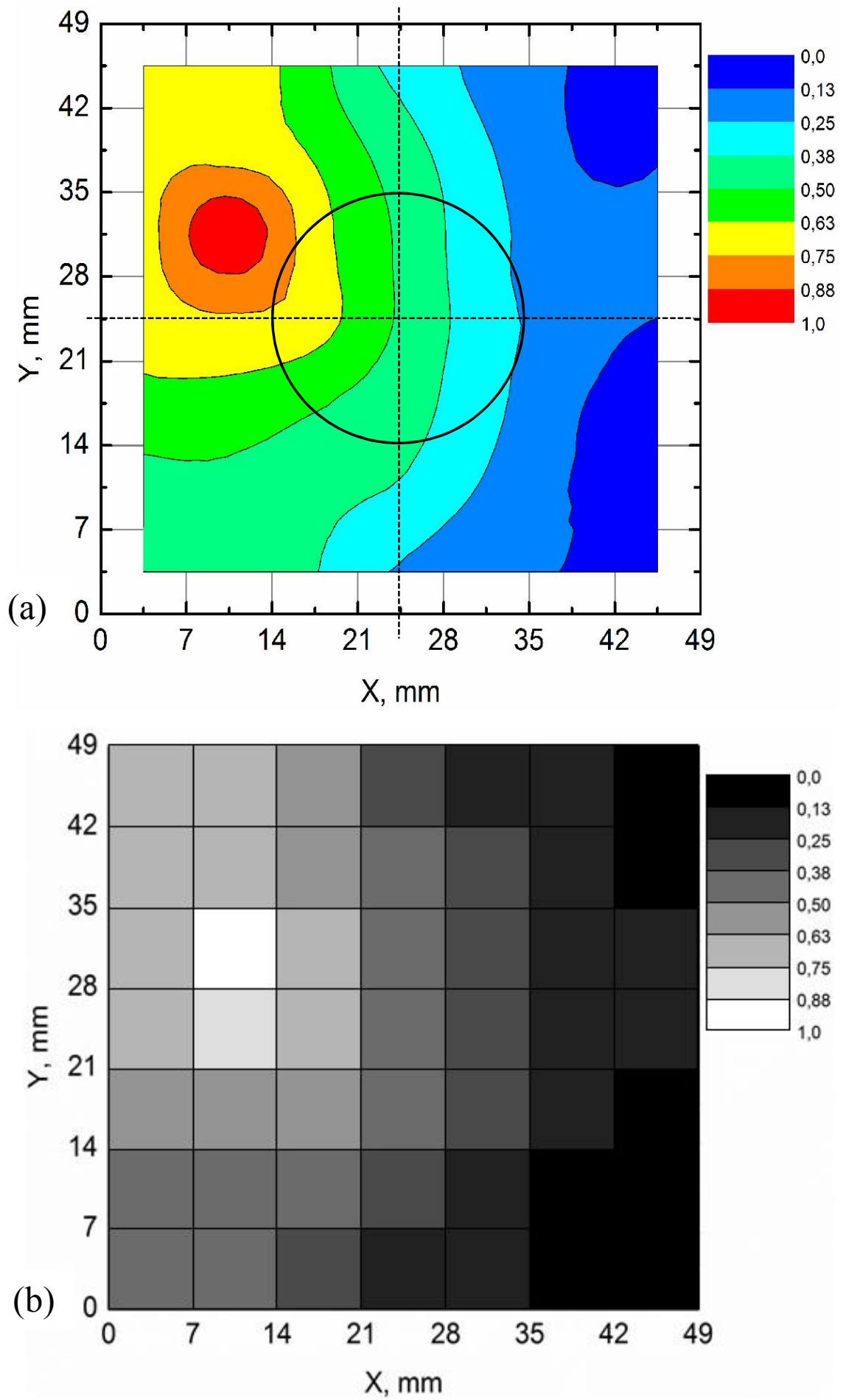

Figura 18. Gráfico do segundo mapeamento, onde o plano X,Y corresponde às coordenadas da posição das amostras e o eixo Z, representado em escala de cores, apresenta o valor normalizado das doses, tomando como referência o valor máximo obtido no mosaico de amostras. (a) Mapa interpolado. O círculo no centro do mapa corresponde à abertura do copo de Faraday. (b) Mapa sem interpolação.

Como pode ser observado a partir das Figuras 17 e 18, nos dois mapeamentos realizados, a região de maior dose é deslocada do centro do gráfico, ficando inclusive fora da posição da abertura do copo de Faraday. Comparando as escalas das doses das Figuras 17 e 18 
no copo de Faraday, notamos que a distribuição das doses apresentam grande variação.

\subsection{SUMÁRIO E CONCLUSÕES}

Neste capítulo foi descrito em detalhes um novo tipo de implantador, aqui denominado "implantador invertido". Foi apresentado um estudo sistemático com a finalidade de caracterizar o implantador, incluindo um mapeamento da densidade do feixe iônico na posição do porta-objeto.

Quanto à eletrônica do implantador invertido, a fonte de alimentação e o sistema de controle do canhão de plasma $\left(V_{p g}\right)$ foram finalizadas e otimizadas usando os recursos do Laboratório de Filmes Finos (LFF). O sistema de alta tensão e o sistema de medição foram montados e desenvolvidos. Foram ainda realizados diversos procedimentos com a finalidade de proteger os circuitos eletrônicos e melhorar a estabilidade geral do sistema.

Foi realizada uma caracterização do implantador invertido quanto à minimizar a divergência do feixe para obter a máxima corrente de feixe iônica no copo de Faraday. Para isso, medidas da corrente iônica foram realizadas mediante a variação da geometria das grades extratoras, onde a situação mais favorável foi a de espaçamento de $3 \mathrm{~mm}$ e abertura das grades de $4 \mathrm{~mm}$. Como resultado dessa caracterização, o implantador invertido apresentou um bom desempenho, gerando feixes comparáveis aos obtidos em abordagem mais convencional de fontes de íons, como é o caso de uma fonte tipo Mevva.

Como parte final da caracterização do implantador invertido, foi realizado mapeamento da densidade do feixe iônico na posição do porta amostras. A região de maior dose se mostrou deslocada do centro do porta amostras, ficando inclusive fora da posição da abertura do copo de Faraday. Assim, o mais indicado é utilizar uma amostra de referência próximo à amostra a ser implantada, para posterior medição da dose por RBS. 


\section{CAPÍTULO 2. ESTUDO DA NEUTRALIDADE DO FEIXE IÔNICO}

\subsection{INTRODUÇÃO}

Um dos parâmetros mais importantes na caracterização do implantador é a energia efetiva de implantação. Essa energia determina a profundidade de penetração do átomo no material implantado e o perfil de implantação.

Neste capítulo discutiremos se o feixe de íons gerado no implantador invertido consiste em um feixe neutro [26], o que viabiliza implantações em amostras isolantes, sem que haja acúmulo de cargas positivas, o que levaria a amostra a um potencial diferente do planejado. Como a avaliação da energia efetiva pode ser feita estudando os perfis de implantação, a ideia foi medir o perfil de profundidade de implantação por microscopia de força atômica condutiva (AFM-C) expondo diferentes níveis da camada condutiva através de corrosão seca. Em seguida, foi realizada medida do perfil de implantação por microscopia eletrônica de transmissão (TEM - Transmission Electron Microscopy) e RBS (Rutherford Backscattering Spectrometry) para amostras de PMMA (Polymethylmethacrylate) que é um material isolante. Os resultados obtidos foram comparados com simulações numéricas realizadas por TRIDYN, o que permitiu a avaliação da neutralidade, ou não, do feixe do implantador invertido.

Como será visto no Capítulo 3, quando o metal implantado ultrapassa a concentração limite de solubilidade do substrato implantado, ocorre espontaneamente a formação de nanopartículas metálicas, gerando uma camada compósita abaixo da superfície [27]. Assim, ao expor essa camada compósita em diferentes níveis de profundidade, avaliaremos a condutividade dessa rede percolada de nanopartículas, gerando informações sobre o perfil de implantação.

\subsection{MATERIAIS E MÉTODOS}

\subsubsection{Amostra de silício com ouro implantado}

O material utilizado como substrato para implantação foi silício (100) tipo n com resistividade entre 1 e $10 \mathrm{Ohm}-\mathrm{cm}$. O material implantado foi ouro, utilizando o implantador invertido descrito no Capítulo 1, sendo a energia de implantação de $50 \mathrm{keV}$ e a dose de 1,2 x $10^{16}$ átomos $/ \mathrm{cm}^{2}$.

Após as implantações, foram realizadas duas corrosões secas utilizando plasma de argônio produzido por um canhão de plasma de catodo oco [28]. O objetivo destas corrosões foi expor, em duas profundidades, a camada compósita de nanopartículas de ouro na matriz de silício. Por fim, foi realizada a caracterização utilizando AFM-C. 


\section{Microscopia de força atômica condutiva (AFM-C)}

AFM-C permite o mapeamento da distribuição de condutividade da superfície, simultaneamente à sua topografia. A técnica possui alta sensibilidade medindo valores de corrente entre centenas de femtoamperes a dezenas de microamperes. A técnica de AFM-C é útil em uma grande variedade de aplicações, incluindo a caracterização de materiais dielétricos, filmes finos, nanotubos de carbono, filmes ferroelétricos, polímeros condutivos, etc.

O equipamento que foi utilizado para esse tipo de pesquisa é um "Cypher $S$ " da empresa Asylum Research da Oxford Instruments. Este equipamento tem um módulo ORCA (Optimized Resistance Conductance Amplifier) que consiste em um porta cantilever especial que inclui um amplificador de transimpendância. O usuário tem duas opções de ganhos, com fatores de $5 \times 10^{7}$ e de $5 \times 10^{9} \mathrm{~V} / \mathrm{A}$, dependendo da escala do valor da corrente. A técnica exige o uso de uma ponta condutora e um contato elétrico entre a superfície da amostra e o porta-objeto, que fornece contato elétrico com sistema de medição. Durante a aquisição das imagens por AFM-C, a ponta se mantem em contato constante com a superfície em análise. Uma voltagem constante é então aplicada entre ponta e amostra e a corrente que flui é usada como componente $z$ no mapa que passaremos a chamar de "mapa de condutividade". A escala de corrente elétrica a ser medida pode ser elevada através do aumento da tensão aplicada entre ponta e amostra ou, inversamente, pode ser reduzida, no caso de altas condutividades, adicionando-se resistores com valores bem definidos.

Para as medidas de AFM-C, as amostras foram montadas sobre um porta-amostra metálico e suas bordas pintadas com uma tinta condutiva composta por partículas de prata, gerando um bom contato elétrico entre a superfície a ser medida e o porta-objeto.

Nas medidas realizadas neste trabalho, a sonda utilizada foi modelo ASYLELEC-01, a diferença de potencial entre ponta e amostra foi fixada em $5 \mathrm{~V}$, as amplitudes de varredura utilizadas foram entre 20 e $30 \mu \mathrm{m}$ e a faixa de correntes medidas foram entre zero e $550 \mathrm{pA}$.

\section{Corrosão}

Para chegar até a camada condutiva foram feitas corrosões do tipo seca por argônio, e utilizado PDMS (Polydimethylsiloxane) como máscara (veja anexo F). Como o argônio é um gás inerte, o processo de corrosão ocorre exclusivamente por interação física, onde os átomos do alvo são removidos por choques mecânicos dos íons de argônio. Através de experimentos preliminares, foi definido que utilizando íons de argônio com energia de $2 \mathrm{keV}$, com pressão de $5 \cdot 10^{-5}$ Torr em substrato de silício, obtem-se taxa de corrosão de $2,5-4,5 \mathrm{~nm} / \mathrm{min}$. Além 
disso, a corrosão por argônio mostrou uma boa qualidade da superfície corroída, gerando rugosidade RMS de 3,9 nm, o que é importante para as medidas por AFM-C.

Note que, corrosão a seco similar a descrita anteriormente pode ser realizada usando o implantador invertido, mas com canhão de gás como fonte de plasma. A vantagem consiste na possibilidade do uso de energias mais elevadas, podendo chegar em $50 \mathrm{keV}$, o que é bem útil para corrosão de substratos mais duros, como por exemplo, amostras de DLC. Embora este trabalho não inclua o uso do implantador invertido para essa finalidade, o anexo D apresenta simulações por TRIDYN, ilustrando esse recurso.

\section{TRIDYN}

O TRIDYN $[15,16]$ é um programa de simulação de Monte Carlo baseado no TRIM (Transport and Range of Ions in Matter) desenvolvido pelo Institute of Ion Beam Physics and Materials Research de Forschungszentrum Dresden-Rossendorf, Alemanha. Esse programa leva em conta mudanças na composição do alvo devido aos átomos já implantados e ao sputtering do material da superfície do substrato, assim, o TRIDYN deve ser utilizado em substituição ao TRIM, quando a composição do substrato é alterada significativamente durante o processo de implantação, o que ocorre com altas doses, como é o caso deste trabalho. Note que, nas simulações TRIDYN não é levado em conta o carregamento de superfícies isolantes, supondo sempre que o feixe é neutro.

\subsubsection{Amostra de PMMA com ouro implantado}

O PMMA (polymethylmethacrylate) 950k foi utilizado como material isolante para a realização de implantação iônica de ouro.

As caracterizações utilizadas no trabalho referente a este capítulo foram TEM e RBS, além das simulações por TRIDYN.

Para a obtenção de cortes transversais ultrafinos para observação por TEM, o PMMA foi depositado sobre uma resina própria para essa finalidade, denominada Araldite 502 (veja anexo F). Então, a implantação iônica de ouro foi realizada com energia de $50 \mathrm{keV}$ e doses de $1 \times 10^{15}$ átomos $/ \mathrm{cm}^{2}$ e $1 \times 10^{16}$ átomos $/ \mathrm{cm}^{2}$. Posteriormente, uma nova camada de resina foi depositada sobre o PMMA. Na Figura 19 é mostrado a configuração do bloco formado. A arquitetura desse bloco consistiu em um filme de PMMA, com cerca de $100 \mathrm{~nm}$ de espessura, entre duas camadas de resina, cada uma com aproximadamente $2 \mathrm{~mm}$ de espessura. 


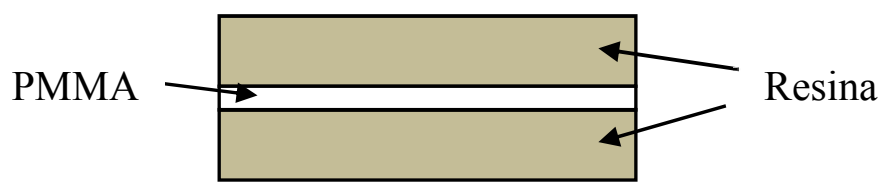

Figura 19. Esquema ilustrando o bloco formado por um filme de PMMA entre duas camadas de resina, para a realização de cortes ultrafinos.

Os cortes ultrafinos foram realizados no Laboratório de Anatomia Patológica do Instituto do Coração do Hospital das Clínicas da Faculdade de Medicina da USP, utilizando um ultramicrótomo da marca Leica, modelo Ultracut UCT. Duas diferentes espessuras foram utilizadas para os cortes ultrafinos: $75 \mathrm{~nm}$ e $150 \mathrm{~nm}$. Na Figura 20 é apresentada uma imagem de microscopia eletrônica de varredura (MEV) de uma tela suporte de cobre para TEM, já com um corte ultrafino da amostra sobre ela.

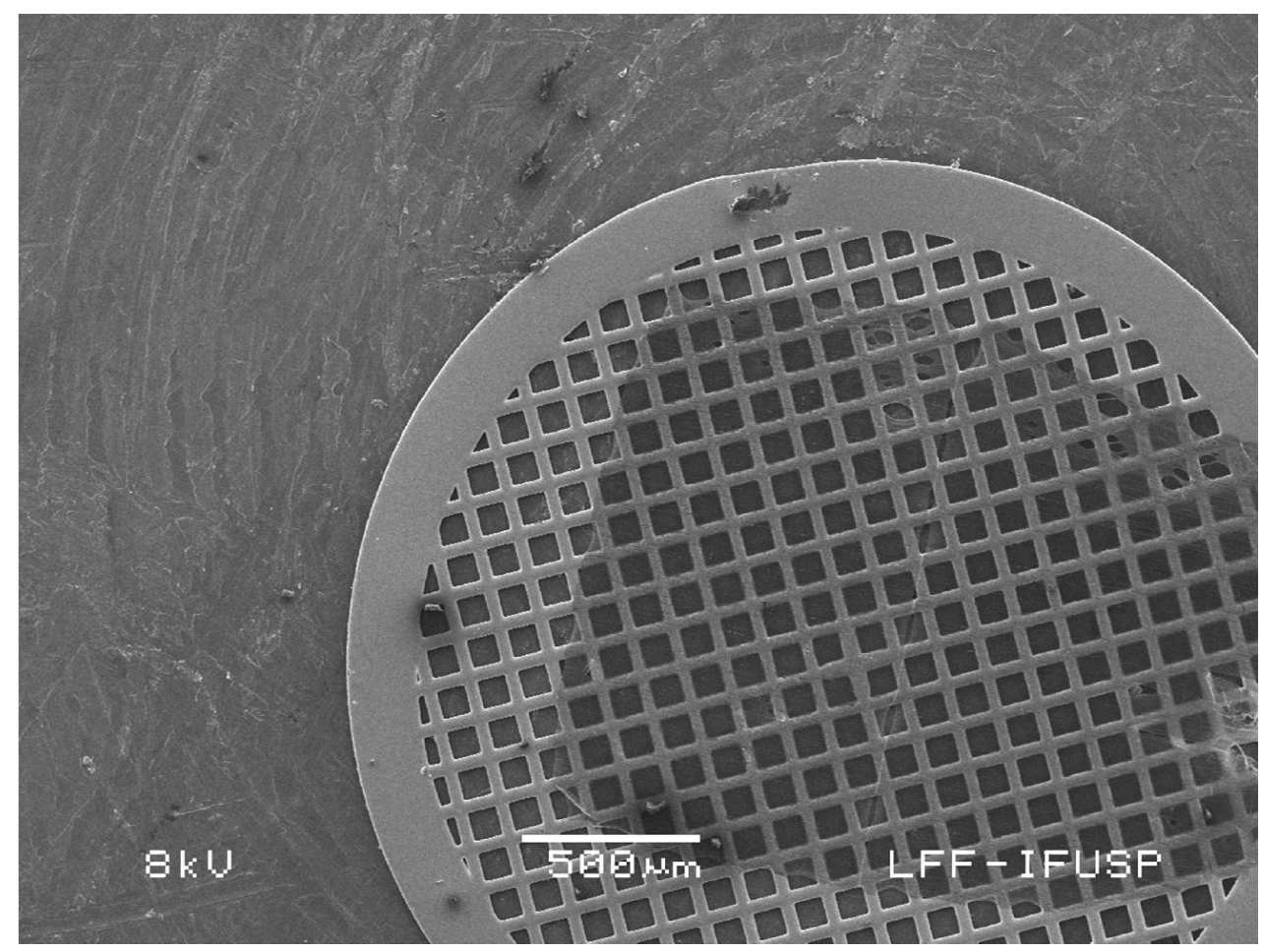

Figura 20. Imagem de MEV de uma tela suporte de cobre para TEM, já com um corte ultrafino da amostra sobre ela.

O microscópio eletrônico de transmissão utilizado para as análises foi um Jeol, modelo JEM-2100, localizado no Centro de Ciência e Tecnologia de Materiais (CCTM) do IPEN (Instituto de Pesquisas Energéticas e Nucleares). A seguir é dada uma breve descrição da técnica de TEM. 


\section{Microscopia eletrônica de Transmissão (TEM)}

Na técnica de microscopia eletrônica de transmissão, um feixe de elétrons colimado, com energia tipicamente entre 50 a $300 \mathrm{keV}$, gerando comprimento de onda entre 0,0055 e $0,0039 \mathrm{~nm}$, incide sobre uma amostra com espessura da ordem de 0,1 $\mu \mathrm{m}$, sendo espalhado por ela. Nessa interação entre feixe e amostra, podem ocorrer espalhamentos elásticos e inelásticos, mas em ambos os casos ocorre mudança na direção da trajetória dos elétrons, o que permitirá a formação da imagem através de lentes magnéticas. Uma abertura colocada logo após a lente objetiva tem o papel de eliminar os elétrons que tiveram grandes perdas de energia na interação com a amostra e os que tiveram suas trajetórias desviadas em grandes ângulos. Assim, na formação da imagem, que é gerada no anteparo fluorescente (ou na CCD) do microscópio, teremos apenas parte dos elétrons distribuídos de forma a gerar os contrastes que definem as estruturas presentes na amostra.

\section{EDS}

A técnica consiste basicamente em identificar os elementos químicos de uma amostra através da distinção das energias dos fótons emitidos por fluorescência.

Ao incidir na amostra um feixe suficientemente energético para arrancar um elétron de uma camada interna de um átomo, o elétron da camada mais externa decairá para a camada mais interna que ficou vazia (para que o átomo fique em estado de menor energia), emitindo um fóton. Este fóton tem uma energia de transição específica e é característica de cada átomo. Sendo este coletado pelo detector e distinguido por sua energia, produzindo um espectro, que é um gráfico de contagens em função da energia. Através dos picos deste gráfico, é possível a identificação dos elementos que compõe a amostra.

\section{RBS}

Uma amostra de PMMA (100 nm de espessura), sobre silício, implantada com energia de $50 \mathrm{keV}$ e dose de $0,75 \times 10^{16}$ átomos $/ \mathrm{cm}^{2}$ de ouro, foi analisada por RBS, obtendo o perfil de concentração de ouro ao longo da profundidade.

\subsection{RESULTADOS}

Foi realizada simulação por TRIDYN utilizando os parâmetros experimentais de energia $(50 \mathrm{keV})$ e dose $\left(1,2 \times 10^{16}\right.$ átomos $\left./ \mathrm{cm}^{2}\right)$ e o estado de carga do ouro foi considerado (+2) (veja anexo E). Como já mencionado no Capítulo 1, os íons de ouro gerados no implantador invertido podem ter estados de carga $+1,+2$ e +3 em proporções de $14 \%, 75 \%$ e $11 \%$ respetivamente. Os íons que têm estado de carga mais elevado, possuem maior energia e, 
portanto, penetram mais profundamente no substrato. Inversamente, os íons que têm estado de carga menor, possuem energia menor e penetram menos no substrato. Considerando que $75 \%$ dos íons apresentam estado de carga +2 , podemos inferir que a maior parte dos íons formarão um pico de concentração em uma dada profundidade. Deste modo, optamos por utilizar um estado de carga de +2 , que também corresponde ao seu valor médio. Assim, nas simulações TRIDYN foi considerada a energia de $50 \mathrm{keV}$ para uma tensão aceleradora de $25 \mathrm{kV}$.

A simulação realizada é apresentada na Figura 21, onde a concentração máxima de íons foi observada na profundidade de $38 \mathrm{~nm}$ (Figura 21).

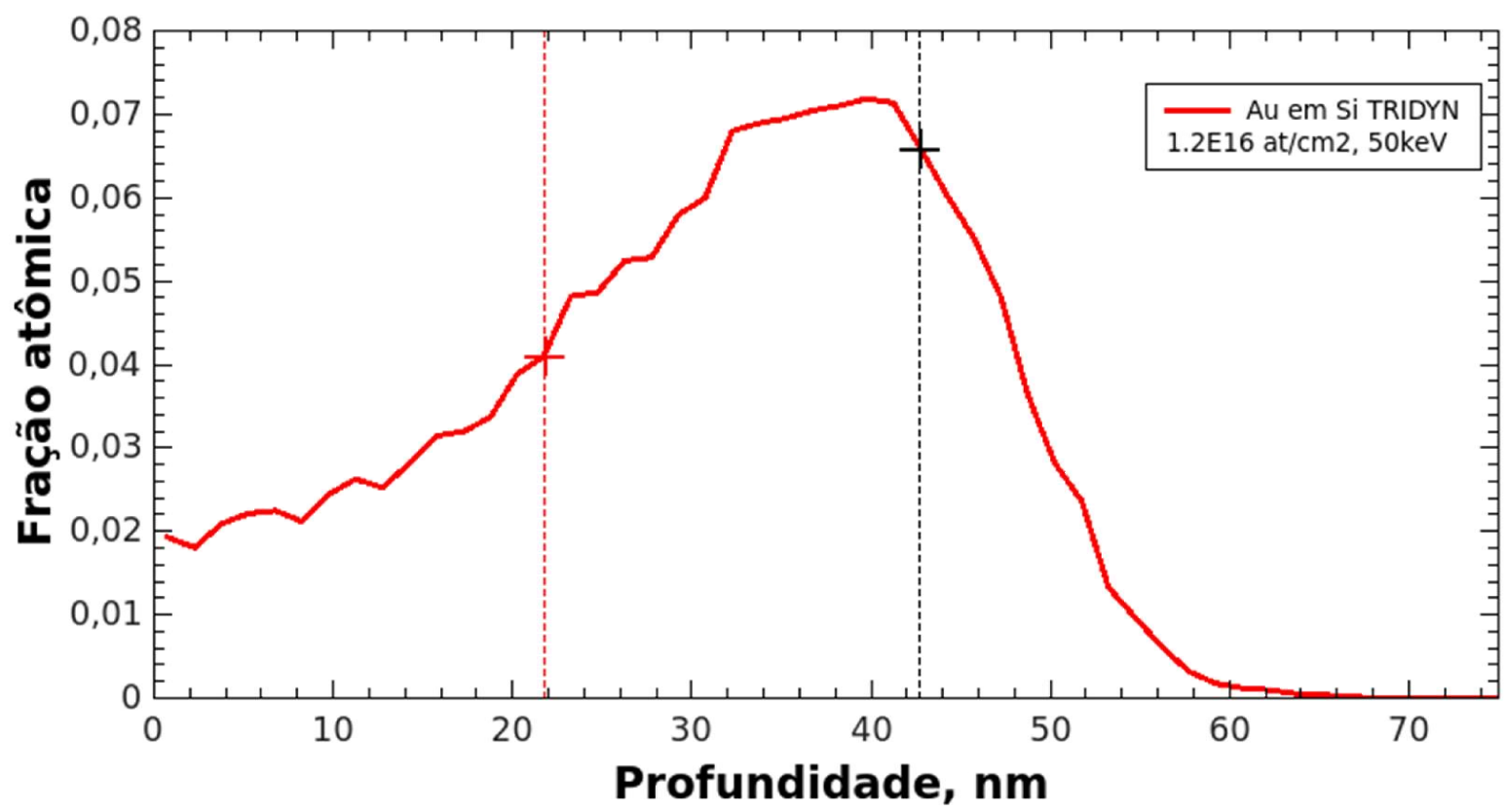

Figura 21. Perfil de implantação de Au com energia de $50 \mathrm{keV}$ em Si, as barras correspondem às profundidades das corrosões realizadas.

Foram realizadas duas corrosões, a primeira com 8 minutos e a segunda com 10 minutos, gerando respectivamente profundidades de corrosão de 21 e $43 \mathrm{~nm}$. A profundidade de corrosão foi medida através de degrau gerado por mascaramento por PDMS utilizando a imagem de topografia do AFM-C.

Na Figura 21 podemos observar a profundidade atingida pelas corrosões realizadas, dentro do perfil de concentração de ouro da amostra implantada.

Foram obtidos mapas da condutividade de superfície não corroída, e de superfícies corroídas em profundidade de 21 e $43 \mathrm{~nm}$. Esses resultados são apresentados nas Figuras 22 e 23 , onde as regiões não corroídas correspondem às regiões mascaradas, com tonalidade mais escura nos mapas de condutividade. Note que, a superfície de silício pode ser considerada como um bom isolante elétrico desde que possui uma camada de óxido de silício nativo. 
Como pode ser observado nas Figuras 22 e 23, a superfície das regiões sem corrosão apresentam baixa condutividade, aumentando na direção das regiões mais profundas, onde fica a camada condutiva. Mas, um resultado importante foi a faixa de corrente observada nos mapas de condutividade, onde as correntes medidas foram na faixa de $500 \mathrm{pA}$ e $30 \mathrm{pA}$ para as amostras com profundidades de corrosão de 21 e 43 nm, respectivamente. Na Figura 21 são apresentadas barras nas profundidades das corrosões realizadas, mostrando que as correntes medidas nos mapas de condutividade não são coerentes com a simulação TRIDYN utilizando energia de $50 \mathrm{keV}$.

(a)

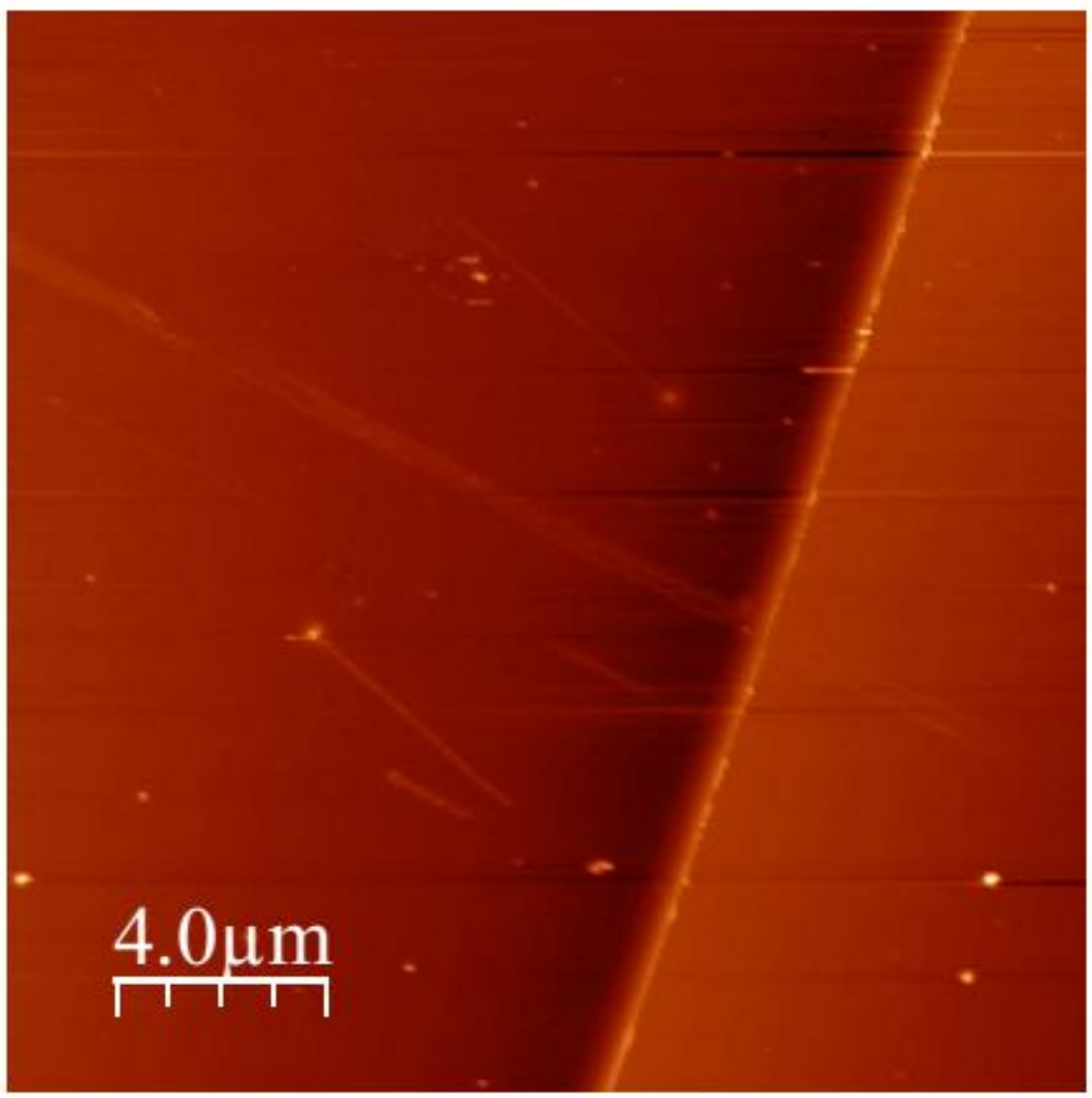




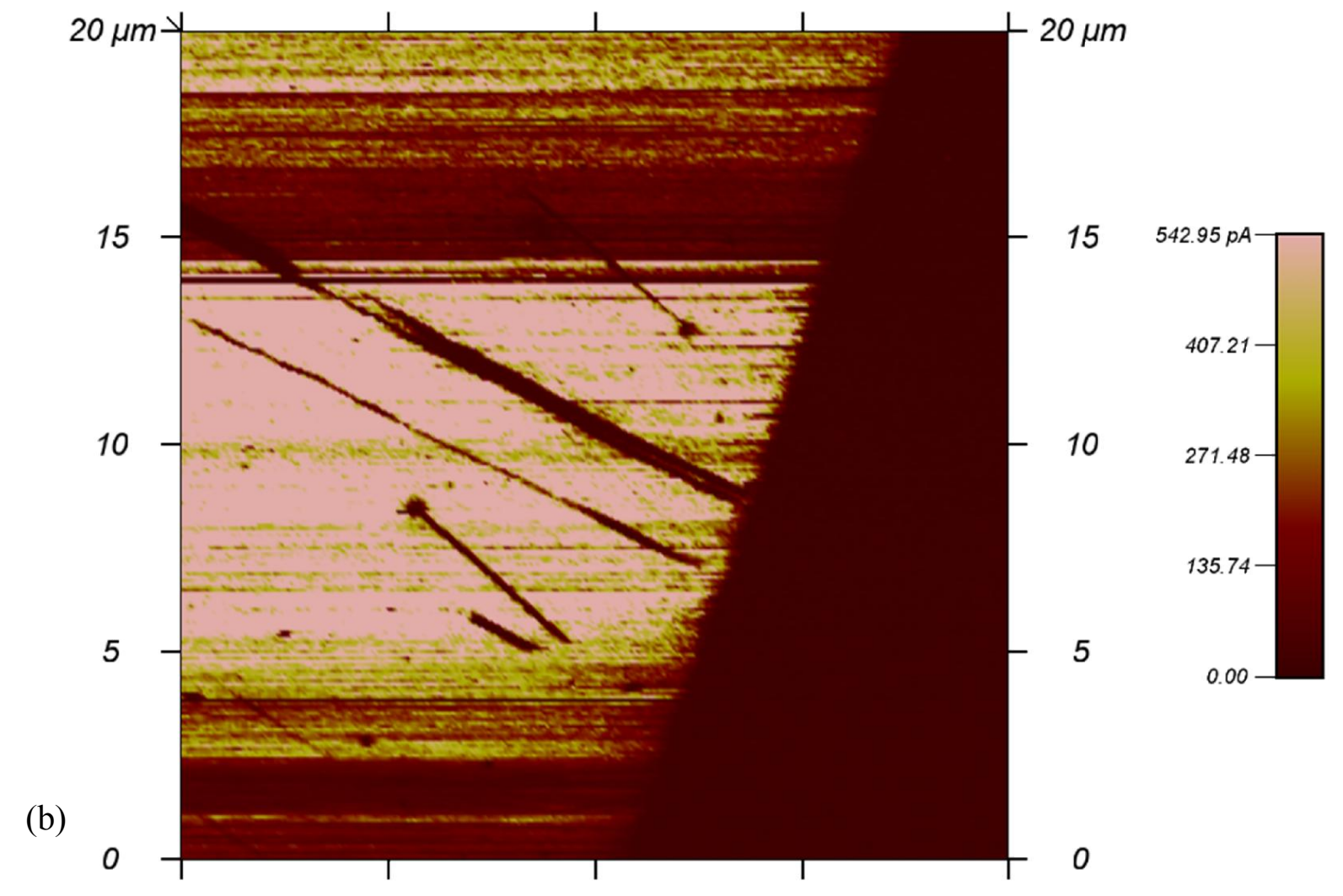

Figura 22. Imagens de AFM-C da amostra corroída em profundidade de $21 \mathrm{~nm}$ : (a) topografia e (b) de ORCA (mapa de condutividade), a região mais escura corresponde à superfície mascarada (não corroída).

(a)

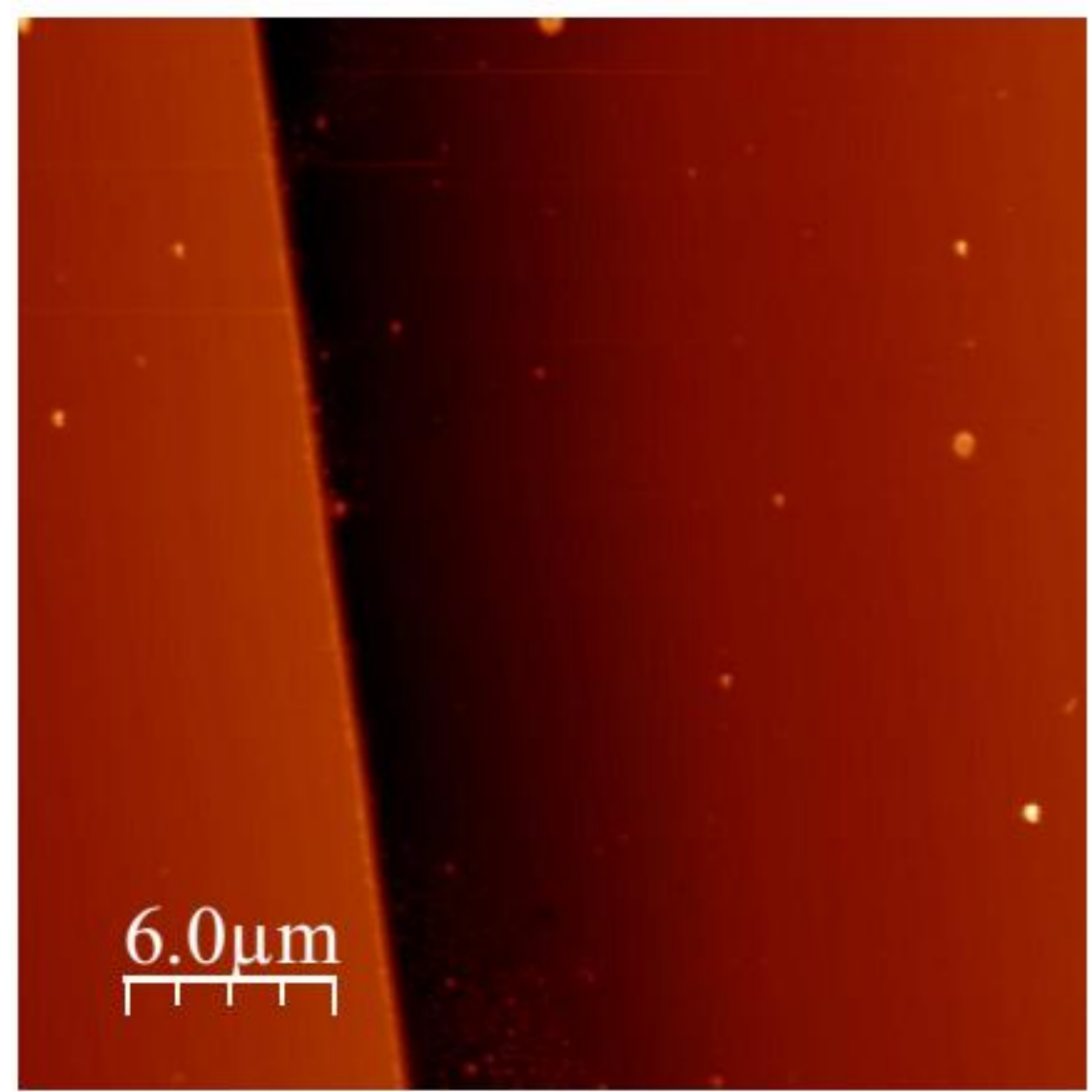




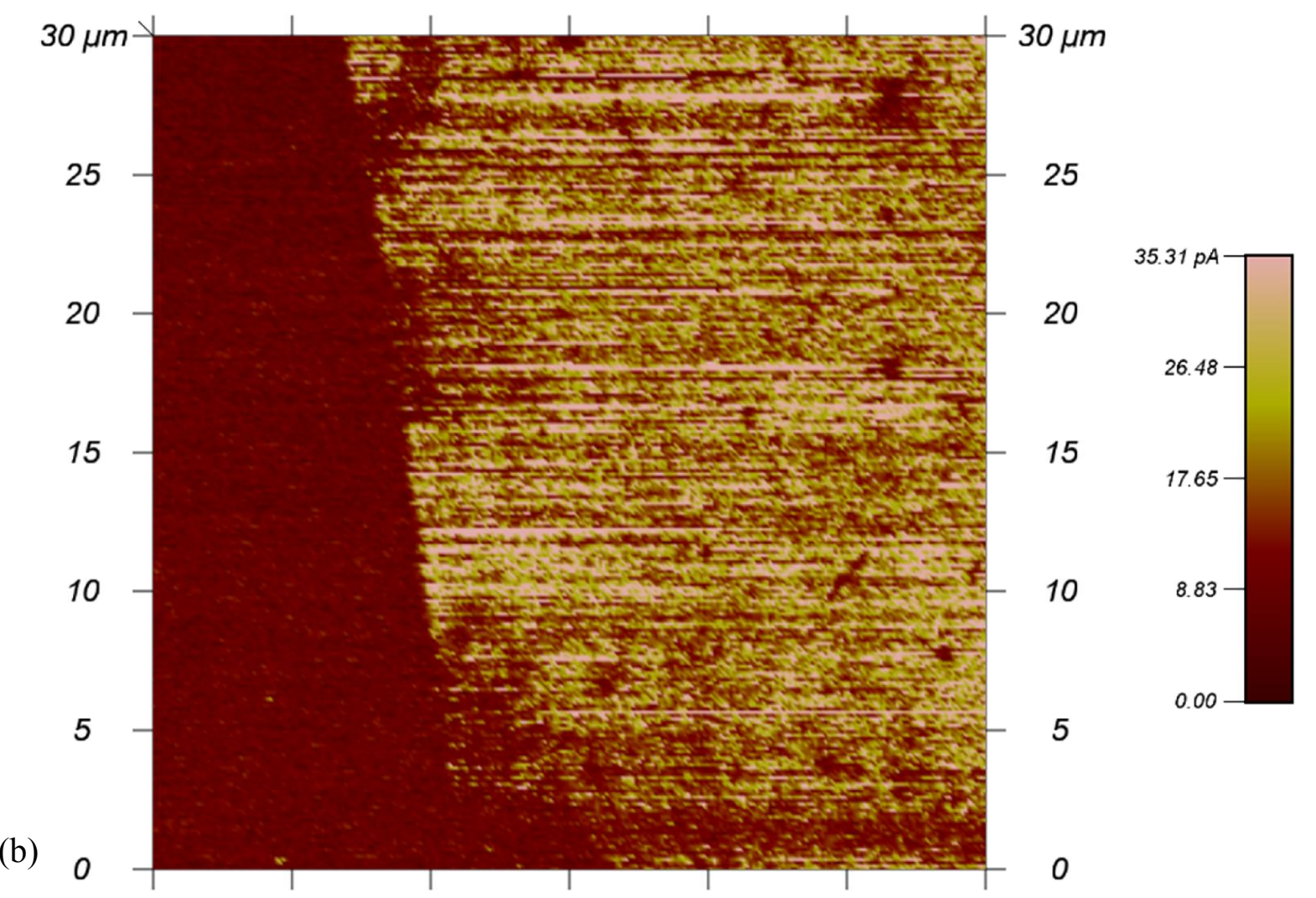

Figura 23. Imagens de AFM-C da amostra corroída em profundidade de 43 nm: (a) topografia e (b) de ORCA (mapa de condutividade), a região mais escura corresponde à superfície mascarada (não corroída).

Inversamente ao observado na simulação TRIDYN na Figura 21, a profundidade de 21 nm deve corresponder a uma maior proximidade do máximo de concentração de ouro, do que a profundidade de $43 \mathrm{~nm}$. Para avaliar se energias menores de implantação podem justificar esses resultados, foi realizada uma série de simulações similares à apresentada na Figura 21, mas com energias de implantação entre 2 e $50 \mathrm{keV}$ com passo de $2 \mathrm{keV}$. Na Figura 24 são apresentadas simulação TRIDYN de implantação de Au em Si com energias de 18, 32 e 50 $\mathrm{keV}$ para dose de implantação de $1.2 \times 10^{16}$ átomos $/ \mathrm{cm}^{2}$, onde as barras correspondem às profundidades das corrosões realizadas.

No que se segue, a Figura 24 será utilizada para uma discussão qualitativa quanto à neutralidade, ou não, do feixe do implantador invertido. Considerando inicialmente a simulação utilizando energia de $18 \mathrm{keV}$, notamos que na profundidade de $43 \mathrm{~nm}$, a concentração de ouro cai a zero; assim, uma corrosão da superfície até essa profundidade, levaria a remoção de todo o ouro implantado, o que é incompatível com a corrente medida por AFM-C nessa profundidade. Considerando agora a simulação utilizando energia de $32 \mathrm{keV}$, notamos que uma corrosão até a profundidade de $21 \mathrm{~nm}$ expõe a camada de ouro na superfície, preservando a maior parte do ouro implantado, e uma corrosão até a profundidade 
de $43 \mathrm{~nm}$, ainda preserva uma pequena concentraçãoo de ouro, o que é compatível com os resultados de AFM-C. Mas, considerando a simulação com energia de $50 \mathrm{keV}$, a mesma conclusão pode ser tirada, o que sugere que qualquer energia entre $50 \mathrm{keV}$ e cerca de $32 \mathrm{keV}$ é compatível com os resultados experimentais obtidos por AFM-C.

Para uma determinação da energia efetiva de implantação, utilizando AFM-C, seria necessário um maior número de dados.

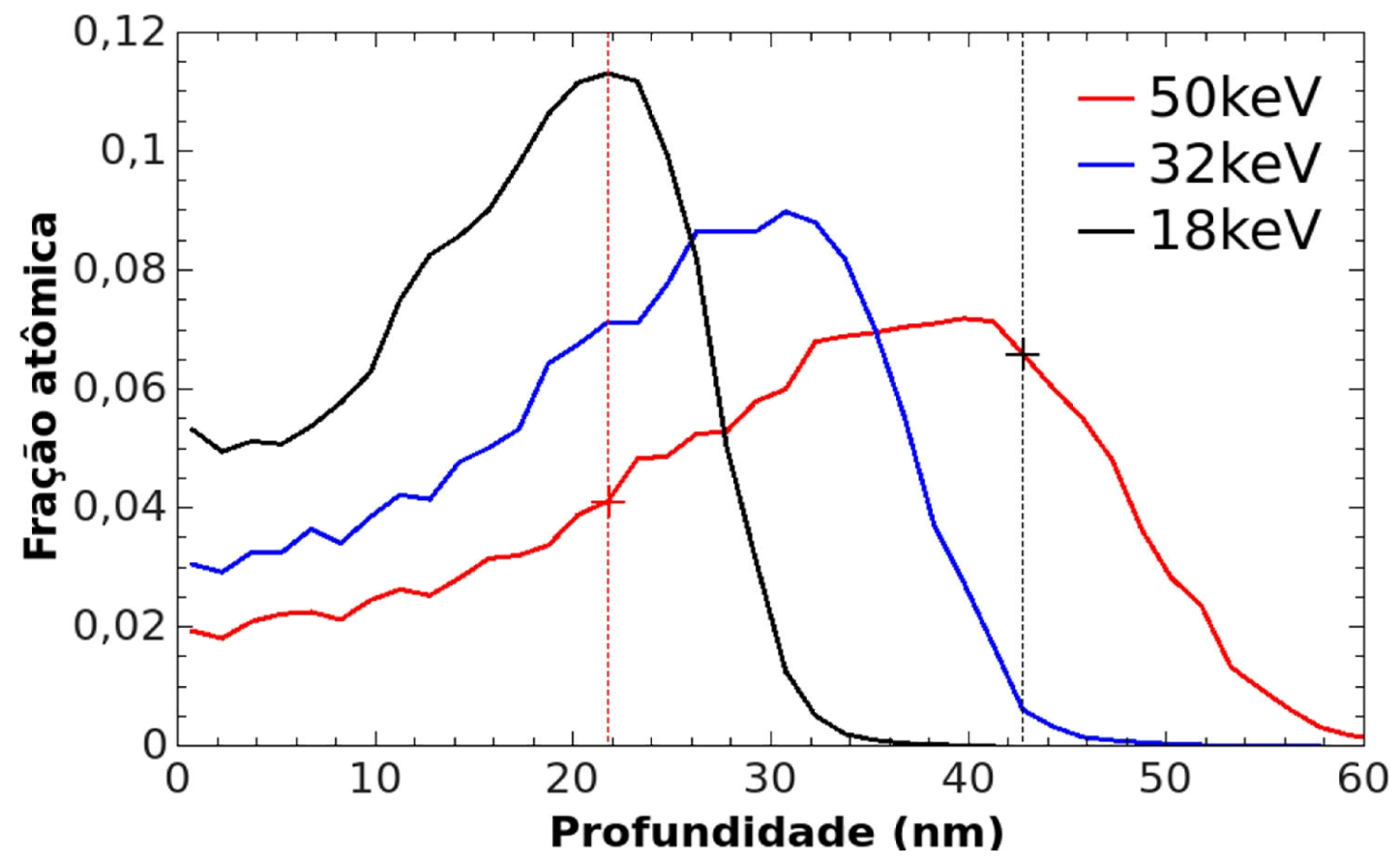

Figura 24. Simulação TRIDYN de implantação de Au em Si com energias de 18, 32 e 50 keV para dose de implantação de $1,2 \times 10^{16}$ átomos $/ \mathrm{cm}^{2}$.

Foi realizado outro estudo, usando substrato de PMMA com implantação de ouro, com a mesma finalidade de verificar a hipótese de neutralidade do feixe do implantador invertdo.

Duas simulações feitas por TRIDYN são apresentadas na Figura 25. Em ambas as simulação foi considerada implantação iônica de ouro em PMMA com energia de $50 \mathrm{keV}$, variando a dose de implantação que foram tomadas: 1 × $10^{15}$ átomos $/ \mathrm{cm}^{2}$ e $1 \times 10^{16}$ átomos $/ \mathrm{cm}^{2}$ (veja anexo E). As simulações resultaram em concentração máxima de íons na profundidade de $71 \mathrm{~nm}$ e $64 \mathrm{~nm}$ (veja Figura 25) para as doses de 1 x $10^{15}$ átomos $/ \mathrm{cm}^{2}$ e $1 \mathrm{x}$ $10^{16}$ átomos $/ \mathrm{cm}^{2}$, respectivamente. Esta diferença pode ser justificada pelo fato dos átomos implantados no início do processo agirem como barreira para os implantados subsequentemente, causando um acúmulo deles mais próximo à superfície; além disso, o processo de sputtering da superfície, durante a implantação, reduz a espessura do substrato (PMMA) acima da camada compósita. 


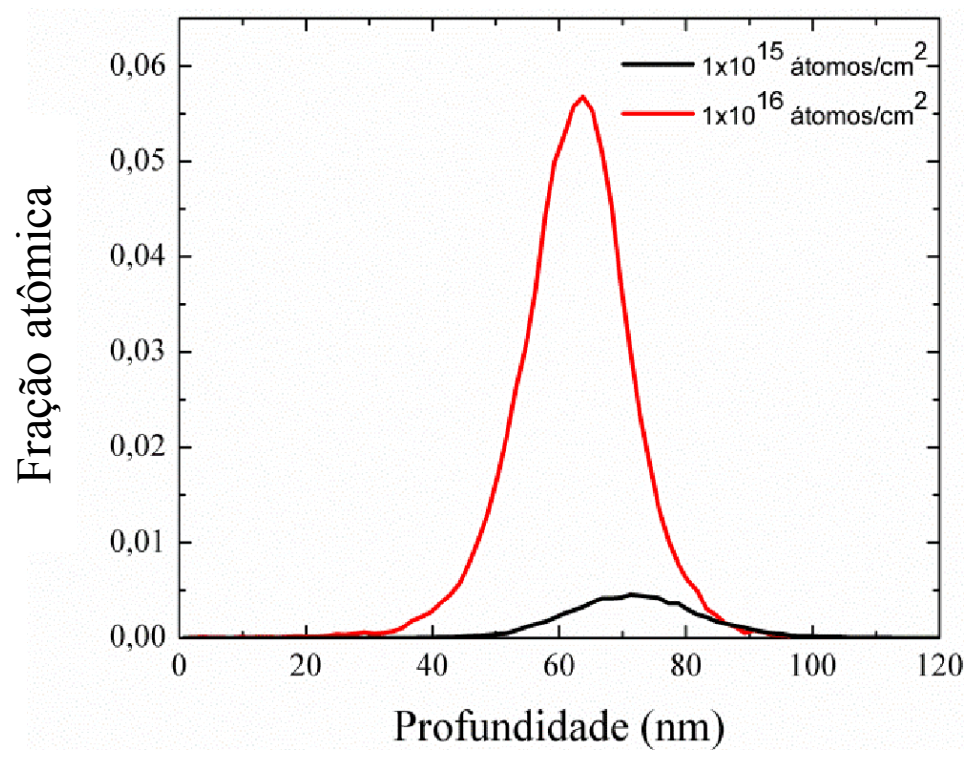

Figura 25. Simulação por TRIDYN de implantação iônica de ouro em PMMA com energia de 50 keV com doses de $1 \times 10^{15}$ átomos $/ \mathrm{cm}^{2}$ (curva preta) e $1 \times 10^{16}$ átomos $/ \mathrm{cm}^{2}$ (curva vermelha).

Imagens de TEM da amostra de PMMA implantada com $1 \times 10^{16}$ átomos $/ \mathrm{cm}^{2}$ de ouro são apresentadas nas Figuras 26 e 27, com diferentes ampliações. Para essas imagens, foram utilizados cortes com espessura nominal de $75 \mathrm{~nm}$. Na Figura 26 é apresentada uma imagem identificando uma região contendo nanopartículas de ouro (regiões mais escuras) com tamanhos entre 1 e $3 \mathrm{~nm}$. Durante a observação no microscópio eletrônico de transmissão foi realizada análise por EDS (Energy Dispersive X-Ray Spectroscopy) confirmando a presença de ouro na região.

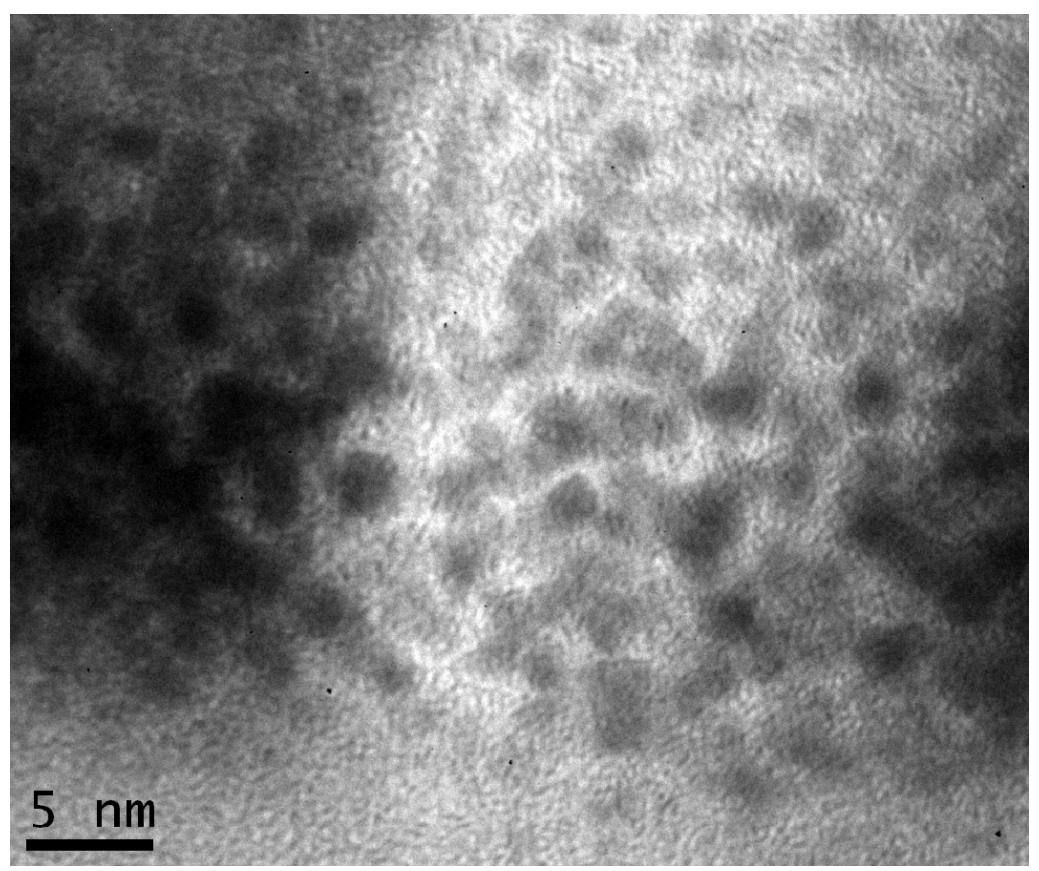

Figura 26. Imagem TEM de PMMA com ouro implantado com energia de $50 \mathrm{keV}$ e dose de $1 \times 10^{16}$ átomos $/ \mathrm{cm}^{2}$. 
A medida de profundidade de concentração máxima de ouro foi feita usando imagens como a apresentada na Figura 27. Nessa figura, duas linhas pontilhadas em vermelho delimitam a camada de PMMA, uma outra linha em cor azul identifica a região de máximo de concentração de ouro. A medida de profundidade máxima de concentração de ouro foi obtida utilizando três imagens distintas e seu valor médio foi de $(66 \pm 4) \mathrm{nm}$.

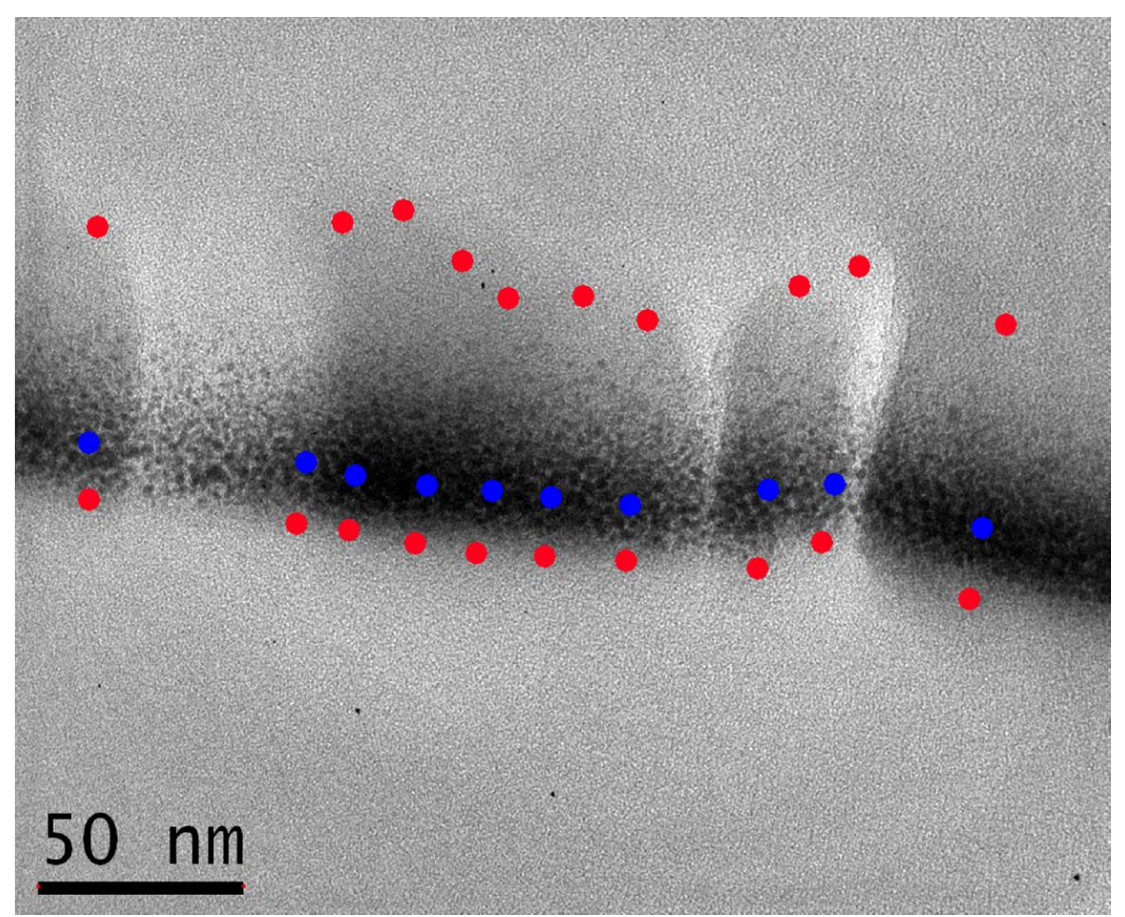

Figura 27. Imagem TEM de PMMA com ouro implantado com energia de $50 \mathrm{keV}$ e dose de $1 \times 10^{16}$ átomos $/ \mathrm{cm}^{2}$. Duas linhas pontilhadas em vermelho delimitam a camada de PMMA, uma outra linha pontilhada em cor azul identifica a região de máximo de concentração de ouro.

A profundidade da concentração máxima de íons obtidos por TRIDYN (64 nm) foi compatível com a obtida por TEM $((66 \pm 4) \mathrm{nm})$. Levando em conta que a simulação TRIDYN considera o feixe iônico neutro, isto é, pressupõe que não haja carregamento na superfície da amostra, o que leva a uma possível conclusão de que o feixe é neutro.

Na Figura 28 é apresentada uma imagem de TEM da amostra implantada com $1 \times 10^{15}$ átomos $/ \mathrm{cm}^{2}$. Para essas imagens, foram utilizados cortes com espessura nominal de $150 \mathrm{~nm}$. A região contem ouro, o que foi identificado através de EDS durante a observação no microscópio eletrônico de transmissão. No entanto, não foram observadas as nanopartículas de ouro, nem mesmo em aumentos maiores.

Para entender esse resultado, é precisa analisar a formação dessas nanopartículas metálicas. Esse fenômeno ocorre espontaneamente e pode ser explicado pela ocorrência de concentração dos átomos metálicos acima do limite de solubilidade no substrato implantado, levando à nucleação e crescimento das nanopartículas metálicas [27]. Dessa forma, podemos 
concluir que a dose de $1 \times 10^{15}$ átomos $/ \mathrm{cm}^{2}$ de ouro não chega a saturar o PMMA a ponto de precipitar o metal na forma de nanopartículas.

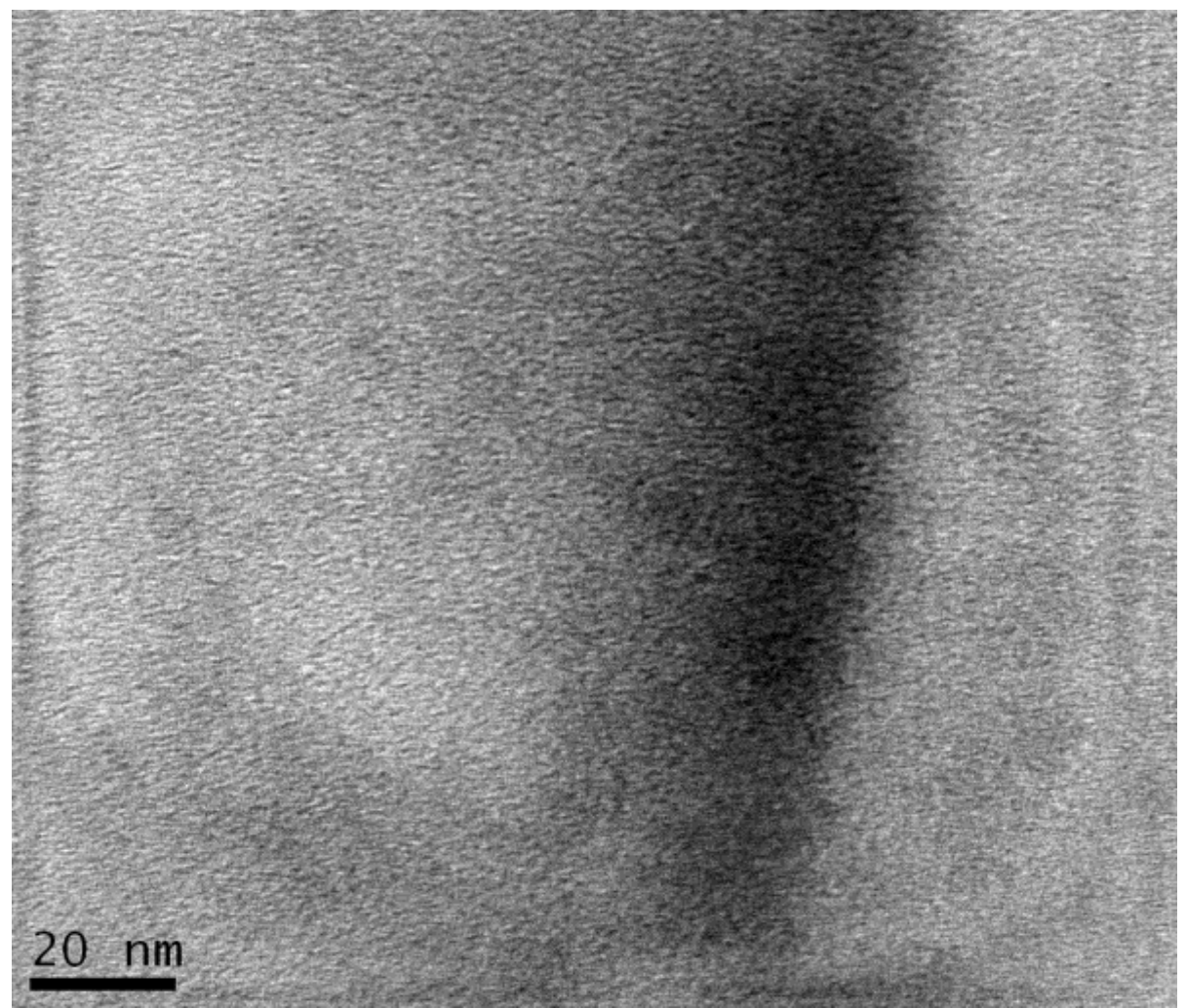

Figura 28. Imagem TEM de PMMA com ouro implantado com energia de $50 \mathrm{keV}$ e dose de $1 \times 10^{15}$ átomos $/ \mathrm{cm}^{2}$.

Uma amostra de PMMA (100 nm de espessura), sobre silício, implantada com energia de $50 \mathrm{keV}$ e dose de $0,75 \times 10^{16}$ átomos $/ \mathrm{cm}^{2}$ de ouro, foi analisada por RBS obtendo o perfil de concentração de ouro ao longo da profundidade. Na Figura 29 é apresentado o perfil obtido por RBS juntamente com o resultado da simulação TRIDYN utilizando energia de $50 \mathrm{keV}$ e dose de $0,75 \times 10^{16}$ átomos $/ \mathrm{cm}^{2}$. 


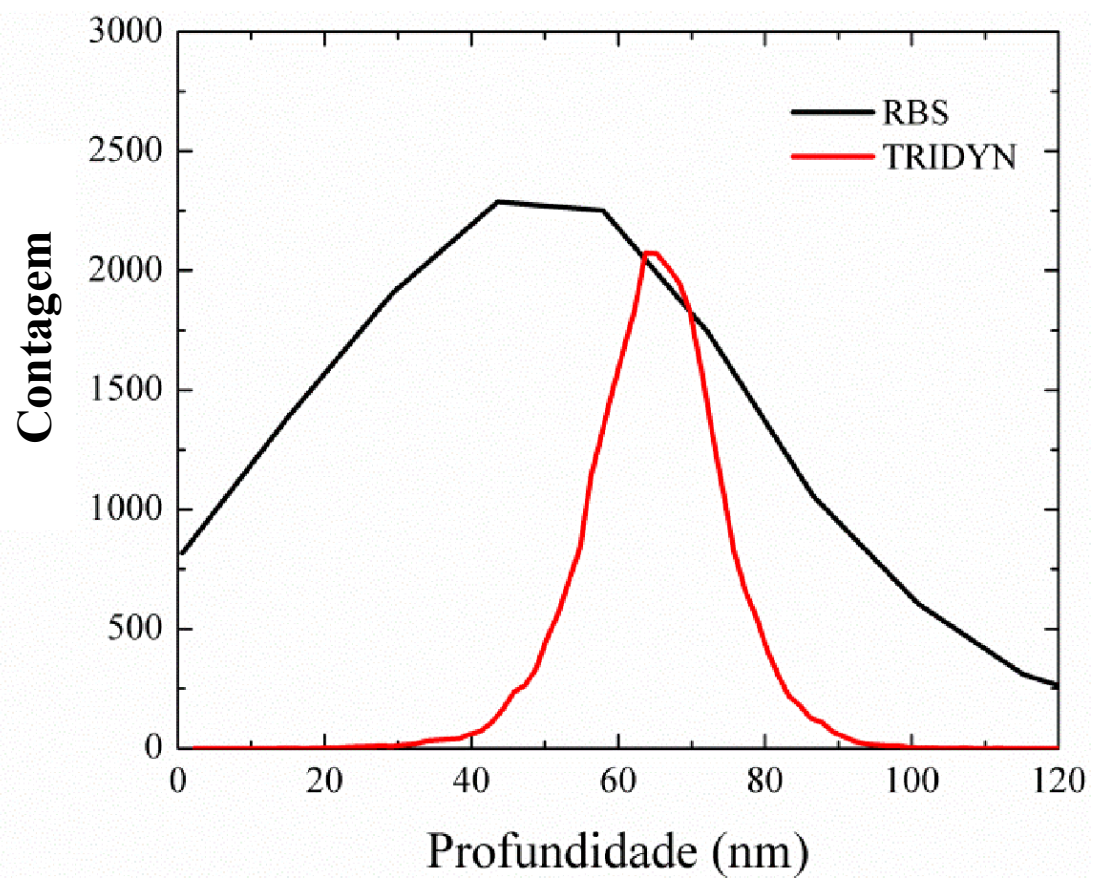

Figura 29. Perfil de concentração de ouro ao longo da profundidade em uma amostra de PMMA implantado com uma dose de $0,75 \times 10^{16}$ átomos $/ \mathrm{cm}^{2}$ e energia de $50 \mathrm{keV}$ obtida por RBS (curva preta) e resultado da simulação utilizando TRIDYN (curva vermelha).

Na Figura 29 observa-se uma não concordância dos picos obtidos por RBS e por TRIDYN, além de um alargamento na curva experimental de RBS. A justificativa para o alargamento está no fato de termos utilizado o estado de carga médio $(+2)$ do ouro para a simulação TRIDYN, enquanto que, na realidade, sabemos que para o ouro temos estados de carga $+1,+2$ e +3 em proporções de 14\%, 75\%, 11\% respetivamente. Assim, 25\% dos átomos implantados não possuíam a energia considerada na simulação, o que justifica a maior largura na curva experimental. A não concordância dos picos pode sugerir que o feixe não é neutro, resultado oposto ao obtido por TEM.

\subsection{SUMÁRIO E CONCLUSÕES}

Neste capítulo foi discutido se o feixe de íons gerado no implantador invertido consistia em um feixe neutro. Para isso foram preparadas amostras de ouro implantado em silício e realizada caracterização por AFM-C após corrosão, e, em seguida, foram preparadas amostras de ouro implantado em PMMA e realizadas caracterizações por TEM e RBS, além de simulações por TRIDYN.

Nas simulações realizadas por TRIDYN foi considerada implantação iônica de ouro em silício com energias de 18,32 e $50 \mathrm{keV}$ com dose de implantação de $1.2 \times 10^{16}$ átomos $/ \mathrm{cm}^{2}$. Amostas de silício implantadas com ouro utilizando energia de feixe de $50 \mathrm{keV}$ 
foram corroídas em profundidades de $21 \mathrm{~nm}$ e $43 \mathrm{~nm}$ e analisadas por AFM-C. Utilizando as simulações TRIDYN concluímos que a energia efetiva de impantação deve estar entre 32 e $50 \mathrm{keV}$. Esse resultado é inconclusivo quanto a determinação da energia efetiva de implantação, sendo necessário um maior número de dados.

Nas simulações de TRIDYN de implantação iônica de ouro em PMMA com energia de $50 \mathrm{keV}$ e doses de implantação de $1 \times 10^{15}$ átomos $/ \mathrm{cm}^{2}$ e $1 \times 10^{16}$ átomos $/ \mathrm{cm}^{2}$, onde obtivemos as profundidades de máxima concentração de íons de $71 \mathrm{~nm}$ e $64 \mathrm{~nm}$ respectivamente.

As análises por TEM da amostra implantada com 1 x $10^{16}$ átomos $/ \mathrm{cm}^{2}$ apresentou regiões contendo nanopartículas de ouro com tamanhos entre 1 e $3 \mathrm{~nm}$, sendo que a presença de ouro foi confirmada por EDS.

Ainda por TEM, foram realizadas medidas de profundidade de concentração máxima de ouro em PMMA, com dose de $1 \times 10^{16}$ átomos $/ \mathrm{cm}^{2}$, utilizando três imagens distintas, e seu valor médio foi de $(66 \pm 4) \mathrm{nm}$. Este valor é compatível com a profundidade da concentração máxima de íons obtidos por TRIDYN (64 nm). A simulação TRIDYN não leva em conta carregamento na superfície, isto é, pressupõe que não haja carregamento na superfície da amostra, o que leva a uma possível conclusão de que o feixe é neutro.

A análise por RBS de uma amostra de PMMA implantada com energia de $50 \mathrm{keV}$ e dose de $0,75 \times 10^{16}$ átomos $/ \mathrm{cm}^{2}$ de ouro, gerou o perfil de concentração de ouro ao longo da profundidade. Comparando os resultados de RBS e simulação de TRIDYN, nas mesmas condições da preparação da amostra, observamos uma não concordância dos picos, o que sugere que o feixe não é neutro, resultado oposto ao obtido por TEM.

Assim, podemos observar que o resultado do trabalho não é conclusivo e deve ser confirmado por outros estudos.

Como continuidade deste trabalho, se faz necessário maior detalhamento do perfil em profundidade por meio de caracterização por AFM-C, além da caracterização das nanopartículas de ouro em silício através de microscopia eletrônica de transmissão. A caracterização mais detalhada pode esclarecer melhor a estrutura do perfil de implantação e, finalmente, confirmar se o feixe é neutro ou não. 


\section{CAPÍTULO 3. APLICAÇÃO PARA O IMPLANTADOR INVERTIDO: NANOCOMPÓSITO FORMADO POR NANOPARTÍCULAS DE TITÂNIO EM MATRIZ DE ALUMINA}

\subsection{INTRODUÇÃO}

Compósitos formados por nanopartículas metálicas incorporadas em um dielétrico isolante são muito importantes por possuírem propriedades elétricas, ópticas e químicas de grande interesse. As aplicações tecnológicas para esses materiais são várias, incluindo as áreas de eletrônica, fotônica e biosensores [29-34]. Como exemplos podemos mencionar um dos principais desafios para o sensoriamento químico e biológico que consiste na detecção de traços de uma substância em uma amostra macroscópica, podendo chegar idealmente à detecção de uma única molécula. Uma forma possível de se obter essa detecção é através de medidas por SERS (Surface-Enhanced Raman Spectroscopy) utilizando um substrato contendo nanopartículas metálicas [35], como por exemplo, nanopartículas de ouro em PMMA (polimetilmetacrilato), obtidas no LFF através de implantação iônica de ouro em filme de PMMA [36]. Neste caso, informações estruturais da molécula de rodamina foram obtidas em altas diluições dessa substância, gerando espectros SERS com boa intensidade e resolução. Outra aplicação consiste na obtenção de isolantes para uso em alta tensão com controle preciso da resistividade da superfície (resistência de folha) do material. Implantação iônica de metal em alumina tem sido utilizada para essa finalidade [11-13], tendo como objetivo remover o acúmulo de cargas da superfície, desse modo, controlando o gradiente de queda de tensão ao longo do componente de um modo uniforme.

A obtenção de nanocompósitos constituídos por nanopartículas metálicas em matriz isolante têm sido extensivamente estudados e a síntese pode ser feita através de métodos químicos [37,38] ou físicos. Os métodos físicos incluem a ablação por laser, deposição química a vapor, fluidos supercríticos dentre outros [39]. A implantação iônica também tem sido utilizada para gerar camada de nanocompósito alguns nanômetros abaixo da superfície do substrato [12,40-54]. Como já mencionado no Capítulo 2, a formação das nanopartículas metálicas se dá espontaneamente e pode ser explicada pela ocorrência de concentração dos átomos metálicos acima do limite de solubilidade no substrato implantado, levando à nucleação e crescimento das nanopartículas metálicas [27].

O implantador invertido foi utilizado para modificação de superfície de alumina, gerando uma camada de nanocompósito logo abaixo de sua superfície, formada por nanopartículas de titânio na matriz de alumina [53]. 
A seguir, será dado detalhamento do modelo teórico de percolação utilizado neste trabalho e, posteriormente, será apresentado o estado da arte para nanocompósitos formados através de implantação iônica. Em seguida é descrita a parte experimental, os resultados e a conclusão referente a este capítulo.

\subsection{MODELO TEÓRICO}

As propriedade elétricas de nanocompósitos formados por nanopartículas metálicas em uma matriz isolante apresenta condutividade elétrica $\sigma$ [55], próximo à transição crítica condutor / isolante, dado pela lei de escala

$$
\sigma \approx \sigma_{0}\left(x-x_{c}\right)^{t}
$$

onde $\sigma_{0}$ é a condutividade de saturação para a qual o material continua a ser um composto, $x$ é a concentração normalizada de átomos metálicos da fase condutora, $x_{c}$ é a concentração crítica ou limiar de percolação, abaixo da qual o composto tem a mesma condutividade que o material isolante da matriz, e $t$ é o expoente crítico. Para materiais nanocompósitos formados por implantação de íons metálicos em um isolante, a concentração normalizada de átomos metálicos $x$ é dada pela razão das doses de implantação iônica $\varphi / \varphi_{0}$, onde $\varphi$ é a dose de implantação e $\varphi_{0}$ (a dose de saturação) é a dose máxima para a qual o material ainda continua a ser um compósito; para doses superiores a $\varphi_{0}\left(x=\varphi / \varphi_{0}>1\right)$, a camada metálica deixa de ser um compósito e passa a assumir as características de um filme fino metálico.

O transporte de elétrons em compósitos formados por partículas condutoras em uma matriz isolante pode ocorrer de duas formas distintas [55]: quando as partículas condutoras estão em contato geométrico, onde a teoria prevê que o expoente crítico $t$ é menor do que 2 $(t<2)$ e o processo é chamado de percolação; ou quando as partículas condutoras não estão em contacto geométrico, e o processo de condução se dá basicamente por tunelamento. Ambos os processos podem contribuir simultaneamente, onde a teoria prevê que o expoente crítico $t$ é maior que $2(t>2)$. É importante notar que na percolação podemos distinguir três regimes: (i) condutor $\left(x>x_{c}\right)$, (ii) transição $\left(x \approx x_{c}\right)$, e (iii) isolante $\left(x<x_{c}\right)$. Assim os parâmetros relevantes para serem definidos experimentalmente são: $\sigma_{0}$ (condutividade de saturação), $\varphi_{0}$ (dose de saturação), $x_{c}$ (concentração normalizada crítica ou limiar de percolação) e $t$ (expoente crítico).

A formação de material particulado é um processo randômico e a ferramenta matemática básica utilizada para o processo de percolação e condução é a estatística (cálculos utilizando Monte Carlo). No entanto, consideremos aqui a teoria de rede de resistores 
desenvolvida por Kirkpatrick [56], na qual o material é tomado como um meio condutor efetivo (teórico) composto por uma mistura de esferas isolantes e condutoras, que pode ser tratado como uma rede de resistores. De acordo com Kirkpatrick, a condutividade efetiva do compósito $\sigma_{m}$ é dada por

$$
\begin{aligned}
\sigma_{m}=[(z x / 2-1) & \left.\sigma_{1}+[z(1-x) / 2-1] \sigma_{2}\right] /(z-2)+ \\
+ & \left.+\left[(z x / 2-1) \sigma_{1}+[z(1-x) / 2-1] \sigma_{2}\right\}^{2}+2(z-2) \sigma_{1} \sigma_{2}\right]^{1 / 2} /(z-2),
\end{aligned}
$$

onde $z$ é o número de ligações em cada nó da rede, $\sigma_{1}$ é a condutividade do material condutor, $\sigma_{2}$ é a condutividade do material isolante e $x$ é a concentração normalizada de átomos metálicos. Assim, essa expressão permite calcular analiticamente a condutividade efetiva $\sigma_{m}$ do compósito. Surpreendentemente, apesar dessa expressão ser baseada na teoria de rede de resistores, as previsões para a condutividade efetiva $\sigma_{m}$ são precisas [56,57], estando em acordo preciso com os cálculos numéricos de Monte Carlo.

\subsection{ESTADO DA ARTE: NANOCOMPÓSITOS FORMADOS ATRAVÉS DE IMPLANTAÇÃO IÔNICA}

A técnica de implantação iônica apresenta versatilidade e flexibilidade, o que permite o desenvolvimento de novos materiais com propriedades exóticas, como os nanocompósitos. Implantação iônica, com altas doses, em um dado substrato utilizando energias que variam de algumas dezenas de elétron-volt a alguns milhares de elétron-volts, gera a formação de nanocompósitos [57,58]. A alta dose de implantação pode criar um estado supersaturado do material implantado, em uma camada logo abaixo da superfície do substrato, levando à formação de nanopartículas desse material. A profundidade e espessura dessa camada compósita devem variar conforme a dose e energia de implantação, mas a escala de profundidade e espessura dessa camada está entre algumas dezenas e algumas centenas de nanômetros. Subsequente tratamento térmico pode alterar a distribuição e tamanho das nanopartículas [47]. A versatilidade da técnica de implantação é devida ao fato que, essencialmente, qualquer elemento na tabela periódica pode ser implantado em praticamente qualquer material selecionado como substrato. Essa versatilidade e as várias combinações possíveis de íons implantados permite uma gama extremamente ampla de nanocompósitos. Por exemplo, a técnica permite o desenvolvimento de compósitos onde duas ou mais fases podem ser combinadas e integradas, criando nanoestruturas tipo core-shell [17,18], o que pode aumentar consideravelmente alguns efeitos optoeletrônicos. A estabilidade mecânica e química de um nanocompósito normalmente é muito boa, uma vez que as nanopartículas são 
formadas abaixo da superfície do substrato e, portanto, protegidas do meio externo.

Nanopartículas metálicas em substratos isolantes foram dos primeiros sistemas de nanocompósitos a serem formados por implantação iônica [59]. No trabalho citado, foi observada uma alta concentração local de precipitados em escala nanométrica, formando uma camada fina logo abaixo da superfície do substrato de vidro. Esta configuração física é muito diferente de vidros compósitos contendo nanocluster feitos a partir de processos de fusão, em que as partículas são dispersas uniformemente por toda a massa. Compósitos formados por nanopartículas metálicas por implantação iônica apresentam efeitos ópticos pronunciados, tais como [60]: (a) absorção devido à ressonância plasmônica de superfície e (b) acentuada susceptibilidade não-linear de terceira ordem. Sendo o substrato isolante, o confinamento espacial dos elétrons livres das nanopartículas metálicas produz um campo electromagnético intensificado devido ao grande momento de dipolo induzido por um campo óptico. Somado a isso, para o caso de nanocristais com diâmetros inferiores a $10 \mathrm{~nm}$, o confinamento das funções de onda dos elétrons, para um volume muito menor do que o livre caminho médio do bulk, produz uma contribuição adicional para a susceptibilidade elétrica.

Muitos outros trabalhos recentes podem ser citados [61-65] onde nanocompósitos formados através de implantação iônica são estudados. Apesar de toda a evolução dessa área, o mecanismo de formação das nanopartículas em matrizes isolantes e polímeros condutores através de implantação iônica é pouco conhecido. A literatura não reporta detalhes muito importantes tais como: (a) distribuição espacial das nanopartículas ao longo da camada compósita e (b) os tamanhos das nanopartículas e a evolução dessa camada em função dos parâmetros experimentais tais como dose implantada, energia de implantação, materiais utilizados como substrato e tipos de íons implantados. Com nossas pesquisas pretendemos determinar outros aspectos de fundamental importância que ainda não são conhecidos: (a) como crescem as nanopartículas com o aumento da dose; (b) verificar se elas crescem até se tocarem ou se há nucleação e crescimento de novas pequenas partículas entre as nanopartículas já existentes.

\subsection{MATERIAIS E MÉTODOS}

As amostras foram preparadas por meio de implantação iônica de titânio em pequenas amostras planas de alumina, utilizando o implantador invertido. Medidas de resistividade in situ foram realizadas durante a implantação. Inicialmente foram recortadas duas placas de alumina, utilizando uma cortadeira diamantada, gerando duas amostras com dimensões de 26 $\mathrm{x} 7,1 \mathrm{~mm}^{2}$ e espessura de $0,5 \mathrm{~mm}$, como apresentado na Figura 30 . Contatos elétricos foram 
formados em ambas as extremidades de cada amostra de alumina. Esses contatos foram feitos através de soldagem entre cerâmica e metal [66], gerando retângulos de 5 x 7,1 mm² em cada extremidade das amostras, representados por área escuras na Figura 30. Antes da soldagem, as amostras foram limpas em banhos ultrassônicos utilizando consecutivamente xileno, acetona e álcool isopropílico, por 5 minutos em cada um desses solventes. Como material de soldagem foi utilizado o níquel, a uma temperatura de cerca de $500{ }^{\circ} \mathrm{C}$. A escolha do níquel como metal para os contatos se baseou no fato de possuir boa condutividade, ser resistente à oxidação e ser de baixo custo.

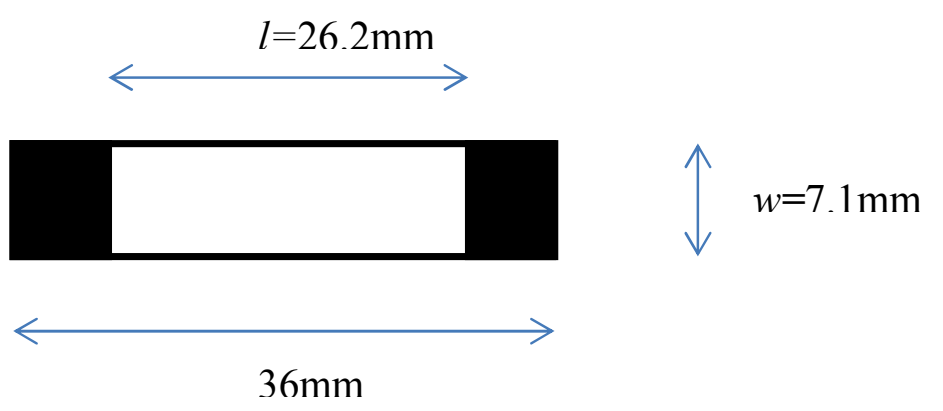

Figura 30. Ilustração esquemática das amostras de alumina, onde as regiões pretas representam os contatos elétricos.

Na Figura 31 é apresentadas imagens de MEV de bordas do contato obtido através de soldagem entre cerâmica e metal, onde é possível observar uma boa molhabilidade do níquel na superfície da alumina. Um aspecto importante a ser ressaltado é que esse tipo de soldagem leva o metal a uma profundidade típica de penetração de cerca de $1 \mu \mathrm{m}$, fornecendo um bom contato elétrico com a camada de nanocompósito que, como veremos, fica a poucos nanômetros abaixo da superfície. 


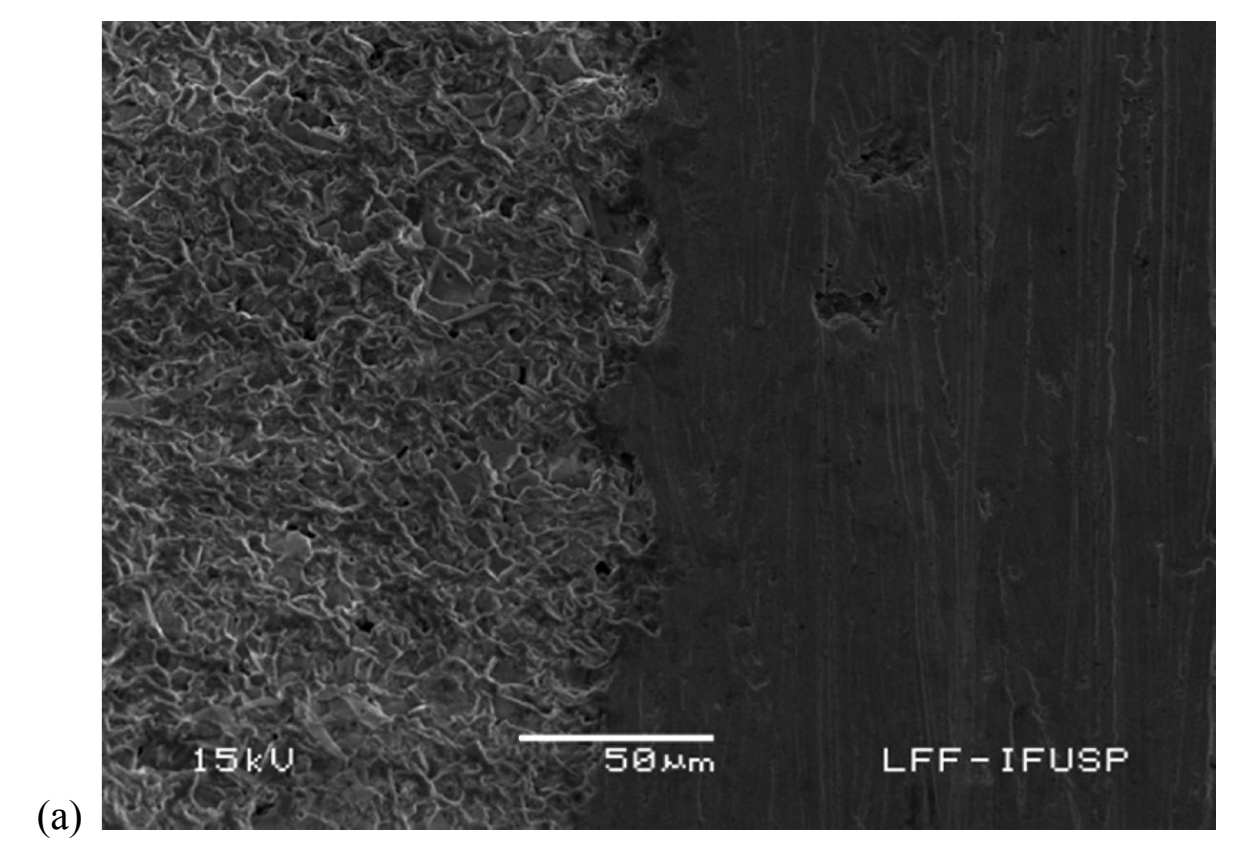

(a)

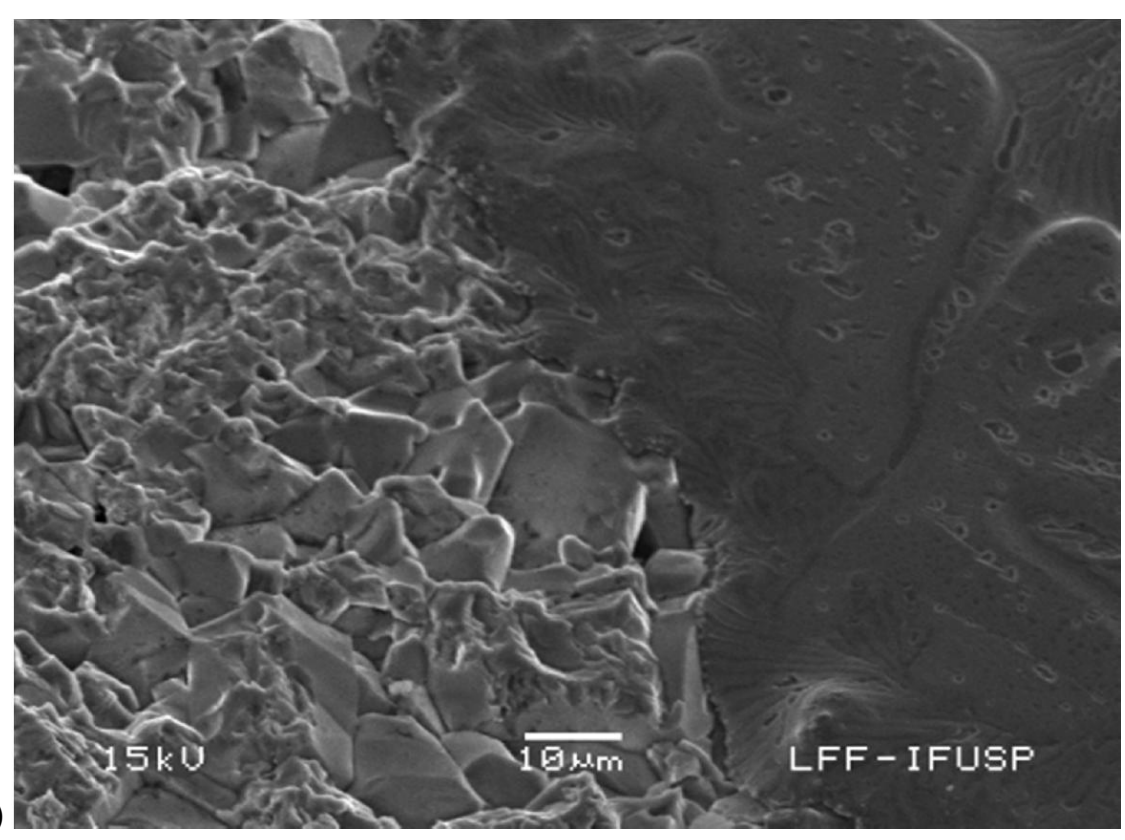

Figura 31. Imagens de MEV de bordas do contato obtido através de soldagem entre cerâmica e metal.

Fios de cobre foram soldados, utilizando liga de estanho (60\%) e chumbo (40\%), nos contatos elétricos (em níquel) nas extremidades das amostras. Esses fios foram ligados a passadores tipo feedthrough, viabilizando contato elétrico das extremidades da amostra no exterior da câmera de vácuo. Esses contatos foram utilizados para a medida de resistência da amostra através de um gigaohmmetro da GOSSEN-METRAWATT GMBH, modelo METRISO 1000D.

Antes da colocação da amostra no implantador invertido, uma calibração da corrente iônica foi realizada para o planejamento do experimento, quanto às doses de implantação. $\mathrm{O}$ 
valor obtido para a corrente iônica foi de $11 \mathrm{~mA} / \mathrm{cm}^{2}$ por pulso.

A amostra foi então posicionada em frente ao copo de Faraday, cobrindo metade de sua entrada, o que permitiu o monitoramento da corrente iônica durante a implantação. Junto à amostra foi colocado um pedaço de carbono vítreo para, posteriormente, fazer o controle de dose final de implantação por RBS.

Antes de iniciar a implantação, já com a câmera com vácuo entre 2 e $3 \times 10^{-6}$ torr, foram realizadas 3 purgas com argônio, elevando a pressão da câmera até cerca de $10^{-4}$ torr e retornando para o vácuo de base entre 2 e $3 \times 10^{-6}$ torr. A justificativa para esse procedimento é reduzir a incorporação de oxigênio na amostra, dada a alta reatividade do oxigênio com íons de titânio.

A implantação de titânio foi realizada com tensão aceleradora de $25 \mathrm{kV}$ e, sendo o estado de carga médio do titânio de $+2,1$, a energia média de implantação foi de $52,5 \mathrm{keV}$. Iniciada a implantação, após uma determinada dose implantada (medida no copo de Faraday) a implantação era interrompida e a resistência da amostra medida através de contatos elétricos externos à câmara. Posteriormente o processo de implantação era retomado e nova dose era implantada, e assim por diante, permitindo a obtenção da resistividade (calculada a partir da geometria da amostra) em função da dose implantada.

Dois experimentos semelhantes e independentes foram realizados para a verificação da reprodutibilidade do processo. No que segue, vamos nos referir a amostras 1 e 2 para estes dois experimentos.

TEM foi realizado em alumina implantada com titânio. Para a preparação da amostra, uma placa de alumina foi riscada com uma ponta de diamante para obter pó de alumina. O pó passou por uma peneira de abertura de malha de 0,062 milímetro para remover grandes grãos. Em seguida, o pó foi depositado em papel de limpeza de lentes, friccionado e o excesso de material removido, deixando na superfície do papel partículas de alumina com tamanhos de grão suficientemente pequenos para observação por TEM. Então, duas implantações de titânio foram realizadas no papel contendo as micropartículas de alumina com energia de $52,5 \mathrm{keV}$ e dose de $0,6 \times 10^{16}$ átomos $/ \mathrm{cm}^{2}$ e $1 \times 10^{16}$ átomos $/ \mathrm{cm}^{2}$.

Após a implantação, uma grade suporte (própria para uso em TEM) de cobre recoberta com um fino filme de formvar e carbono foi umedecida em água deionizada e friccionada sobre a superfície do papel que continha o pó de alumina implantado com titânio, obtendo assim a preparação final para TEM. Amostra com e sem implantação de titânio foram observadas por TEM. Na Figura 32 é apresentada uma imagem de MEV de uma preparação de amostra para TEM, como descrito acima. 
O microscópio eletrônico de transmissão utilizado para as análises foi um Jeol, modelo JEM-2100, localizado no Centro de Ciência e Tecnologia de Materiais (CCTM) do IPEN (Instituto de Pesquisas Energéticas e Nucleares).

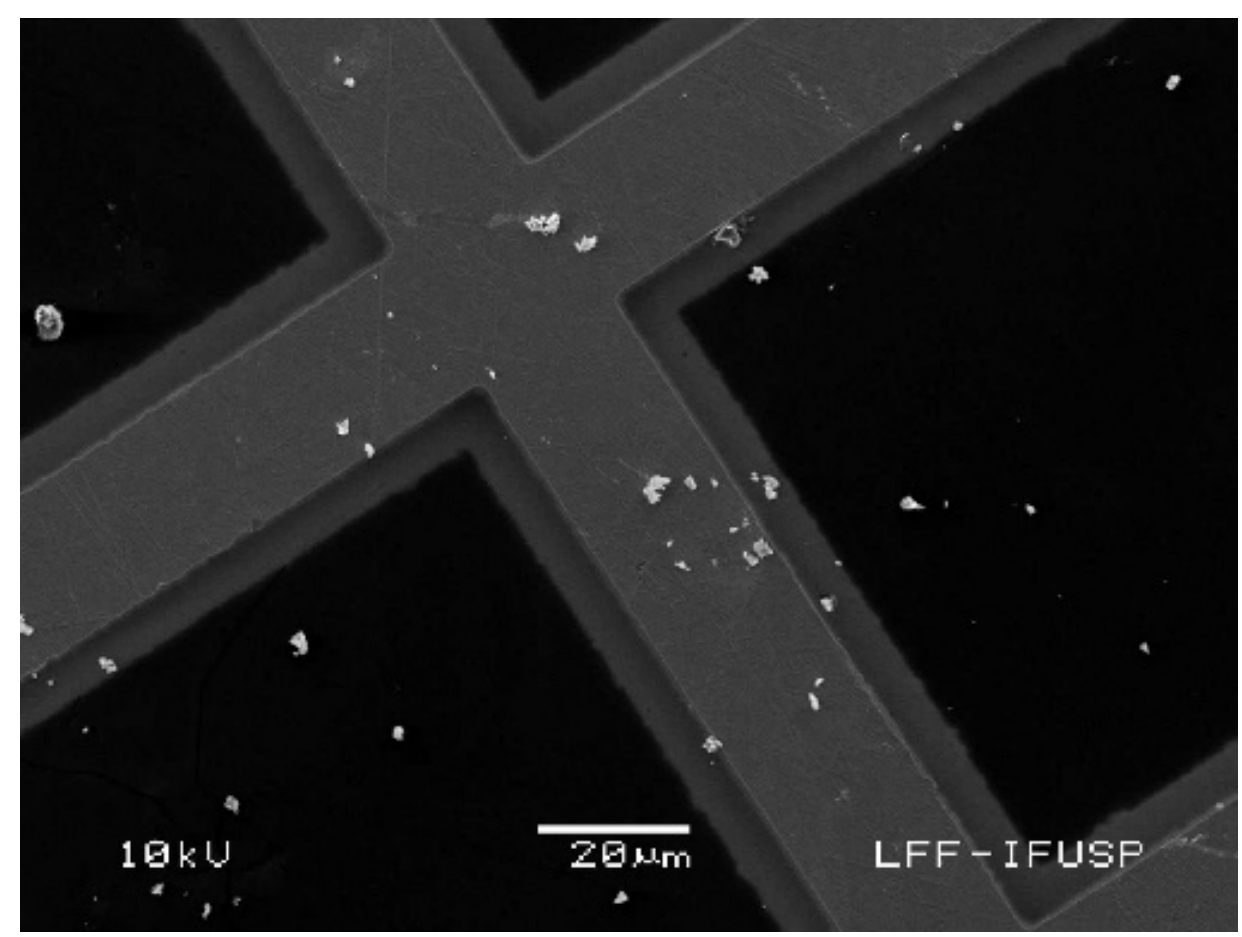

Figura 32. Imagem de MEV de uma preparação de amostra de alumina em pó para TEM.

Simulação computacional utilizando o software TRIDYN [15,16] foi utilizado para estimar os perfis de profundidade dos íons de titânio implantados no substrato de alumina.

RBS foi utilizado no trabalho deste capítulo para duas finalidades. A primeira foi para confirmar as doses de titânio implantado em alumina de todas as amostras e a segunda finalidade foi obter o perfil de titânio em profundidade na alumina.

\subsection{RESULTADOS}

Imagens de TEM de pó de alumina com titânio implantado são apresentadas na Figura 33. Em ambas as doses analisadas foram visualizadas nanopartículas de titânio no interior dos grãos de alumina, dose de $0.6 \times 10^{16} \mathrm{~cm}^{2}$ (Figura 33(a)) e dose de $1 \times 10^{16} \mathrm{~cm}^{2}$ (Figura 33(b)). Durante a observação no microscópio eletrônico de transmissão foi realizada análise por EDS confirmando a presença de titânio na região. $\mathrm{O}$ valor médio encontrado para o tamanho das nanopartículas foi de $20 \mathrm{~nm}$. 

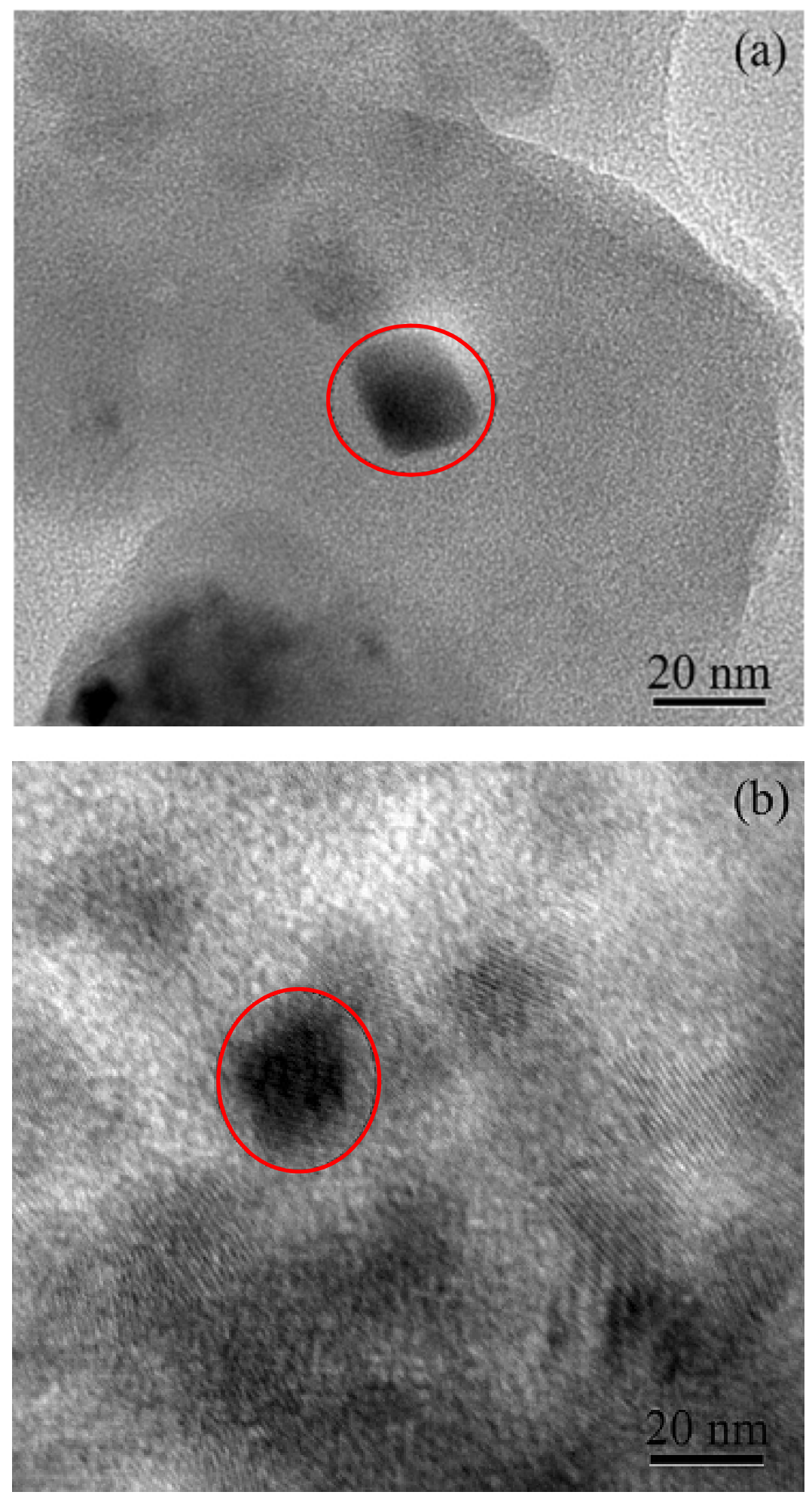

Figura 33. Imagens de TEM de pó de alumina com titânio implantado, permitindo a visualização direta das nanopartículas de titânio no interior dos grãos de alumina, ressaltados com círculos nas imagens. (a) Dose implantada de $0.6 \times 10^{16}$ átomos $/ \mathrm{cm}^{2}$ e (b) Dose implantada de $1 \times 10^{16}$ átomos $/ \mathrm{cm}^{2}$. Durante a observação foi realizada análise por EDS confirmando a presença de titânio na região [53]. 
Para obtermos a condutividade da alumina ao longo do processo de implantação de titânio, tivemos como medida experimental a resistência entre os contatos elétricos da amostra. Assim, foi necessário utilizar a geometria da amostra para o cálculo da condutividade. A equação utilizada foi

$$
R=\rho \cdot \frac{l}{w \cdot \delta}
$$

onde $\rho$ é a resistividade da camada compósita, $R$ é resistência entre os contatos elétricos, $l$ e $w$ são dados na Figura 30 e $\delta$ é espessura da camada de nanocompósito. Mas a resistividade é o inverso da condutividade $(\sigma)$, assim

$$
\sigma=1 / \rho=\frac{l}{R \cdot w \cdot \delta}
$$

A espessura da camada de nanocompósito $(\delta)$ foi estimada utilizando simulação por TRIDYN com os parâmetros experimentais: energia de $52.5 \mathrm{keV}$ e estado de carga de titânio de 2.1. Com a finalidade de estimar $\delta$, diferentes doses foram usadas para a simulação TRIDYN: $0,5 \times 10^{16} ; 1 \times 10^{16} ; 2 \times 10^{16}$ e $3 \times 10^{16}$ átomos $/ \mathrm{cm}^{2}$ (veja anexo E).

Na Figura 34 é apresentados os perfis de profundidade das simulações TRIDYN, fornecendo a fração atômica do titânio em função da profundidade. Fica claro pela Figura 34, como esperado, que quanto maior a dose, maior o pico de máxima concentração de titânio, nota-se também que a profundidade do máximo de concentração diminui com o aumento da dose, estando entre $25 \mathrm{~nm}$ (para a maior dose) e $29 \mathrm{~nm}$ (para a menor dose). A justificativa para isso está relacionada ao fato dos átomos implantados no início do processo agirem como barreira para os implantados subsequentemente, causando um acúmulo deles mais próximo à superfície, além do processo de sputtering da superfície, durante a implantação, que reduz a espessura do substrato (alumina) acima da camada compósita. Quanto à estimativa da espessura da camada de nanocompósito $(\delta)$, podemos observar que, apesar das alturas dos picos das curvas variarem consideravelmente com a dose, as larguras se mantêm aproximadamente constante e da ordem de $55 \mathrm{~nm}$. Assim, este valor foi tomado para a espessura da camada de nanocompósito $\delta=55 \mathrm{~nm}$. 


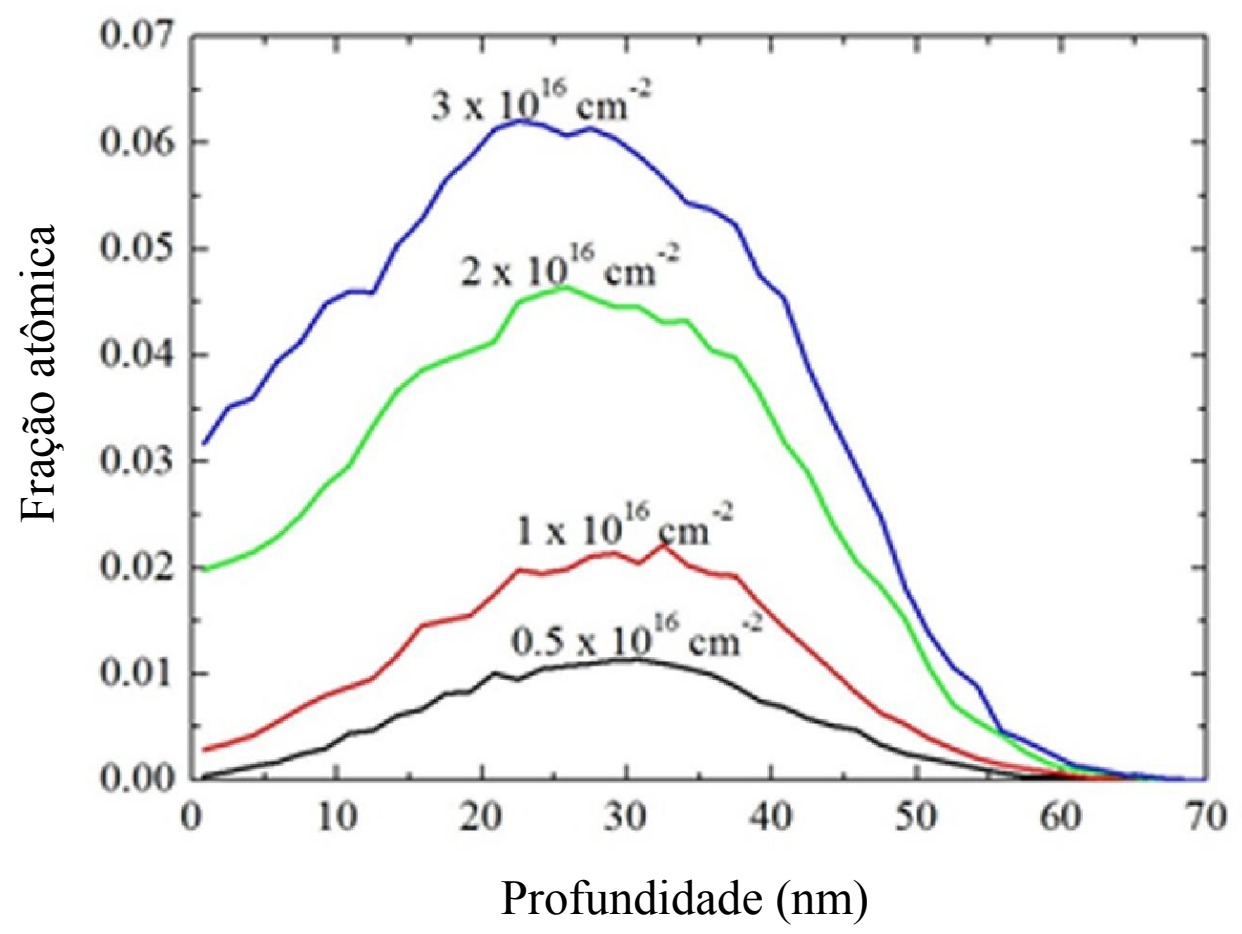

Figura 34. Simulações por TRIDYN de implantação iônica de titânio em alumina com energia de $52.5 \mathrm{keV}$ e doses entre 0.5 e $3 \times 10^{16}$ átomos $/ \mathrm{cm}^{2}$ [53].

Na Figura 35 são apresentados os resultados de RBS e simulação por TRIDYN do perfil em profundidade da fração de titânio implantado em alumina com dose de $1 \times 10^{16}$ átomos $/ \mathrm{cm}^{2}$ e energia de $52,5 \mathrm{keV}$. Os resultados são coincidentes, apresentando picos em ambas as curvas por volta de $30 \mathrm{~nm}$, apesar de um pequeno alargamento da curva experimental (RBS) quando comparada à simulação TRIDYN. A justificativa para o alargamento está no fato de termos utilizado o estado de carga médio $(+2,1)$ do titânio para a simulação TRIDYN, enquanto que, na realidade, sabemos que para o titânio temos estados de carga $+1,+2$ e +3 em proporções de $11 \%, 75 \%, 14 \%$ respetivamente. Assim, 25\% dos átomos implantados não possuíam a energia considerada na simulação, o que justifica a maior largura na curva experimental. No entanto esse efeito de alargamento é pequeno e os picos são coincidentes, mostrando boa concordância entre a parte experimental e a simulação por TRIDYN. 


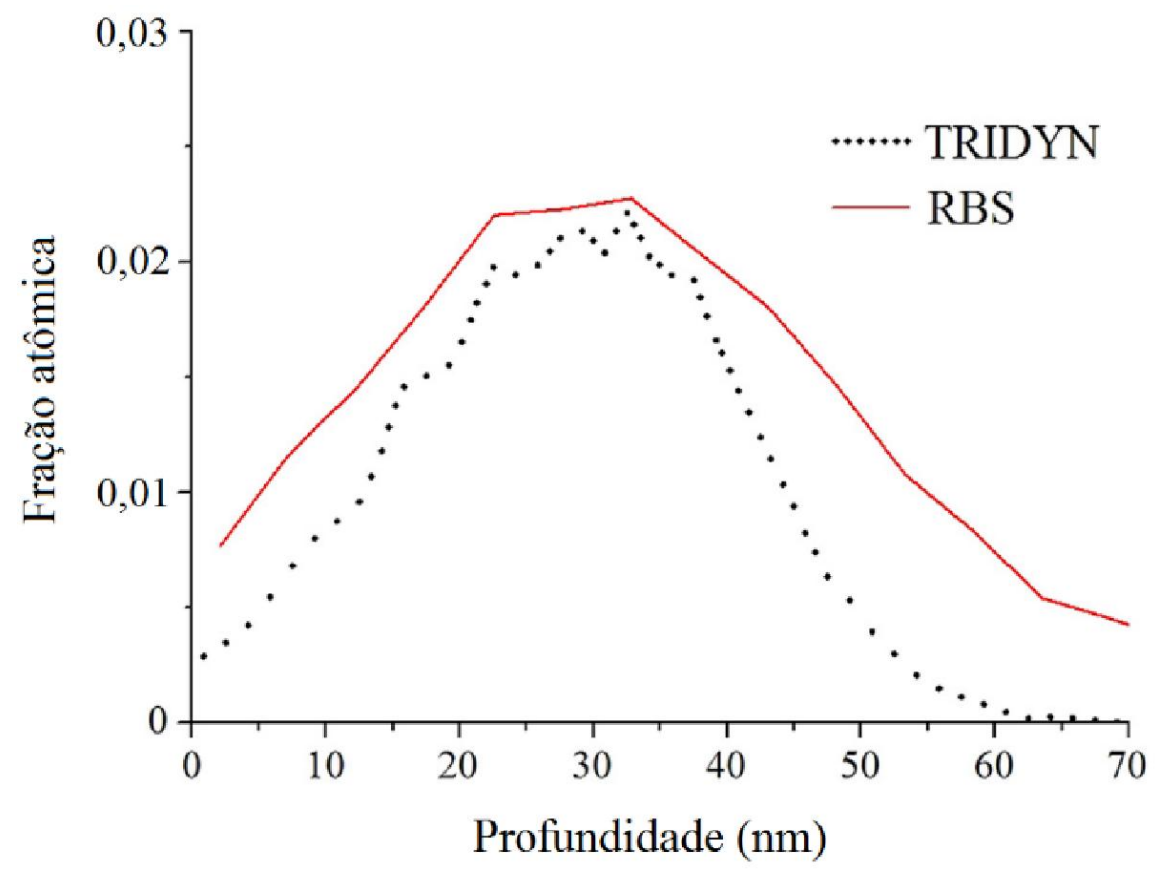

Figura 35. Resultados de RBS e simulação por TRIDYN do perfil em profundidade da fração de titânio implantado em alumina com dose de $1 \times 10^{16}$ átomos $/ \mathrm{cm}^{2}$ e energia de $52,5 \mathrm{keV}$ [53].

Das simulações por TRIDYN, podemos inferir que as nanopartículas de titânio devem se formar a cerca de $30 \mathrm{~nm}$ da superfície, que é a profundidade de máxima concentração de titânio na alumina. Para utilizarmos a Eq.(2), será assumido que as nanopartículas de titânio, formadas abaixo da superfície de alumina, geram uma camada bidimensional, limitando o número de vizinho próximos de cada nanopartícula de titânio entre $z=5$ e $z=6$.

Retomando as medidas elétricas realizadas, foi possível calcular a condutividade da camada nanocompósita utilizando a Eq.(4), em função da dose de titânio implantada. Na Figura 36 é apresentados os gráficos da condutividade dos nanocompósitos (amostras 1 e 2) em função da dose implantada. Nesse gráfico foi observado excelente acordo para as duas medidas independentes (amostras 1 e 2), comprovando a reprodutibilidade dos resultados. 


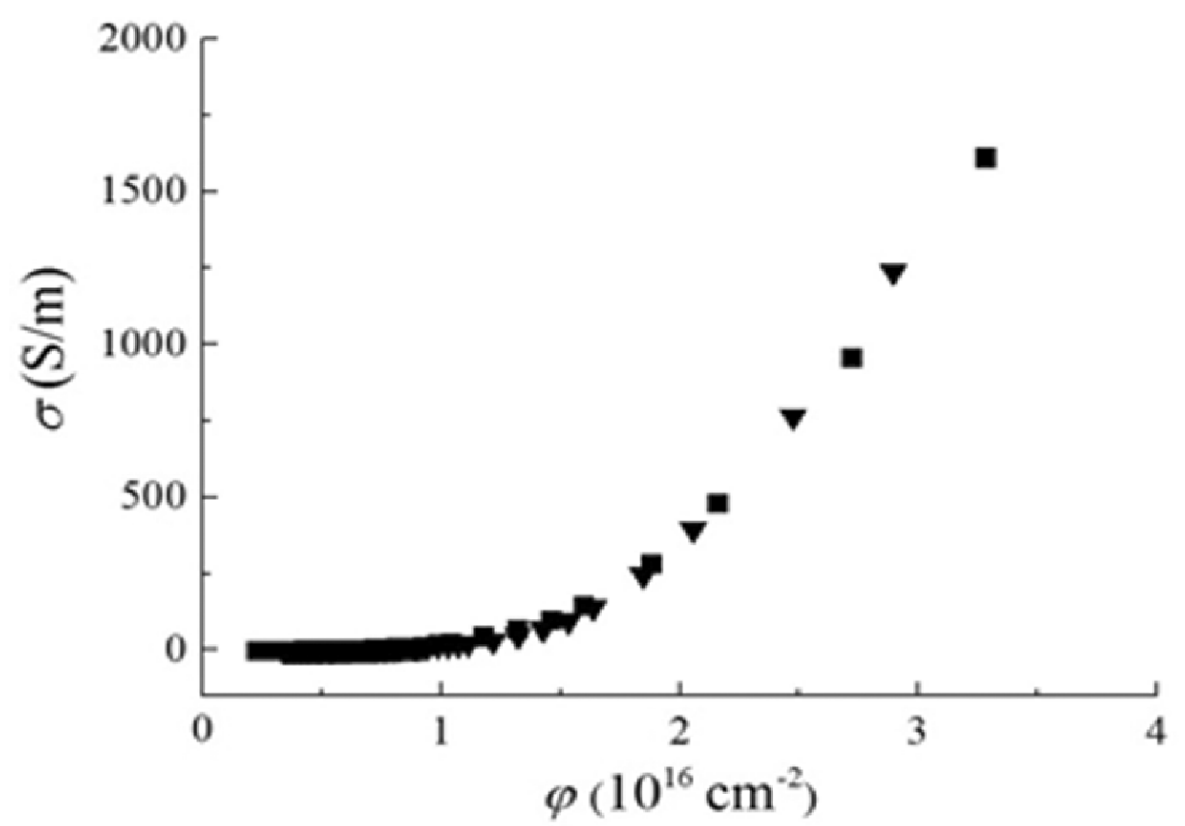

Figura 36. Medidas de condutividade $\sigma$ em função da dose de titânio implantado $\varphi$ em alumina. Os pontos no gráfico apresentados como quadrados e triângulos e correspondem a resultados de dois experimentos independentes (amostras 1 e 2) [53].

As Eq.(1) e Eq.(2) foram utilizadas para a determinação da dose de saturação $\varphi_{0}$, da condutividade de saturação $\sigma_{0}$, e do expoente crítico $t$, como será descrito a seguir. No caso da Eq.(2) (Kirkpatrick), utilizamos $\sigma_{1}=2,4 \times 10^{6} \mathrm{~S} / \mathrm{m}$ e $\sigma_{2}=1 \times 10^{-12} \mathrm{~S} / \mathrm{m}$. Para isso, substituímos $x=\varphi / \varphi_{0}$ e $x_{c}=\varphi_{c} / \varphi_{0}$ na Eq. (1), onde $\varphi_{c}$ é a dose de percolação, e derivamos com relação a $\varphi$, obtendo

$$
\frac{d \sigma}{d \varphi}=\frac{\sigma_{0} t}{\varphi_{0}}\left(\frac{\varphi}{\varphi_{0}}-\frac{\varphi_{c}}{\varphi_{0}}\right)^{(t-1)}
$$

que pode ser expresso como

$$
\ln \left(\frac{d \sigma}{d \varphi}\right)=\ln \left(\frac{\sigma_{0} t}{\varphi_{0}}\right)+(t-1) \ln \left(\frac{\varphi}{\varphi_{0}}-\frac{\varphi_{c}}{\varphi_{0}}\right) .
$$

Eq. (6) pode ser vista como uma equação linear do tipo

$$
Y=C+\alpha X
$$

onde $Y=\ln \left(\frac{d \sigma}{d \varphi}\right), C=\ln \left(\frac{\sigma_{0} t}{\varphi_{0}}\right), \alpha=(t-1)$ e $X=\ln \left(\frac{\varphi}{\varphi_{0}}-\frac{\varphi_{c}}{\varphi_{0}}\right)$, sendo $\sigma$ e $\varphi$ são valores experimentais, e $\sigma_{0}, \varphi_{0}, \varphi_{c}$ e $t$ são valores a serem determinados. Para resolver essa equação, temos que considerar os valores experimentais $\sigma^{*}$ em função de $\varphi^{*}$, e os valores previstos para $x_{c}=\varphi_{c} / \varphi_{0}$ a partir da Eq. (2), considerando $z$ entre 5 e 6 , como mencionado anteriormente. A partir desses dados, ajustes utilizando a Eq. (7) devem ser efetuados para diferentes valores experimentais de $\left(\sigma_{0}^{*}, \varphi_{0} *\right)$. Para cada ajuste podemos verificar a auto consistência do resultado, tomando os valores de $t$ e $C$ obtidos e calculando $\ln \left(\frac{\sigma_{0}^{*} t}{\varphi_{0}^{*}}\right)$. Quando 
$C$ coincide com o valor de $\ln \left(\frac{\sigma_{0}^{*} t}{\varphi_{0}^{*}}\right)$, então, a dupla $\left(\sigma_{0}^{*}, \varphi_{0}{ }^{*}\right)$ é a condutividade de saturação e dose de saturação correta, respectivamente, e $t$ fica também determinado.

O resultado obtido para a dose de saturação foi $\varphi_{0}=2,2 \times 10^{16}$ átomos $/ \mathrm{cm}^{2}$, que é a dose máxima para a qual o material continua a ser um nanocompósito, e para a condutividade de saturação foi $\sigma_{0}=480 \mathrm{~S} / \mathrm{m}$. A dose de percolação obtida foi $\varphi_{\mathrm{c}}=0,84 \times 10^{16}$ átomos $/ \mathrm{cm}^{2}$, que é a dose abaixo da qual o material tem a mesma condutividade que a matriz isolante, o que corresponde à $x_{c}=0,38$. O expoente crítico obtido foi $t=1,4 \mathrm{e}$, como a condição $t<2$ é satisfeita, o processo de condutividade se dá devido a percolação, sendo o tunelamento desprezível [55].

Na Figura 37 é apresentado o gráfico normalizado da condutividade do nanocompósito $\left(\sigma / \sigma_{0}\right)$ em função da dose de titânio implantada $\left(\varphi / \varphi_{0}\right)$.

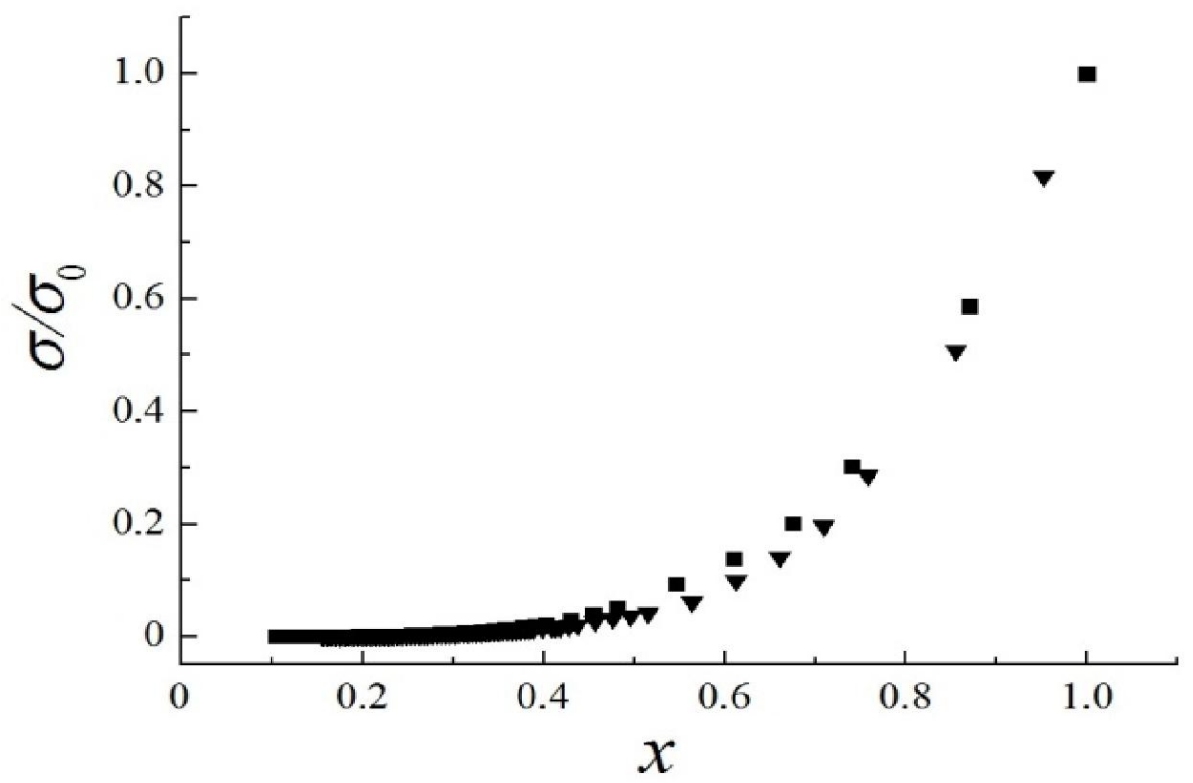

Figura 37. Gráfico normalizado da condutividade do nanocompósito $(\sigma / \sigma 0)$ em função da dose de titânio implantada $(\varphi / \varphi 0)[53]$.

Um experimento em paralelo foi realizado onde uma amostra de alumina com dose de titânio implantado de $1,2 \times 10^{16}$ átomos $/ \mathrm{cm}^{2}$ foi avaliada durante 383 dias, medindo-se sua condutividade em função do tempo. O resultado é apresentado no anexo $G$, onde pode-se observar que a resistividade aumentou significativamente ao longo do tempo. Dessa forma podemos inferir que o titânio deve reagir com o oxigênio, não apenas durante a implantação, mas posteriamente também, assim, alterando a condutividade do nanocompósito abaixo da superfície da amostra. Esse oxigênio pode ser proveniente do ar, desde que o experimento foi realizado em ambiente aberto, ou pode ser da própria matriz (óxido de alumínio - alumina). 


\subsection{SUMÁRIO E CONCLUSÕES}

O implantador invertido foi utilizado para modificação de superfície de alumina, gerando uma camada de nanocompósito logo abaixo de sua superfície, formada por nanopartículas de titânio na matriz de alumina. Medidas de resistividade in situ foram realizadas durante a implantação. A implantação de titânio foi realizada com tensão aceleradora de $25 \mathrm{kV}$ e, sendo o estado de carga médio do titânio de $+2,1$, a energia média de implantação foi de $52,5 \mathrm{keV}$. Utilizando modelos teóricos de percolação foi possível determinar a dose de saturação $\varphi_{0}=2,2 \times 10^{16}$ átomos $/ \mathrm{cm}^{2}$, que é a dose máxima para a qual o material continua a ser um nanocompósito, e para a condutividade de saturação foi $\sigma_{0}=480$ $\mathrm{S} / \mathrm{m}$. A dose de percolação obtida foi $\varphi_{\mathrm{c}}=0,84 \times 10^{16}$ átomos $/ \mathrm{cm}^{2}$, que é a dose abaixo da qual o material tem a mesma condutividade que a matriz isolante. $\mathrm{O}$ expoente crítico obtido foi $t=$ 1,4 e, como a condição $t<2$ é satisfeita, o processo de condutividade se dá devido a percolação, sendo o tunelamento desprezível.

TEM foi realizado em alumina implantada com energia de $52,5 \mathrm{keV}$ e dose de $0,6 \mathrm{x}$ $10^{16}$ átomos $/ \mathrm{cm}^{2}$, o que permitiu a visualização direta das nanopartículas que apresentaram dimensões da ordem de $20 \mathrm{~nm}$.

Simulações por TRIDYN, considerando energia de implantação de $52,5 \mathrm{keV}$ e dose de $1 \times 10^{16}$ átomos $/ \mathrm{cm}^{2}$, demostraram que as nanopartículas de titânio devem se formar a cerca de $30 \mathrm{~nm}$ da superfície, que é a profundidade de máxima concentração de titânio na alumina. Resultados de RBS, do perfil em profundidade da fração de titânio implantado em alumina com dose de $1 \times 10^{16}$ átomos $/ \mathrm{cm}^{2}$ e energia de $52,5 \mathrm{keV}$, estavam de acordo com a simulação TRIDYN.

Medidas de resistividade do nanocompósito, de nanopartículas de titânio em matriz de alumina, ao longo de 383 dias mostraram um aumento significativo ao logo do tempo, sugerindo oxidação do titânio logo abaixo da superfície (veja anexo G). 


\section{CONCLUSÃO}

Neste trabalho foi descrito em detalhes um novo implantador invertido. Foi apresentado um estudo com a finalidade de caracterizar o implantador. Quanto à eletrônica do implantador invertido, a fonte de alimentação e o sistema de controle do canhão de plasma foram finalizadas e otimizadas. O sistema de alta tensão e o sistema de medição foram montados e desenvolvidos. Foi realizada uma caracterização do implantador invertido quanto à minimizar a divergência do feixe para obter a máxima corrente de feixe iônico. A melhor configuração foi obtida com as grades de espaçamento de $3 \mathrm{~mm}$ e abertura de $4 \mathrm{~mm}$. E como parte final da caracterização do implantador invertido, foi realizado mapeamento da densidade do feixe iônico na posição do porta amostras.

Em seguida, foi realizado um estudo sobre a neutralidade do feixe de íons gerado no implantador invertido por três métodos. Primeiramente, foi realizada caracterização por AFMC após corrosão de duas amostras de silício com ouro implantado. Comparando esses resultados com simulações TRIDYN, concluído que a energia efetiva de implantação pode estar entre $50 \mathrm{keV}$ e cerca de $32 \mathrm{keV}$, o que não permite concluir se o feixe é neutro ou não. $\mathrm{O}$ segundo método consistiu na análise por TEM de amostra de PMMA com ouro implantado. As imagens apresentaram regiões contendo nanopartículas de ouro com tamanhos entre 1 e 3 $\mathrm{nm}$, sendo que a presença de ouro foi confirmada por EDS. Foram também realizadas medidas de perfil de implantação por TEM que mostraram valor médio de pico de concentração na profundidade de $(66 \pm 4) \mathrm{nm}$. Este resultado está em acordo com perfil obtido por TRIDYN $(64 \mathrm{~nm})$ que sugere a neutralidade do feixe. O terceiro método se refere à medida por RBS de amostras de PMMA implantadas com ouro, confrontadas com simulações TRIDYN. Os resultados mostraram uma não concordância dos picos das curvas experimental e simulada, resultado oposto ao TEM. Assim, concluimos que não foi adequadamente confirmado se o feixe do implantador é neutro ou não, e há necessidade de realização novos estudos.

Finalizando o trabalho, o implantador invertido foi utilizado para modificação de superfície de alumina, gerando uma camada de nanocompósito logo abaixo de sua superfície, formada por nanopartículas de titânio na matriz de alumina. Medidas de resistividade in situ foram realizadas durante a implantação. A implantação de titânio foi realizada com energia média de implantação de $52,5 \mathrm{keV}$. Utilizando modelos teóricos de percolação foi possível determinar a dose de saturação $\varphi_{0}=2,2 \times 10^{16}$ átomos $/ \mathrm{cm}^{2}$, dose de percolação obtida foi $\varphi_{\mathrm{c}}=$ $0,84 \times 10^{16}$ átomos $/ \mathrm{cm}^{2}$ e expoente crítico $t=1,4$. Concluindo, como a condição $t<2$ é satisfeita, o processo de condutividade se dá devido a percolação. TEM foi realizado em 
alumina implantada que permitiu a visualização direta das nanopartículas de titânio que apresentaram dimensões da ordem de $20 \mathrm{~nm}$. Simulações por TRIDYN, demostraram que as nanopartículas de titânio devem se formar a cerca de $30 \mathrm{~nm}$ da superfície, que está de acordo com resultados obtidos por RBS. Uma amostra de nanocompósito de nanopartículas de titânio em matriz de alumina, preparada com dose acima da percolação, foi observada através de medidas de resistividade ao longo de 383 dias que mostraram um aumento significativo ao longo do tempo, sugerindo oxidação do titânio logo abaixo da superfície. 


\section{ANEXO A. PUBLICAÇÕES REALIZADAS DURANTE O TRABALHO}

1. R. E. Spirin, M. C. Salvadori, F. S. Teixeira, L. G. Sgubin, M. Cattani, and I. G. Brown. Nanocomposite formed by titanium ion implantation into alumina". Journal of Applied Physics 116, 184306 (2014).

2. M. C. Salvadori, F. S. Teixeira, L. G. Sgubin, W. W. R. Araujo, R. E. Spirin, M. Cattani, E. M. Oks, and I. G. Brown. "Gold ion implantation into alumina using an "inverted ion source" configuration". Review of Scientific Instruments 85, 02B502 (2014).

3. M. C. Salvadori, M. R. S. Oliveira, R. Spirin, F. S. Teixeira, M. Cattani, I. G. Brown. "Microcavity-array superhydrophobic surfaces: Limits of the model". Journal of Applied Physics 114, 174911-1-7 (2013).

4. M. C. Salvadori, F. S. Teixeira, L. G. Sgubin, W. W. R. Araujo, R. E. Spirin, E. M. Oks and I. G. Brown. "Performance of an inverted ion source". Review of Scientific Instruments $84,023506-1-5$ (2013).

5. M. C. Salvadori, F. S. Teixeira, L. G. Sgubin, W. W. R. Araujo, R. E. Spirin, E. M. Oks, K. M. Yu, I. G. Brown. "Low cost ion implantation technique". Applied Physics Letters 101, 224104-1- 4 (2012).

6. M. C. Salvadori, F. S. Teixeira, W. W. R. Araújo, L. G. Sgubin, R. E. Spirin, M. Cattani, I. G. Brown. "Gold nanoparticle formation in diamond-like carbon using two different methods: gold ion implantation and co-deposition of gold and carbon". Journal of Applied Physics 112, 074312-1- 6 (2012).

7. Sochugov, N. S., Oskirko V. O., Spirin R. E. A power supply for magnetron sputtering systems. Instruments and Experimental Techniques (New York), v. 56, p. 178-184, (2013) 


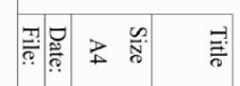

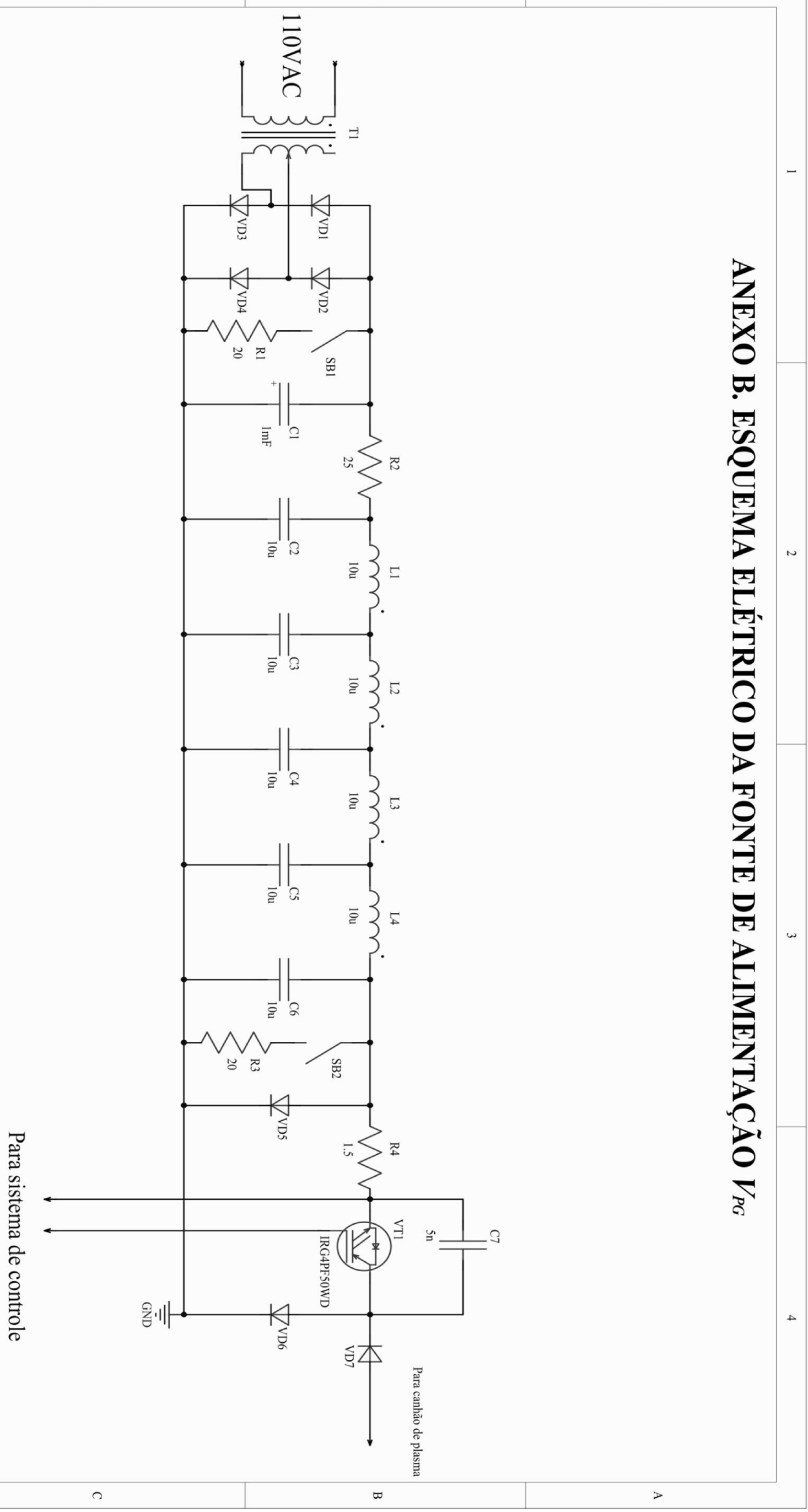

$\nabla$ 


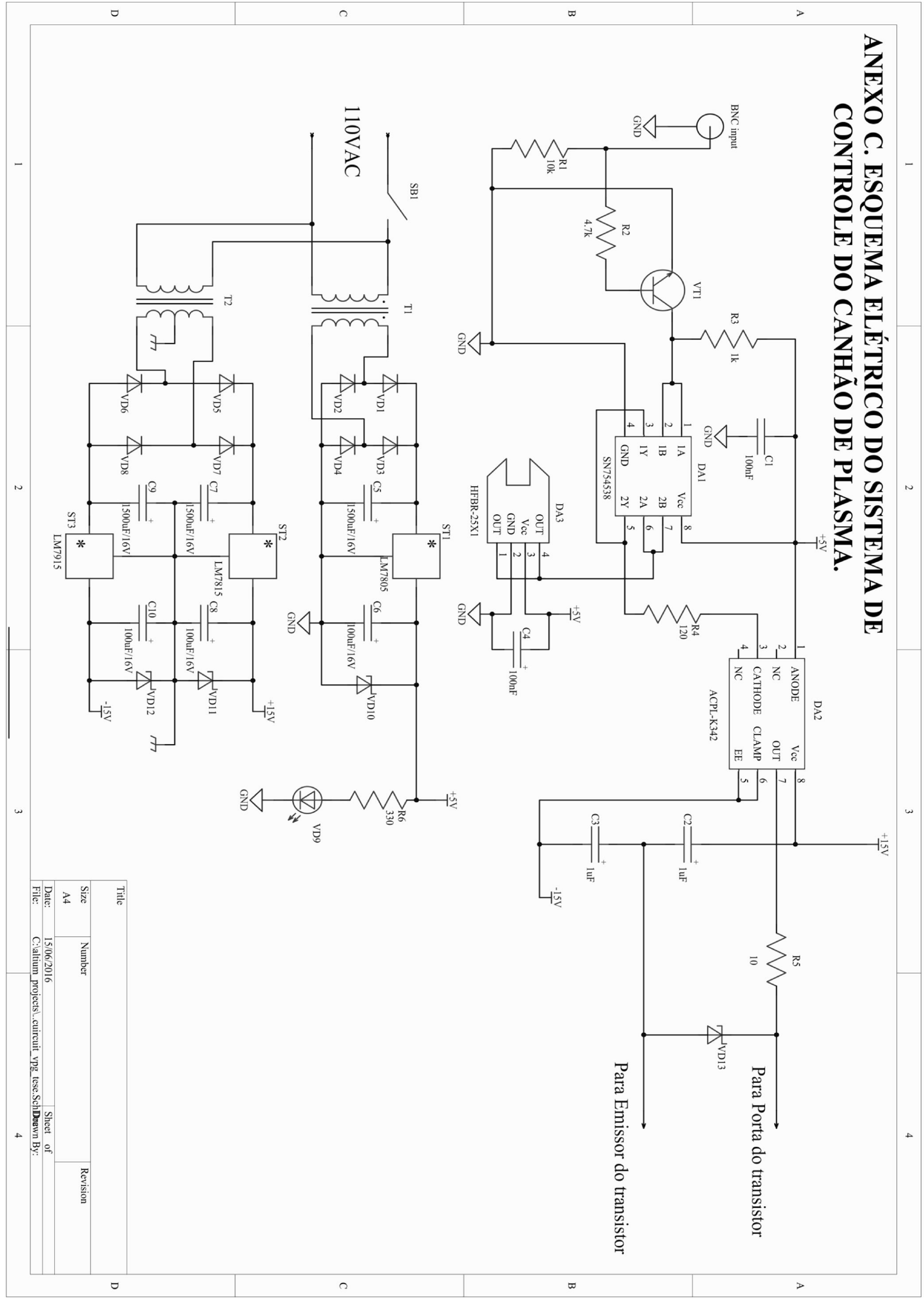




\section{ANEXO D. ESTUDO DE APLICAÇÃO DO IMPLANTADOR INVERTIDO PARA CORROSÃO SECA}

Uma das aplicações do implantador invertido é sua utilização para corrosão seca, este equipamento pode acelerar os íons e usar sua energia para bombardear a superfície. Neste caso a corrosão é um processo físico quando os átomos do alvo são removidos por choques mecânicos dos íons do gás. O valor da energia dos íons deve ser menor do que no processo de implantação, mas suficientemente alta para poder remover os átomos do alvo, isto é, superior à energia de ligação dos átomos à superfície. Simultaneamente pode ocorrer corrosão envolvendo reações químicas, dita corrosão reativa.

Existem vários fatores que afetam a eficiência da corrosão, tais como: ângulo entre feixe e alvo, energia dos íons, tipo de íons, fator de reação química, etc. A simulação do processo de corrosão foi realizada através do programa TRIDYN, no qual os fatores considerados foram tipo de íon, sua energia e o ângulo de incidência do feixe de ions na amostra (veja anexo E).

Uma primeira série de simulações consistiu da obtenção do número de átomos espalhados do alvo, por íon incidente, em função do ângulo de incidência do feixe. O ângulo considerado é definido pelo feixe e a normal à superfície. Nessa série de simulações foi considerado o silício como substrato e como íons incidentes foram utilizados os átomos de argônio com energia de $2 \mathrm{keV}$. O argônio foi escolhido por ser um gás inerte, podendo-se desconsiderar o fator químico do processo. Os resultados estão apresentados na Figura D.1. É possível observar que com o ângulo de 70 graus, a taxa de corrosão é máxima.

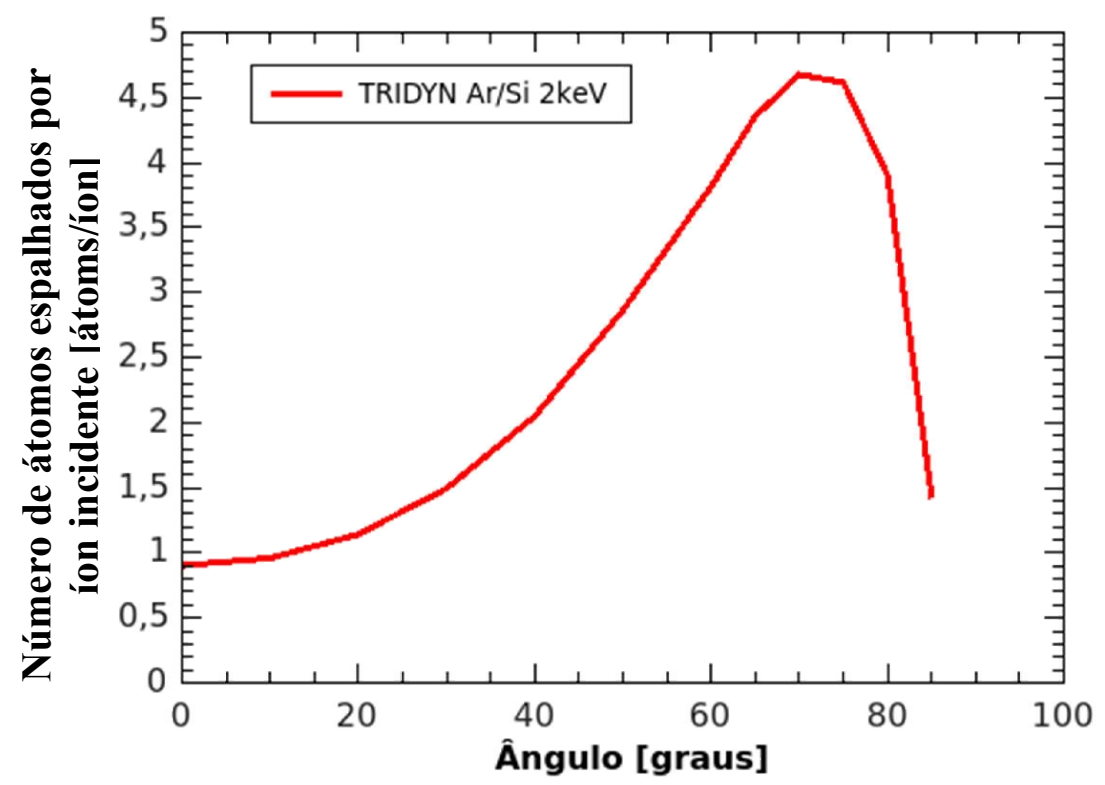

Figura D.1. Série de simulações TRIDYN do número de átomos espalhados do alvo, por íon incidente, em função do ângulo de incidência do feixe para o caso de alvo de silício e feixe de ions de argônio. 
Uma outra série de simulações foi realizada com incidência do feixe normal à superfície, obtendo-se o número de átomos espalhados do alvo, por íon incidente, em função da energia do feixe. Os resultados dessa série de simulações estão epresentados na Figura D.2.

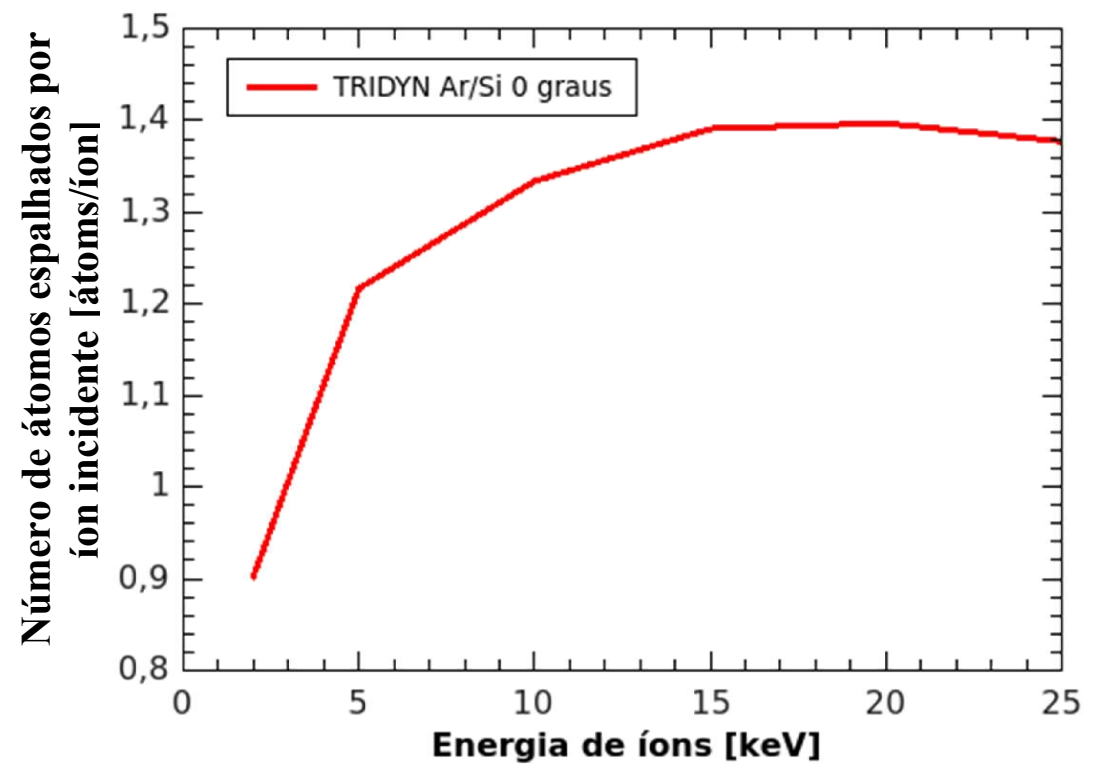

Figura D.2. Série de simulações com incidência do feixe normal à superfície, gerando o número de átomos espalhados do alvo, por íon incidente, em função da energia do feixe, para o caso de alvo de silício e feixe de ions de argônio.

Na Figura D.2 é apresentado o aumento da energia dos íons de argônio até $15 \mathrm{keV}$. Após este valor a taxa de corrosão permanece praticamente inalterada, mostrando que não se faz necessário aumentar ainda mais a energia.

Uma forma de se prever a taxa de corrosão $d / t_{c}$, onde $t_{c}$ o tempo de corrosão, $d$ a profundidade de corrosão no tempo $t_{c}$, é através de equação [68]:

$$
Y(d)=\frac{e d A}{I_{p} t_{c} a^{3}} \quad(\mathrm{D} .1)
$$

onde $Y$ corresponde ao número de átomos espalhados do alvo por íon incidente (que pode ser conseguido por TRIDYN), $e$ sendo a carga do elétron, $I_{p}$ a corrente iônico do feixe (que deve ser medido experimentalmente), $A$ a área da amostra e $a^{3}$ o volume médio do átomo do material da amostra dado por

$$
a^{3}=\frac{M_{C}}{R_{o} N_{A}}(\mathrm{D} .2)
$$

onde $N_{A}$ é o número de Avogadro, $M_{\mathrm{C}}$ a massa atômica e $R_{o}$ a densidade do material. 


\section{ANEXO E. PROGRAMAS PARA SIMULAÇÃO POR TRIDYN}

Este anexo será útil para um usuário do TRIDYN reproduzir os resultados de simulação obtidos neste trabalho.

O código dos programas para cada tipo de experimento está apresentado neste anexo. Todos os parâmetros do programa e sua finalidade estão identificados no manual do TRIDYN.

1. Composição Ti/Alumina

O titânio foi usado como material a ser implantado em substrato de alumina com energia de implantação de 52,5 keV e ângulo de incidência de 0 grau.

TA1Nxxxx.IN

1000

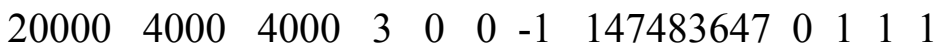

$0.1 \mathrm{E}+01 \quad 1 \quad 1 \quad 1$

$\begin{array}{lllllll}0.500 \mathrm{E}+04 & 0.500 \mathrm{E}+04 & 300 & 0.500 \mathrm{E}+04 & 0 & 300 & 0\end{array}$

$\begin{array}{llllllll}22.0 & 47.9 & 0.00 & 19.0 & 0.100 & 0.00 & 0.568 \mathrm{E}-01 & 1.0\end{array}$

52500. 0. 1. 1. 4.889999874 .889999874 .88999987

$\begin{array}{llllllll}13.0 & 27.0 & 0.00 & 16.0 & 0.100 & 0.400 & 0.146 & 1.0\end{array}$

0. 0. 0.1 .3 .35999993 .35999993 .3599999

$\begin{array}{llllllll}8.00 & 16.0 & 0.00 & 20.0 & 0.100 & 0.600 & 0.104 & 1.0\end{array}$

0. 0. 0. 1. 2. 2 . 2 .

2. Composição Au/PMMA

O ouro foi usado como material a ser implantado em substrato de PMMA com energia de implantação de $50 \mathrm{keV}$ e ângulo de incidência de 0 grau.

ED11xxxx.IN

1000

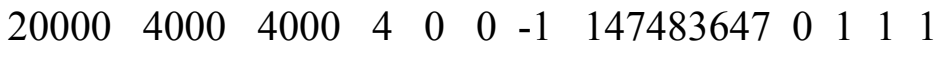

$0.1 \mathrm{E}+01 \quad 1 \quad 1 \quad 1$

750. 750. $300750 . \quad 0300 \quad 0$

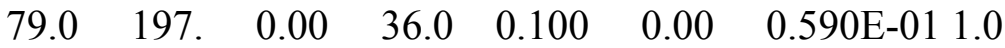

50000. 0. 1. 1. 3.799999953 .799999953 .799999953 .79999995

$\begin{array}{llllllll}1.00 & 1.01 & 0.00 & 20.0 & 0.100 & 0.805 \mathrm{E}-01 & 0.657 \mathrm{E}-01 & 1.0\end{array}$

0. 0. 0. 1. 2. 2. 2. 2 .

$\begin{array}{llllllll}6.00 & 12.0 & 0.00 & 25.0 & 0.100 & 0.600 & 0.178 & 1.0\end{array}$

0. 0 . 0. 1. 7.409999857 .409999857 .409999857 .40999985 
$\begin{array}{llllllll}8.00 & 16.0 & 0.00 & 20.0 & 0.100 & 0.320 & 0.826 \mathrm{E}-01 & 1.0\end{array}$

0. 0. 0. 1. 2. 2. 2. 2 .

3. Corrosão $\mathrm{Ar} / \mathrm{Si}$

$\mathrm{O}$ argônio foi usado como feixe para substrato de Si com energia de corrosão de $2 \mathrm{keV}$ e ângulo de incidência de 0 grau.

SiArxxxx.IN

1000

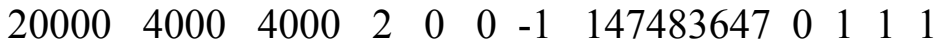

$0.100 \mathrm{E}+01 \quad 1 \quad 1 \quad 1$

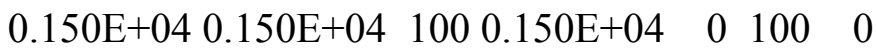

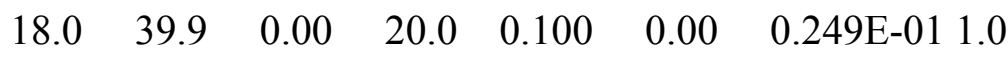

2000. 0. 1. 1. 0. 0 .

$\begin{array}{llllllll}14.0 & 28.1 & 0.00 & 13.0 & 0.100 & 1.00 & 0.498 \mathrm{E}-01 & 1.0\end{array}$

0. 0. 0. 1. 4.699999814 .69999981

4. Composição $\mathrm{Au} / \mathrm{Si}$

O ouro foi usado como material a ser implantado em substrato de silício com energia de implantação de $50 \mathrm{keV}$ e ângulo de incidência de 0 grau.

Au50xxxx.IN

1000

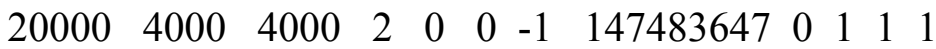

$0.120 \mathrm{E}+01 \quad 1 \quad 1 \quad 1$

$\begin{array}{lllllll}0.150 \mathrm{E}+04 & 0.150 \mathrm{E}+04 & 100 & 0.150 \mathrm{E}+04 & 0 & 100 & 0\end{array}$

$\begin{array}{llllllll}79.0 & 197 . & 0.00 & 36.0 & 0.100 & 0.00 & 0.590 \mathrm{E}-01 & 1.0\end{array}$

50000. 0. 1. 1. 3.799999953 .79999995

$\begin{array}{llllllll}14.0 & 28.1 & 0.00 & 13.0 & 0.100 & 1.00 & 0.498 \mathrm{E}-01 & 1.0\end{array}$

0. 0. 0. 1. 4.699999814 .69999981 


\section{ANEXO F. RECEITAS DAS SOLUÇÕES E MATERIAIS UTILIZADOS NOS EXPERIMENTOS}

\section{Preparação da resina}

1. Misturar os reagentes nas seguintes proporções:

Araldite $502-4 \mathrm{ml}$

DDSA $-4.5 \mathrm{ml}$

DMP-30 - $0.14 \mathrm{ml}$

2. Mexer essa mistura durante 5 minutos;

3. Pegar a quantidade necessária e colocar no molde de silicone;

4. Levar o molde à estufa com temperatura de $60^{\circ} \mathrm{C}$ e secar durante 24 horas.

\section{Preparação da amostra com PMMA}

1. A limpeza da amostra pode ser efetuada utilizando álcool isopropílico no banho ultrasônico por 5 minutos;

2. Secagem da amostra em fluxo de gás nitrogênio;

3. Deposição de PMMA 950k A2 sobre a resina utilizando um spinner, de aconrdo com a receita especificada abaixo*;

4. A amostra com PMMA depositado deve ser secada por 20 minutos na placa quente a temperatura de $180^{\circ} \mathrm{C}$;

5. Após o tempo de secagem, desligar a placa quente e deixar amostra resfriar em temperatura ambiente.

*Programa de rotação do spinner

RPM1 1100

RAMP1 0001

TIME1 0001

RPM2 4000

RAMP2 0001

TIME2 0045

RPM1 4000

RAMP1 0001

TIME1 0001

RAMP4 0001

Esse programa do spinner pode ser utilizado para deposição de PMMA sobre qualquer tipo de 
substrato.

\section{Receita do PDMS}

1. Utilizar um recipiente de plástico, pois este facilita a remoção do PDMS

2. Misturar o agente de cura com a base do PDMS em proporções 1: 10, respectivamente;

3. Misturar até formar uma massa homogênea;

4. Utilizando uma bomba de vácuo remover todas as bolhas de ar (tempo indeterminado);

5. Depositar o PDMS sobre a superfície de amostra;

6. Colocar a amostra com PDMS na placa quente a $100^{\circ} \mathrm{C}$ e deixar polimerizar por no mínimo $30 \mathrm{~min}$. 


\section{ANEXo G. OBSERVAÇÃo dA AMOSTRA DE ALUMINA COM TITÂNiO IMPLANTADO}

\section{INTRODUÇÃO}

No capítulo 3 foi realizado um estudo detalhado de uma amostra de alumina modificada através de implantação de titânio. O titânio é um metal altamente reativo na presença de oxigênio. Dessa forma, pode-se supor que as nanopartículas formadas no interior da alumina, como descrito no capítulo 3, possam ser alteradas ao longo do tempo, através de incorporação de oxigênio. Isso pode ocorrer através de possível porosidade da alumina, levando o oxigênio do ar até as nanopartículas, reduzindo sua condutividade elétrica, alterando a condutividade geral da amostra.

O objetivo do experimento foi comprovar a hipótese que o titânio reage com o oxigênio não apenas durante a implantação, mas também posteriormente. $\mathrm{Na}$ câmara de vácuo, onde foram feitas as implantações, havia oxigênio residual devido ao ar ambiente, o que já leva à incorporação de uma certa quantidade de oxigênio juntamente com a implantação de titânio. Para minimização este efeito, antes de iniciar o processo, a câmara sempre era purgada por um gás inerte, como o argônio.

\section{MATERIAIS E MÉTODOS}

Foi criada uma amostra de alumina modificada por implantação de titânio e realizada uma série de medidas de resistividade, a fim de se determinar as alterações da estrutura da amostra ao longo do tempo. Como a taxa de oxidação de titânio em alumina se mostrou baixa, o experimento foi realizado durante um período de 383 dias, mantendo as condições de umidade e temperatura controladas.

As medidas foram efetuadas através de três métodos diferentes. $\mathrm{O}$ primeiro e o segundo métodos consistiram nas medidas das amostras utilizando um equipamento para medir alta resistência, chamado Gigaohmmetro da GOSSEN-METRAWATT GMBH, modelo METRISO 1000D. Quando se aplica tensão aos contatos elétricos da amostra, o dispositivo apresenta a resistência do nanocompósito. A diferença entre o primeiro e o segundo método é o valor de tensão aplicada, no primeiro caso utilizou-se $100 \mathrm{~V}$ e no segundo $1000 \mathrm{~V}$. A aplicação de tensão maior pode "ligar" mais nanopartículas que têm conexão com compósito de maior resistência, assim, a condutividade total se torna maior. No terceiro método a amostra foi conectada em série com uma fonte de alimentação de 9V (DC SWITCHING POWER SUPPLY PS3005) e um picoamperímetro. Neste caso, a amostra foi utilizada como um resistor que limita a corrente do circuito, e então, o picoamperímetro fez as medidas dessa 
corrente. Ajustando a resistência do picoamperímetro em 0 , a tensão da fonte fíca integralmente aplicada no nanocompósito e, utilizando a lei do Ohm, pode-se calcular a sua resistência.

\section{RESULTADOS}

Utilizando os resultados do capítulo 3 e pela equação (4), é possível determinar a condutividade do nanocompósito da amostra observada. Na Figura G.1 é apresentado o gráfico da alteração de condutividade da amostra durante o período de 383 dias.

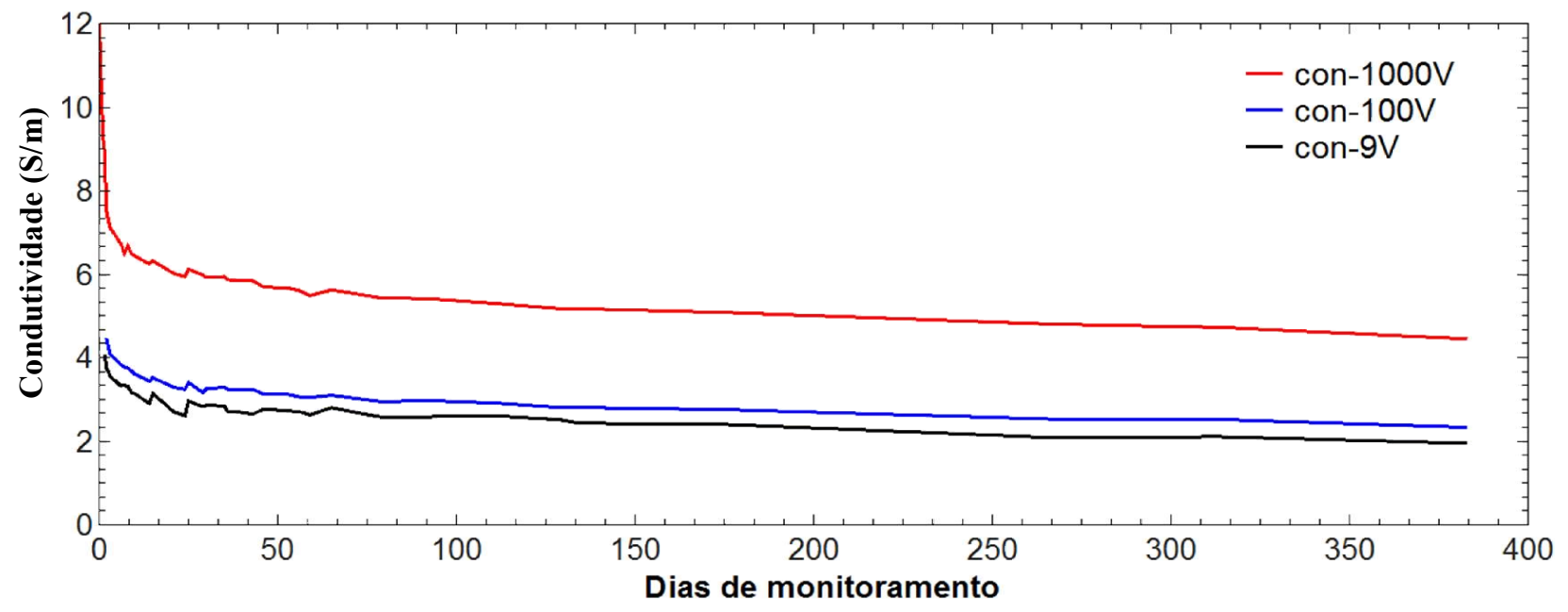

Figura G.1. Alteração de condutividade da amostra durante tempo de 383 dias, para diferentes tensões aplicadas.

Todos os três métodos mostraram grande alteração de condutividade durante todo o período de monitoramento, especialmente durante os 50 primeiros dias. A variação total foi de aproximadamente $40 \%$ para alta tensão e de $50 \%$ para baixa tensão.

\section{SUMÁRIO E CONCLUSÕES}

O implantador invertido foi utilizado para modificação de superfície de alumina por implantação de titânio realizada com energia média de $52,5 \mathrm{keV}$. Para minimização do efeito de oxidação, a câmara foi purgada com argônio, e finalmente, a amostra obtida foi acondicionada em uma sala com temperatura e umidade controlados, mas exposta ao ar atmosférico.

Durante o tempo de 383 dias, a amostra foi observada através de medidas de condutividade do nanocompósito. Os resultados mostraram grande alteração de condutividade durante todo o período de observação, alteração essa causada pela oxidação dos átomos de titânio. No primeiro mês a variação foi cerca de $40 \%$, aumentando mais $10 \%$ no restante do período. 
A alteração da condutividade foi causada por algum tipo de modificação do nanocompósito ao longo do tempo. No entanto, essa modificação não foi identificada, ficando em aberto para uma continuidade deste trabalho. Um possível experimento pode ser realizado de forma similar a descrita neste trabalho, mas mantendo a amostra em vácuo ou em ambiente com ausência de oxigênio. A razão disso seria para a aplicação dessa tecnologia de implantação iônica em circuitos integrados que, em geral, têm encapsulamento. Desta forma, o nanocompósito não terá contato com ambiente, e assim suas propriedades possivelmente poderão ser mantidas ao longo do tempo. 


\section{REFERÊNCIAS BIBLIOGRÁFICAS}

[1] BOLSTER, Robert N.; SINGER, Irvin L. Surface hardness and abrasive wear resistance of nitrogen-implanted steels. Applied Physics Letters, v. 36, n. 3, p. 208-209, 1980.

[2] MANDL, S.; RAUSCHENBACH, B. Formation of Wear Resistant Steel Surfaces by Plasma Immersion Ion Implantation. In: AIP Conference Proceedings. IOP INSTITUTE OF PHYSICS PUBLISHING LTD, 2003. p. 635-638.

[3] Stephen E. Harding B.A. (Oxon). The Improvement in Wear Resistance of Ion Implanted Materials. MSc Dissertation AERE Harwell/ Brighton Polytechnic (1977).

[4] TAMURA, Yutaka et al. Mechanical Properties of Surface Nitrided Titanium for Abrasion Resistant Implant Materials. Materials Transactions, v. 43, n. 12, p. 3043-3051, 2002.

[5] MALEKI-GHALEH, H. et al. Effect of surface modification by nitrogen ion implantation on the electrochemical and cellular behaviors of super-elastic NiTi shape memory alloy. Journal of Materials Science: Materials in Medicine, v. 25, n. 12, p. 2605-2617, 2014.

[6] HUANG, N. et al. Surface Modification of Blood Contacting Biomedical Implants by Plasma Processes. In: PLASMA PHYSICS: 11th International Congress on Plasma Physics: ICPP2002. AIP Publishing, 2003. p. 330-334.

[7] KROTKUS, A. et al. Picosecond carrier lifetime in GaAs implanted with high doses of As ions: An alternative material to low-temperature GaAs for optoelectronic applications. Applied physics letters, v. 66, n. 24, p. 3304-3306, 1995.

[8] STECKL, A. J. et al. Review of focused ion beam implantation mixing for the fabrication of GaAs-based optoelectronic devices. Journal of Vacuum Science \& Technology B, v. 13, n. 6, p. 2570-2575, 1995.

[9] CARMODY, C. et al. Ion-implanted $\operatorname{In}_{0.53} \mathrm{Ga}_{0.47} \mathrm{As}$ for ultrafast optoelectronic applications. Applied physics letters, v. 82, n. 22, p. 3913-3915, 2003.

[11] SALVADORI, M. C. et al. Gold ion implantation into alumina using an "inverted ion source” configurationa). Review of Scientific Instruments, v. 85, n. 2, p. 02B502, 2014.

[12] SALVADORI, M. C. et al. Electrical conductivity of gold-implanted alumina nanocomposite. Nuclear Instruments and Methods in Physics Research Section B: Beam Interactions with Materials and Atoms, v. 310, p. 32-36, 2013.

[13] LIU, F. et al. Surface resistivity tailoring of ceramics by metal ion implantation. Surface and Coatings Technology, v. 103, p. 46-51, 1998.

[14] Ziegler, J. F., Biersack, J. P., Littmark, U., \& Ziegler, J. F. The stopping and ranges of ions in solids, Vol. 1. 1985 (new edition in 1996)). 
[15] MÖLLER, W.; ECKSTEIN, W. Tridyn-A TRIM simulation code including dynamic composition changes. Nuclear Instruments and Methods in Physics Research Section B: Beam Interactions with Materials and Atoms, v. 2, n. 1, p. 814-818, 1984.

[16] MÖLLER, Wolfhard; ECKSTEIN, Wolfgang; BIERSACK, J. P. Tridyn-binary collision simulation of atomic collisions and dynamic composition changes in solids. computer physics communications, v. 51, n. 3, p. 355-368, 1988.

[17] EDELMAN, I. S. et al. Study of morphology, magnetic properties, and visible magnetic circular dichroism of $\mathrm{Ni}$ nanoparticles synthesized in $\mathrm{SiO} 2$ by ion implantation. Physical Review B, v. 87, n. 11, p. 115435, 2013.

[18] LEVENEUR, Jérôme et al. Iron-based bimagnetic core/shell nanostructures in SiO2: a TEM, MEIS, and energy-resolved XPS analysis. Journal of Nanoparticle Research, v. 14, n. 10, p. 1-9, 2012.

[19] Salvadori, M. C., Teixeira, F. D. S., Sgubin, L. G., Araujo, W. W. R. D., Spirin, R. E., Oks, E. M., ... \& Brown, I. G. Low cost ion implantation technique. Applied Physics Letters, 101(22), 224104, 2012.

[20] Salvadori, M. C., Teixeira, F. S., Sgubin, L. G., Araujo, W. W. R., Spirin, R. E., Oks, E. M., \& Brown, I. G. Performance of an inverted ion source. Review of Scientific Instruments, 84(2), 023506, 2013.

[21] Martins, D. R., Salvadori, M. C., Verdonck, P., \& Brown, I. G. Contamination due to memory effects in filtered vacuum arc plasma deposition systems. Applied physics letters, 81(11), 1969-1971, 2002.

[22] Salvadori, M. C., Melo, L. L., Vaz, A. R., Wiederkehr, R. S., Teixeira, F. S., \& Cattani, M. Platinum and gold thin films deposited by filtered vacuum arc: morphological and crystallographic grain sizes. Surface and Coatings Technology, 200(9), 2965-2969, 2006.

[23] DOOLITTLE, L. R. Computer code RUMP, based on: Nucl. Instr. and Meth. B, v. 9, p. 334, 1985.

[24] SHIRAISHI, Hiroshi; BROWN, Ian G. Performance of a high-current metal vapor vacuum arc ion source. Review of scientific instruments, v. 61, n. 12, p. 3775-3782, 1990.

[25] GREEN, T. S. Intense ion beams. Reports on Progress in Physics, v. 37, n. 10, p. 1257, 1974.

[26] SALVADORI, M. C. et al. Self-neutralized ion beam. Journal of Applied Physics, v. 110, n. 8, p. 083308, 2011.

[27] STEPANOV, Andrey L.; HOLE, D. E.; TOWNSEND, P. D. Formation of silver nanoparticles in soda-lime silicate glass by ion implantation near room temperature. Journal 
of non-crystalline solids, v. 260, n. 1, p. 65-74, 1999.

[28] Oks, E., Shandrikov, M., Salvadori, C., \& Brown, I. Low-energy dc ion source for low operating pressure. Review of Scientific Instruments, 85(8), 083502, 2014.

[29] G. Mie. Beiträge zur Optik trüber Medien, speziell kolloidaler Metallösungen. Annalen der Physik 330, 377-445, 1908.

[30] LOESCHNER, Katrin; KIESOW, Andreas; HEILMANN, Andreas. Periodic Structure Formation in Polymer Films with Embedded Gold Nanoparticles. In: Advances in Solid State Physics. Springer Berlin Heidelberg, 2008. p. 73-86.

[31] MAIER, Stefan Alexander. Plasmonics: fundamentals and applications. Springer Science \& Business Media, 2007.

[32] KREIBIG, Uwe; VOLLMER, Michael. Theoretical Considerations. In: Optical Properties of Metal Clusters. Springer Berlin Heidelberg, 1995. p. 13-201.

[33] L. Nicolais, G. Carotenuto, Metal-Polymer Nanocomposites, Wiley, Hoboken, NJ, 2005.

[34] EL-SAYED, Ivan H.; HUANG, Xiaohua; EL-SAYED, Mostafa A. Surface plasmon resonance scattering and absorption of anti-EGFR antibody conjugated gold nanoparticles in cancer diagnostics: applications in oral cancer. Nano letters, v. 5, n. 5, p. 829-834, 2005.

[35] HERRERA, Gloria M.; PADILlA, Amira C.; HERNANDEZ-RIVERA, Samuel P. Surface enhanced Raman scattering (SERS) studies of gold and silver nanoparticles prepared by laser ablation. Nanomaterials, v. 3, n. 1, p. 158-172, 2013.

[36] FERREIRA, Jacqueline et al. Tailored SERS substrates obtained with cathodic arc plasma ion implantation of gold nanoparticles into a polymer matrix. Physical Chemistry Chemical Physics, v. 14, n. 6, p. 2050-2055, 2012.

[37] S. Ganesh, S. Amit, Perspectives on the Science and Technology of Nanoparticle Synthesis. In Nanomaterials Handbook (CRC Press: Boca Raton, FL, USA) 2006.

[38] D. Ä. Lawrence, R. Ryan. Synthesis of Metal Colloids in Catalyst Preparation (CRC Press: New York, NY, USA) 2006; pp. 93-137.

[39] G. B. Sergeev. Synthesis and Stabilization of Nanoparticles in Nanochemistry (Elsevier Science: Amsterdam, Netherlands) 2006; pp. 7-36.

[40] POPOK, Vladimir. Ion implantation of polymers: formation of nanoparticulate materials. Reviews on Advanced Materials Science, v. 30, n. 1, p. 1-26, 2012.

[41] Salvadori, M. C. B. D. S., Cattani, M. S. D., Teixeira, F. D. S., Brown, I. G. Conducting polymer formed by low energy gold ion implantation. Applied Physics Letters, 93(7), 2008.

[42] TEIXEIRA, Fernanda de Sá et al. Gold-implanted shallow conducting layers in polymethylmethacrylate. Journal of Applied Physics, v. 105, n. 6, p. 064313, 2009. 
[43] TEIXEIRA, Fernanda de Sá et al. Surface plasmon resonance of gold nanoparticles formed by cathodic arc plasma ion implantation into polymer. Journal of Vacuum Science \& Technology B, v. 27, n. 5, p. 2242-2247, 2009.

[44] Teixeira, F. D. S., Salvadori, M. C., Cattani, M., \& Brown, I. G. Electrical, optical, and structural studies of shallow-buried Au-polymethylmethacrylate composite films formed by very low energy ion implantation. Journal of Vacuum Science \& Technology A, 28(4), 818$823,2010$.

[45] Teixeira, F. D. S., Salvadori, M. C., Cattani, M., \& Brown, I. G. Structural properties of buried conducting layers formed by very low energy ion implantation of gold into polymer. Journal of Applied Physics, 106(5), 056106, 2009.

[46] Teixeira, F. D. S., Salvadori, M. C., Cattani, M., \& Brown, I. G. Structure of disordered gold-polymer thin films using small angle x-ray scattering. Journal of Applied Physics, 108(9), 093505, 2010.

[47] TEIXEIRA, Fernanda de Sá et al. Annealing effects on nanostructured goldpolymethylmethacrylate composites: Small-angle x-ray scattering analysis. Journal of Applied Physics, v. 111, n. 10, p. 104311, 2012.

[48] Salvadori, M. C., Teixeira, F. S., Cattani, M., \& Brown, I. G. Electrical conductivity of platinum-implanted polymethylmethacrylate nanocomposite. Journal of Applied Physics, 110(11), 114905, 2011.

[49] Salvadori, M. C., Teixeira, F. D. S., Araújo, W. W. R. D., Sgubin, L. G., Spirin, R. E., Cattani, M., \& Brown, I. G. Gold nanoparticle formation in diamond-like carbon using two different methods: Gold ion implantation and co-deposition of gold and carbon. Journal of Applied Physics, 112(7), 074312, 2012.

[50] Salvadori, M. C., Teixeira, F. D. S., Cattani, M., Nikolaev, A., Savkin, K. P., Oks, E. M., ... \& Brown, I. G. On the electrical conductivity of Ti-implanted alumina. Journal of Applied Physics, 111(6), 063714, 2012.

[51] BEYER, R.; BORANY, J. von. Determination of size and density of embedded Ge nanocrystals in $\mathrm{SiO}_{2}$ by scanning force microscopy using a tomographic approach. Surface and Interface Analysis, v. 44, n. 8, p. 1018-1021, 2012.

[52] TAKAHIRO, K. et al. Well-ordered arranging of Ag nanoparticles in $\mathrm{SiO} 2 / \mathrm{Si}$ by ion implantation. Applied Surface Science, v. 258, n. 19, p. 7322-7326, 2012.

[53] SPIRIN, R. E. et al. Nanocomposite formed by titanium ion implantation into alumina. Journal of Applied Physics, v. 116, n. 18, p. 184306, 2014.

[54] Salvadori, M. C., Teixeira, F. D. S., Sgubin, L. G., Cattani, M., \& Brown, I. G. Surface 
modification by metal ion implantation forming metallic nanoparticles in an insulating matrix. Applied Surface Science, 310, 158-163, 2014.

[55] VIONNET-MENOT, Sonia et al. Tunneling-percolation origin of nonuniversality: theory and experiments. Physical Review B, v. 71, n. 6, p. 064201, 2005.

[56] KIRKPATRICK, Scott. Classical transport in disordered media: scaling and effectivemedium theories. Physical Review Letters, v. 27, n. 25, p. 1722, 1971.

[57] KIRKPATRICK, Scott. Percolation and conduction. Reviews of modern physics, v. 45, n. 4, p. $574,1973$.

[58] X. T. Zu, X. Xiang, S. Zhu, et al. Embedded Optical-Electrical Nanomaterials Fabricated by Ion Implantation, Editors C. J. Dixon and O. W. Curtanes. Nanofabrication, Patterning and Self Assembly, Nanotechnology Science and Technology, pp 525-557 (2010).

[59] ARNOLD, G. W.; BORDERS, J. A. Aggregation and migration of ion-implanted silver in lithia-alumina-silica glass. Journal of Applied Physics, v. 48, n. 4, p. 1488-1496, 1977.

[60] MELDRUM, Al et al. Nanocomposite materials formed by ion implantation. Advanced Materials, v. 13, n. 19, p. 1431-1444, 2001.

[61] ZHAN, Wei-ting et al. Photocatalytic activity of ferric oxide/titanium dioxide nanocomposite films on stainless steel fabricated by anodization and ion implantation. International Journal of Minerals, Metallurgy, and Materials, v. 20, n. 8, p. 725-732, 2013.

[62] TIAN, Huifeng et al. Nonenzymatic glucose sensor based on nickel ion implantedmodified indium tin oxide electrode. Electrochimica Acta, v. 96, p. 285-290, 2013.

[63] KHARCHENKO, Andrej et al. Correlation of electronic and magnetic properties of thin polymer layers with cobalt nanoparticles. Particle \& Particle Systems Characterization, v. 30, n. 2, p. 180-184, 2013.

[64] ALGUERÓ, Miguel et al. Thin Film Multiferroic Nanocomposites by Ion Implantation. ACS applied materials \& interfaces, v. 6, n. 3, p. 1909-1915, 2014.

[65] LI, D. Y. et al. Relaxor Ferroelectricity and Magnetoelectric Coupling in $\mathrm{ZnO}-\mathrm{Co}$ Nanocomposite Thin Films: Beyond Multiferroic Composites. ACS applied materials \& interfaces, v. 6, n. 7, p. 4737-4742, 2014.

[66] DE BRUIN, H. J.; MOODIE, A. F.; WARBLE, C. E. Ceramic-metal reaction welding. Journal of Materials Science, v. 7, n. 8, p. 909-918, 1972.

[67] CATTANI, M.; SALVADORI, M. C. Insulator-Conductor Transition: A Brief Theoretical Review. arXiv preprint arXiv:0903.3587, 2009.

[68] SEAH, M. P.; NUNNEY, T. S. Sputtering yields of compounds using argon ions. Journal of Physics D: Applied Physics, v. 43, n. 25, p. 253001, 2010. 